Subscriber access provided by Caltech Library

\title{
Article
}

\section{Evolution of a Strategy for the Enantioselective Total Synthesis of (+)-Psiguadial B}

Lauren M Chapman, Jordan C Beck, Caitlin R. Lacker, Linglin Wu, and Sarah E. Reisman

J. Org. Chem., Just Accepted Manuscript • DOI: 10.1021/acs.joc.8b00728 • Publication Date (Web): 04 May 2018

Downloaded from http://pubs.acs.org on May 7, 2018

\section{Just Accepted}

"Just Accepted" manuscripts have been peer-reviewed and accepted for publication. They are posted online prior to technical editing, formatting for publication and author proofing. The American Chemical Society provides "Just Accepted" as a service to the research community to expedite the dissemination of scientific material as soon as possible after acceptance. "Just Accepted" manuscripts appear in full in PDF format accompanied by an HTML abstract. "Just Accepted" manuscripts have been fully peer reviewed, but should not be considered the official version of record. They are citable by the Digital Object Identifier (DOI®). "Just Accepted" is an optional service offered to authors. Therefore, the "Just Accepted" Web site may not include all articles that will be published in the journal. After a manuscript is technically edited and formatted, it will be removed from the "Just Accepted" Web site and published as an ASAP article. Note that technical editing may introduce minor changes to the manuscript text and/or graphics which could affect content, and all legal disclaimers and ethical guidelines that apply to the journal pertain. ACS cannot be held responsible for errors or consequences arising from the use of information contained in these "Just Accepted" manuscripts. 


\title{
Evolution of a Strategy for the Enantioselective Total Synthesis of (+)-Psiguadial B
}

\author{
Lauren M. Chapman, Jordan C. Beck ${ }^{\ddagger}$, Caitlin R. Lacker*, Linglin Wu, Sarah E. Reisman* \\ The Warren and Katharine Schlinger Laboratory for Chemistry and Chemical Engineering, Division of Chemistry and Chemi- \\ cal Engineering, California Institute of Technology, Pasadena, California 91125, United States
}

ABSTRACT: (+)-Psiguadial B is a diformyl phloroglucinol meroterpenoid that exhibits anti-proliferative activity against the HepG2 human hepatoma cancer cell line. This full account details the evolution of a strategy that culminated in the first enantioselective total synthesis of (+)-psiguadial B. A key feature of the synthesis is the construction of the trans-cyclobutane motif by a Wolff rearrangement with in situ catalytic, asymmetric trapping of the ketene. An investigation of the substrate scope of this method to prepare enantioenriched 8-aminoquinolinamides is disclosed. Three routes toward (+)-psiguadial B were evaluated that featured the following key steps: 1) an ortho-quinone methide hetero-Diels-Alder cycloaddition to prepare the chroman framework; 2) a Prins cyclization to form the bridging bicyclo[4.3.1]decane system, and 3) a modified Norrish-Yang cyclization to generate the chroman. Ultimately, the successful strategy employed a ring-closing metathesis to form the seven-membered ring and an intramolecular $\mathrm{O}$-arylation reaction to complete the polycyclic framework of the natural product.

\section{- INTRODUCTION}

Plant extracts used in traditional folk medicine have long served as rich sources of structurally complex, bioactive compounds. For example, the bark, leaves, and fruit of the Psidium guajava plant are known for their medicinal properties, and have been used to treat ailments such as diabetes and hypertension. ${ }^{1}$ Efforts to isolate and characterize the bioactive constituents have identified a variety of diformyl phloroglucinol meroterpenoids with interesting structures, ${ }^{2}$ including 1 and $\mathbf{2}$ (Figure 1), which inhibit phosphodiesterase4 (PDE4D2), a drug target for inflammatory and respiratory diseases. ${ }^{3}$ In 2010, Shao and coworkers reported the discovery of four new meroterpenoids, psiguadials A-D (3-6), ${ }^{4,5}$ which exhibit potent cytotoxicity against the HepG2 human hepatoma cancer cell line $\left(\mathrm{IC}_{50}=46-128 \mathrm{nM}\right)$. The most potent antiproliferative agent in this family, (+)-psiguadial B (3), is unique from a structural standpoint in that it possesses a strained bicyclo[4.3.1]decane terpene core, fused to a transcyclobutane ring.

Biosynthetically, this motif is proposed to arise via a mixed terpene-polyketide pathway. ${ }^{5}$ Intramolecular cyclization of farnesyl pyrophosphate (7) generates humulyl cation $\mathbf{8},{ }^{6}$ which undergoes stereoselective ring closure guided by caryophyllene synthase to produce $\beta$-caryophyllene (9, Scheme 1). Michael reaction of $\mathbf{9}$ with ortho-quinone methide (o-QM) 10-likely derived from the known $P$. guajava metabolite 3,5-dimethyl-2,4,6-trihydroxybenzophenone ${ }^{7}$-is proposed to afford tertiary carbocation $11,{ }^{8}$ which can cyclize to give (-)-guajadial (1) ${ }^{1 \mathrm{~g}}$ and (+)-psidial A (12), ${ }^{9}$ isomeric natural products that have also been isolated from $P$. guajava. Alternatively, carbocation 11 can isomerize through proton trans- fer processes to form tertiary carbocation $13,{ }^{5}$ which can undergo transannular ring closure to generate bridgehead cation 14. Finally, this species can be trapped by the pendant phenol to furnish (+)-psiguadial B (3). Cramer ${ }^{8,10}$ and Lee ${ }^{11}$ have validated this biosynthetic hypothesis by semi-syntheses of 3, 1, and 11, from $\beta$-caryophyllene (9).

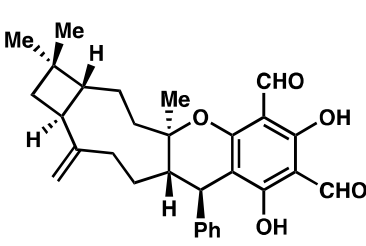

(-)-guajadial (1) PDE4D2 $I C_{50}=1.62 \mu \mathrm{M}$

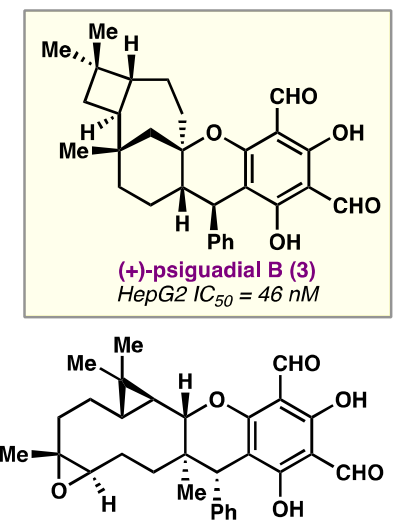

(+)-psiguadial C (5) HepG2 $I C_{50}=105 \mathrm{nM}$

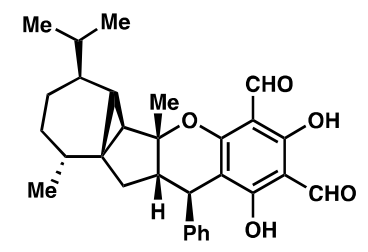

(+)-psiguajadial B (2) PDE4D2 IC $50=5.03 \mu \mathrm{M}$

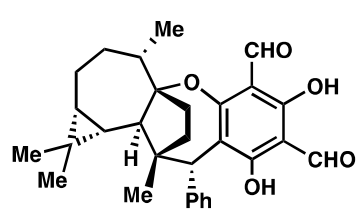

$(-)$-psiguadial A (4) HepG2 IC $50=61 \mathrm{nM}$

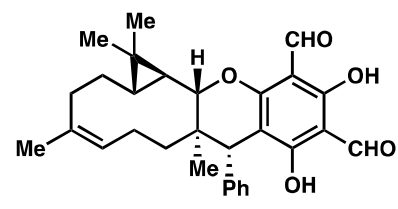

(+)-psiguadial D (6) HepG2 $/ C_{50}=128 \mathrm{nM}$
Figure 1. Bioactive diformyl phloroglucinol meroterpenoids isolated from Psidium guajava. 
Scheme 1. Proposed biosynthesis of (+)-psiguadial B.

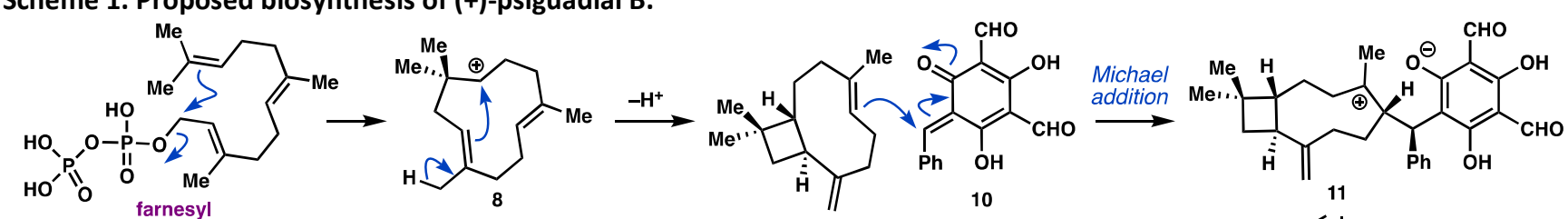
pyrophosphate (7) $\beta$-caryophyllene (9)

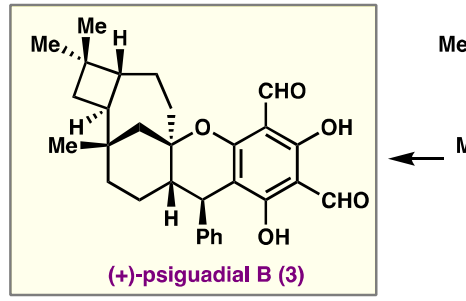

While semi-synthetic approaches to phloroglucinol meroterpenoids provide direct access to $\beta$-caryophyllene-derived natural products, we viewed an abiotic approach to $\mathbf{3}$ as an opportunity to develop new chemistry and strategy concepts that could be applicable in broader synthetic contexts. Here, we describe a full account of our efforts to develop an enantioselective total synthesis of (+)-psiguadial B (3), ${ }^{12,13}$ which was enabled by an asymmetric Wolff-rearrangement to construct the trans-fused cyclobutane.

\section{- DESIGN PLAN: FIRST GENERATION STRATEGY}

As disclosed in our prior communication, ${ }^{12}$ the construction of the central bicyclo[4.3.1]decane, which is trans-fused to a cyclobutane, was recognized as the primary synthetic challenge posed by 3 . Closer analysis identified the C1-C2 bond (Figure 2 ), which links the $A$ and $C$ rings through vicinal stereogenic centers, as a strategic disconnection. On the basis of this analysis, we were interested in forming this bond by a $\mathrm{Pd}$-catalyzed $\mathrm{C}\left(\mathrm{sp}^{3}\right)-\mathrm{H}$ alkenylation reaction between cyclobutane 18 and vinyl iodide 19.

Having identified a tactic to join the $A$ and $C$ rings, a retrosynthesis of $\mathbf{3}$ was conceived in which the 7-membered $\mathrm{B}$ ring would be generated via a late-stage intramolecular Prins cyclization, thus allowing simplification of $\mathbf{3}$ to $\mathbf{1 5}$. Although the ring closure to form this strained system was expected to be challenging, the Prins reaction has been previously used for the preparation of bridging polycycles. ${ }^{14}$ Tricycle 15 could be assembled through a bioinspired ortho-quinone methide hetero-Diels-Alder (o-QMHDA) reaction between enol ether 17 and an $0-Q M$ generated from $16 .{ }^{15}$ Although o-QMHDA reactions are widely used to construct chroman frameworks, simple acyclic enol ethers or styrenes are typically employed as dienophiles, and are used in excess to avoid o-QM dimerization. ${ }^{16}$ In contrast, the proposed strategy necessitates use of a functionalized cyclic enol ether, ideally as the limiting reagent. At the outset of these studies, we were unaware of any reported examples in which cyclohexanone-derived enol ethers were employed as dienophiles in o-QMHDA cycloadditions; thus, the proposed studies could potentially contribute 


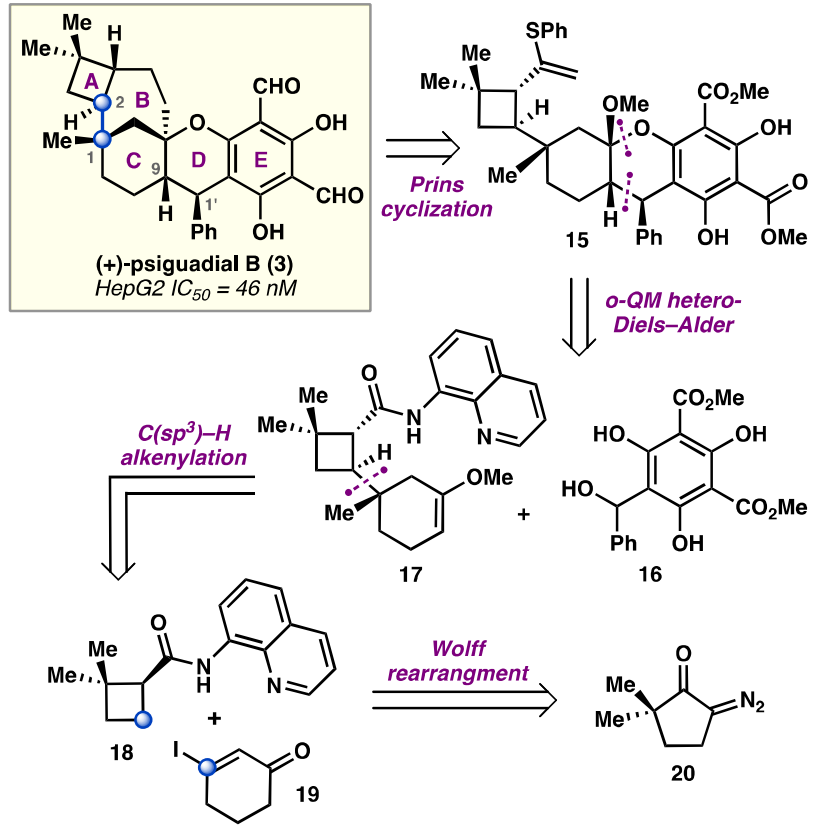

Figure 2. First generation retrosynthetic analysis.

A key question presented by the proposed retrosynthesis was how best to synthesize cyclobutane $\mathbf{1 8}$ in enantioenriched form. Elegant studies by $\mathrm{Fu}$ and coworkers had demonstrated that $\mathrm{N}$-acylpyrroles can be prepared with excellent enantioselectivity from the reaction between aryl ketenes (e.g. 21) and 2-cyanopyrrole (22) using chiral DMAP catalyst 23 (Scheme 2a). ${ }^{22}$ We hypothesized that a similar transformation could be used to prepare $\mathbf{1 8}$ directly from $\mathbf{2 0}$ by using 8-aminoquinoline (29) as a nucleophile in the presence of an appropriate catalyst. While there were no examples from Fu's work in which the ketene was generated in situ photochemically, a single example from Lectka showed that a ketene could be generated in situ by a Wolff rearrangement, and engage in an enantioselective reaction (Scheme $2 b$ ). ${ }^{23}$

Scheme 2. Enantioselective reactions with ketenes. a) Fu, 2002: enantioselective amide formation with isolable, aryl ketenes

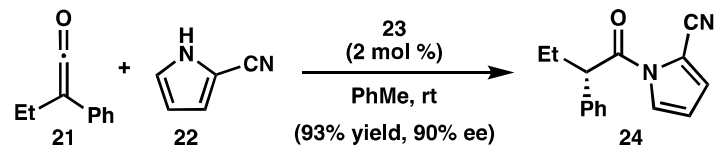

b) Lectka, 2004: enantioselective ester formation with an aryl diazoketone

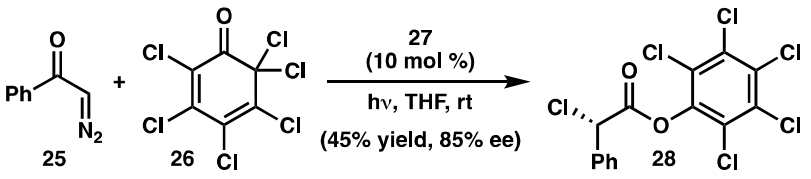

c) This work: enantioselective amide formation with alkyl diazoketones

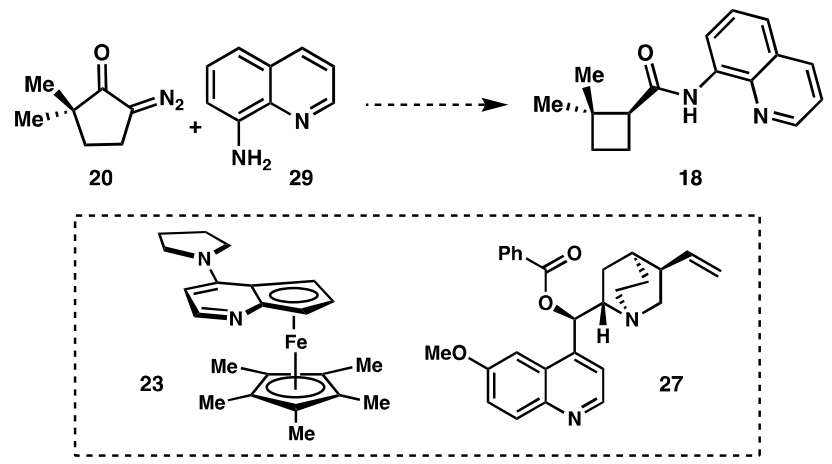

Following a survey of chiral nucleophilic catalysts known to engage with ketenes, ${ }^{22-24}$ it was discovered that irradiation of a mixture of $\mathbf{2 0}$ and 3 equiv $\mathbf{2 9 ^ { 2 5 }}$ in the presence of $50 \mathrm{~mol}$ $\%(+)$-cinchonine (30) produced $\mathbf{1 8}$ in $61 \%$ yield, and $79 \%$ ee (Table 1, entry 1). Investigation of various solvents revealed that THF provided the highest levels of enantioselectivity. ${ }^{26}$ More concentrated reaction mixtures led to lower yields, presumably due to poor light penetration as a result of the sparing solubility of $\mathbf{3 0}$ in THF. When scaling the reaction to quantities relevant for total synthesis $(30 \mathrm{mmol})$, the catalyst loading of $\mathbf{3 0}$ could be reduced to $10 \mathrm{~mol} \%$, which provided 18 in $62 \%$ yield and $79 \%$ ee (see Scheme 3). Moreover, enantiomerically pure $\mathbf{1 8}$ was obtained after a single recrystallization by layer diffusion.

Although our total synthesis efforts focused on the preparation of 18, we wondered if this tandem Wolff rearrangement/enantioselective addition reaction could be applied to other $\alpha$-diazoketone substrates. Unfortunately, substantially lower levels of enantioinduction (9-64\% ee) were observed using $\mathbf{3 0}$ as a catalyst with these substrates (Table 1, entries $9,17,25$, and 33). Evaluation of alternative cinchona derivatives 31-37 revealed that synthetically useful levels of enantioselectivity could be achieved for each substrate, depending on the catalyst. For instance, while 31-37 produced 18 with lower enantioinduction (16-64\% ee, entries 2-8), catalysts 34 and $\mathbf{3 3}$ proved optimal for the 6 - and 7-membered analogs of 20, providing amides $\mathbf{4 2}$ and $\mathbf{4 3}$ in $\mathbf{7 2}$ and $73 \%$ ee, respectively (entries 13 and 20). When these reactions were conducted on preparative scale, the catalyst loading could be dropped to 20 mol \%, providing cyclopentyl amide $\mathbf{4 2}(n=2)$ in $81 \%$ yield and $68 \%$ ee and cyclohexyl amide $\mathbf{4 3}(n=3)$ in $67 \%$ yield and $65 \%$ ee. ${ }^{26}$ On the other hand, benzo-fused diazoketones, 40 
and 41, performed best in the presence of dimeric cinchona catalysts $\mathbf{3 7}$ and $\mathbf{3 6}$ (entries 32 and 39). At present, a general catalyst for the tandem Wolff rearrangement/enantioselective addition of 8-aminoquinoline has not been identified, though further mechanistic investigations may inform future efforts to improve the generality of this reaction.

Table 1. Optimization and exploration of substrate scope for tandem Wolff rearrangement/ketene addition.

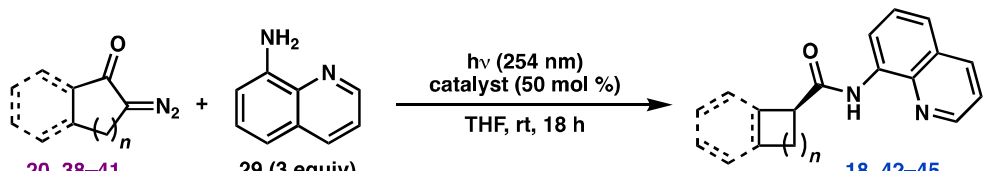

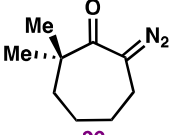

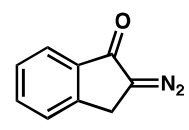

40

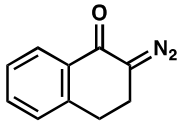

41

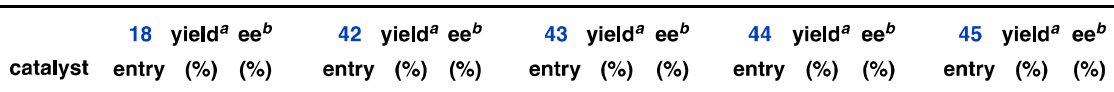

\begin{tabular}{|c|c|c|c|c|c|c|c|c|c|c|c|c|c|c|c|}
\hline 30 & 1 & $61^{c}$ & 79 & 9 & 64 & 58 & 17 & 49 & 64 & 25 & 48 & 9 & 33 & 54 & 35 \\
\hline 31 & 2 & 50 & 24 & 10 & 52 & 64 & 18 & 60 & 7 & 26 & 43 & 7 & 34 & 65 & 42 \\
\hline 32 & 3 & 64 & -57 & 11 & 62 & -22 & 19 & 56 & -51 & 27 & 48 & -3 & 35 & 38 & -20 \\
\hline 33 & 4 & 67 & 64 & 12 & 69 & 50 & 20 & $59^{c}$ & 71 & 28 & 48 & 25 & 36 & 42 & 23 \\
\hline 34 & 5 & 58 & 48 & 13 & $77^{c}$ & 71 & 21 & 55 & -39 & 29 & 40 & 7 & 37 & 61 & 41 \\
\hline 35 & 6 & 65 & -54 & 14 & 66 & 0 & 22 & 54 & -34 & 30 & 48 & -26 & 38 & 42 & -23 \\
\hline 36 & 7 & 90 & -16 & 15 & 60 & -59 & 23 & 65 & -7 & 31 & 47 & -5 & 39 & $42^{c}$ & -75 \\
\hline 37 & 8 & 50 & 53 & 16 & 49 & -23 & 24 & 50 & 37 & 32 & $31^{c}$ & 34 & 40 & 35 & -1 \\
\hline
\end{tabular}

${ }^{a}$ Reactions performed on $0.050 \mathrm{mmol}$ scale and irradiated for 18 hours. Yield determined by ${ }^{1} \mathrm{H}$ NMR analysis versus an added internal standard. ${ }^{b}$ Determined by SFC using a chiral stationary phase. ${ }^{c}$ Reactions performed on $0.200 \mathrm{mmol}$ scale and irradiated for $\mathbf{4 8}$ hours, isolated yield reported.

\section{Scheme 3. $\mathrm{C}\left(\mathrm{sp}^{3}\right)-\mathrm{H}$ alkenylation and quaternary center formation via conjugate addition.}
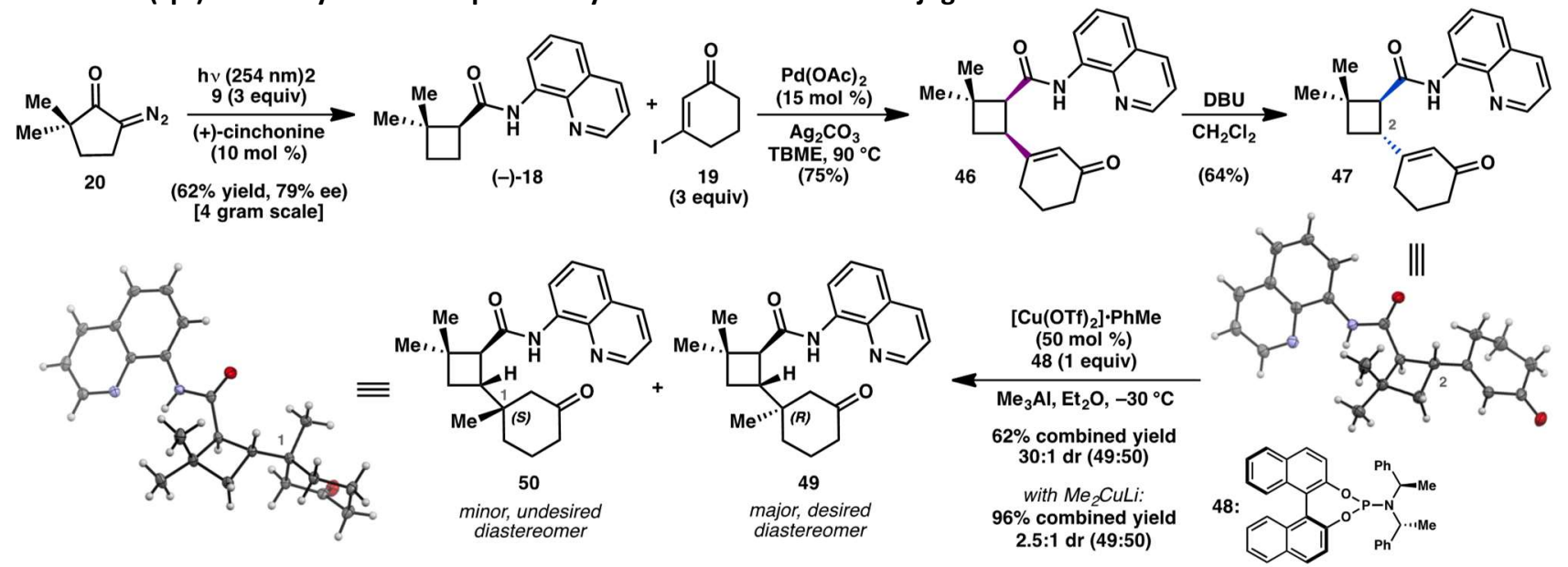

Having identified conditions to prepare multigram quantities of 18 in enantiopure form, we were pleased to find that treatment of 18 with $\mathrm{Pd}(\mathrm{OAc})_{2}(15 \mathrm{~mol} \%), \mathrm{Ag}_{2} \mathrm{CO}_{3}$, and 19 in TBME at $90{ }^{\circ} \mathrm{C}$ smoothly effected the $\mathrm{C}\left(\mathrm{sp}^{3}\right)-\mathrm{H}$ alkenylation reaction to give $\mathbf{4 6}$ in $\mathbf{7 5 \%}$ yield on gram scale (Scheme 3 ). Exposure of 46 to DBU furnished the requisite transcyclobutane via selective epimerization at $\mathrm{C} 2$, as determined by deuterium-labeling studies. ${ }^{26} \mathrm{It}$ was at this stage that single crystals of trans-cyclobutane $\mathbf{4 7}$ suitable for X-ray diffraction were obtained. Unfortunately, $\mathbf{4 7}$ was found to be in the incorrect enantiomeric series for elaboration to natural $\mathbf{3}$. To our dismay, this problem could not be circumvented by simply employing (-)-cinchonidine (32) in the tandem Wolff rearrangement/asymmetric ketene addition, as this pseudoenantiomeric catalyst afforded (+)-18 in only $57 \%$ ee (Table 1 , entry 3). Nevertheless, we elected to advance (-)-47 in the interest of validating the key reactions in our retrosynthetic analysis as soon as possible.

To this end, attention turned to formation of the $\mathrm{C} 1$ quaternary center (Scheme 3). Subjection of cis-cyclobutane $\mathbf{4 6}$ to a number of standard conjugate addition conditions provided only trace yields of the corresponding product (not 
shown), presumably due to steric encumbrance by the proximal large aminoquinoline group. On the other hand, treatment of trans-cyclobutane $\mathbf{4 7}$ with excess Gilman's reagent smoothly furnished $\mathbf{4 9}$ and $\mathbf{5 0}$ in near quantitative yield as a 2.5:1 mixture of diastereomers, respectively. Separation of the diastereomers by HPLC allowed single crystals of $\mathbf{5 0}$ to be obtained, and X-ray analysis unambiguously confirmed that the major diastereomer (49) possessed the desired $(R)$ configuration of the methyl group at the $\mathrm{C} 1$ quaternary center.

In an effort to improve the diastereoselectivity of this transformation, we turned to asymmetric catalysis. Fortunately, application of the conditions developed by Alexakis and coworkers for copper-catalyzed conjugate addition ${ }^{27}$ provided 49 in $62 \%$ yield and $30: 1 \mathrm{dr}$, albeit using $50 \mathrm{~mol} \%$ $\left[\mathrm{Cu}(\mathrm{OTf})_{2}\right] \bullet \mathrm{PhMe}$ and a stoichiometric equivalent of phosphoramidite ligand 48 . Presumably, the high catalyst loading is required due to the presence of the highly-coordinating 8aminoquinolinamide, which can deactivate the catalyst or inhibit turnover.

With the quaternary center secured, ketone $\mathbf{4 9}$ was converted to the corresponding dimethyl ketal $\mathbf{5 1}$ (Scheme 4a), a precursor to the dienophile for the o-QMHDA reaction (vide infra). While phenolic aldol conditions ${ }^{28}$ failed to produce 16 , this acid-labile $o$-QM precursor was prepared from phloroglucinol $54^{29}$ via the morpholine adduct $(\mathbf{5 5}$, Scheme $4 \mathrm{~b}) .{ }^{30} \mathrm{~A}$ control experiment determined that heating of 51 to $170{ }^{\circ} \mathrm{C}$ in toluene results in thermal extrusion of methanol to afford a 1:1 mixture of enol ethers 17 (Scheme 5). ${ }^{31}$ When a mixture of $\mathbf{5 1}$ and $\mathbf{1 6}$ was heated to $170{ }^{\circ} \mathrm{C}$ for $21 \mathrm{~h}$, the cycloadduct was obtained in $68 \%$ yield, albeit as a complex mixture of diastereomers.

\section{Scheme 4. Synthesis of $o$-QMHDA cycloaddition reactants.}
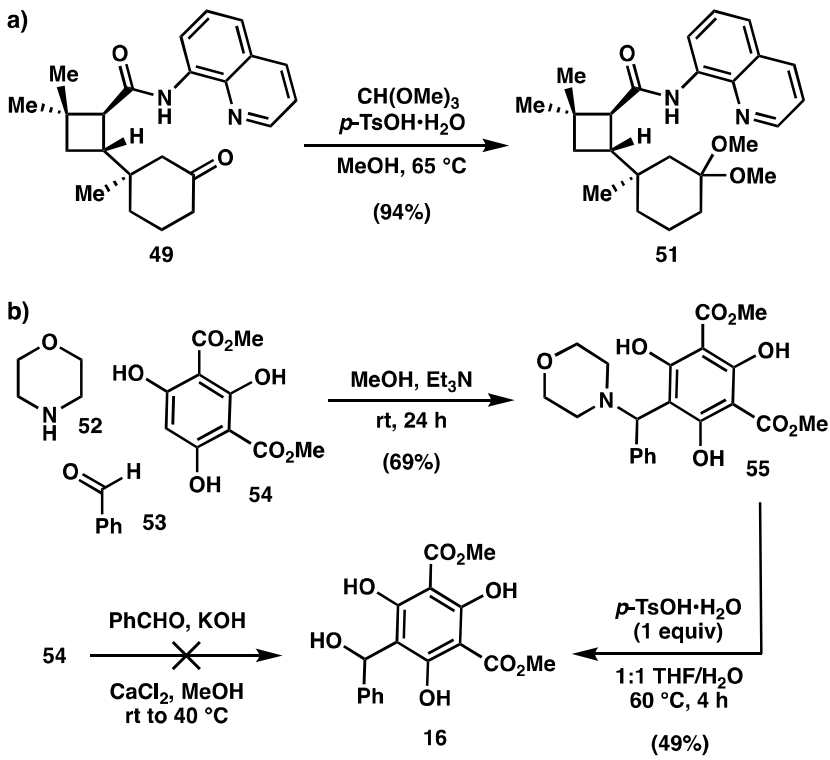

Scheme 5. Evaluation of the thermal o-QMHDA cycloaddition.

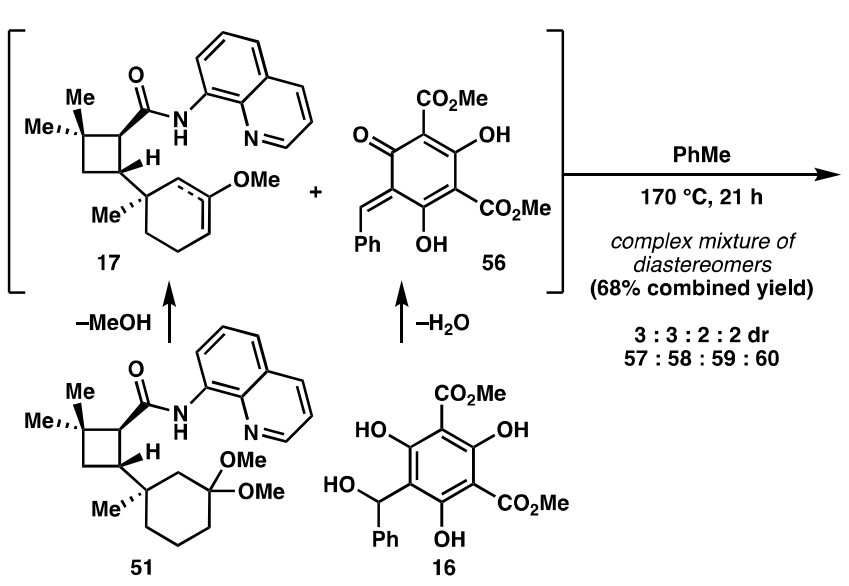

Analytically pure samples of the four highest abundance diastereomers (57-60) were obtained by HPLC purification. Spectroscopic analysis by 2D NMR led to the assignment of $\mathbf{5 7}$ and $\mathbf{5 8}$ as the two major diastereomers, which bear the expected relative anti relationship between $\mathrm{C} 9$ and $\mathrm{C} 1{ }^{\prime}$. The formation of these products in a $\sim 1: 1$ ratio indicates that $\mathbf{1 7}$ does not exert significant facial selectivity in the 0 -QMHDA reaction. The trans-fused isomer, $\mathbf{6 0}$, presumably results from thermal equilibration of the ketal under the reaction conditions.

In considering how to improve the selectivity for desired diastereomer 57, we drew inspiration from Evans' highly enantioselective inverse-demand hetero-Diels-Alder chemistry,

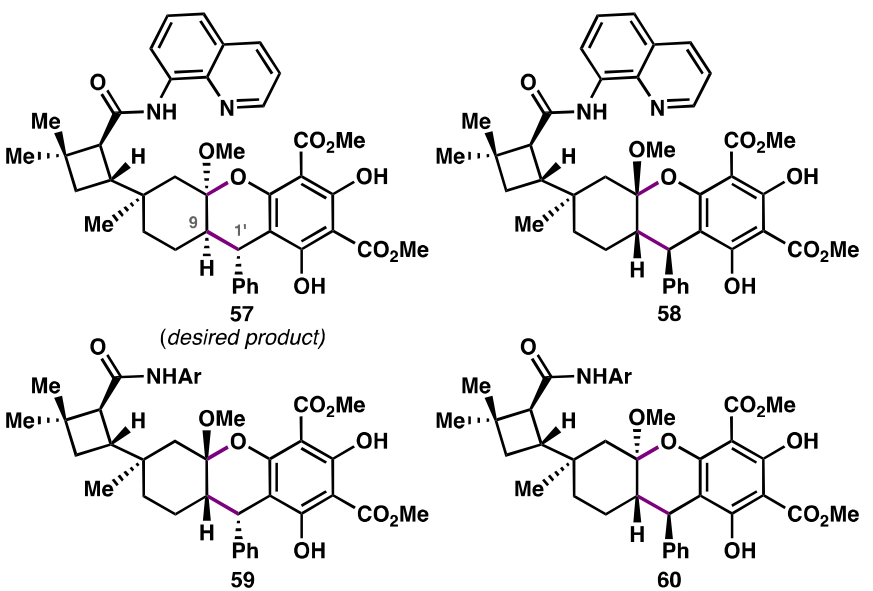

which proceeds via bidentate coordination of heterodienes such as $\mathbf{6 1}$ to a chiral Cu(II)-BOX Lewis acid catalyst (Scheme 6a). ${ }^{32}$ We envisioned that chelation of the aminoquinoline in $\mathbf{1 7}$ to a $\mathrm{Cu}$ complex could engage $\mathbf{5 6}$ as depicted in Scheme $6 \mathrm{~b}$, thereby directing the $o-\mathrm{QM}$ to the top face of enol ether 17 (Scheme 6b). Formation of $\mathbf{5 6}$ could be induced by the equivalent of triflic acid generated via complexation of $\mathrm{Cu}(\mathrm{OTf})_{2}$ with aminoquinoline. ${ }^{17,33}$

To test this hypothesis, enol ether $\mathbf{1 7}$ was prepared by heating in $\mathrm{PhMe}^{34}$ and after exchanging the solvent for $\mathrm{CH}_{2} \mathrm{Cl}_{2}, \mathrm{Cu}(\mathrm{OTf})_{2}$ and 16 were added. Analysis of the crude reaction mixture by ${ }^{1} \mathrm{H}$ NMR revealed that although the ratio of 57:58 had improved relative to the thermal reaction, signif- 
icant quantities of the undesired isomers, 59 and 60, were still formed. Moreover, this reaction suffered from lower overall yields due to rapid hydrolysis of $\mathbf{1 7}$ and reversion of $\mathbf{1 6}$ to phloroglucinol 54. At this stage, it was clear that implementation of this strategy would require a significant investment in reaction optimization and we felt that such an effort would only be warranted if the proposed late-stage Prins reaction were proved feasible. Thus, attention turned to assessing this key reaction in a model system.

To this end, the aminoquinoline auxiliary in $\mathbf{5 1}$ was reductively cleaved by treatment with Schwartz's reagent to furnish aldehyde 62, which was homologated to alkyne 63 using the Ohira-Bestmann reagent (Scheme 7). Nickelcatalyzed hydrothiolation ${ }^{35}$ proceeded with good regioselectivity to give vinyl sulfide $\mathbf{6 5}$ in low yield, mainly due to the facile conversion of this intermediate to a mixture of enol ethers $\mathbf{6 4}$ under the reaction conditions.

Scheme 6. Attempted auxiliary-directed cycloaddition. a) Evans, 2000: enantioselective hetero-Diels-Alder

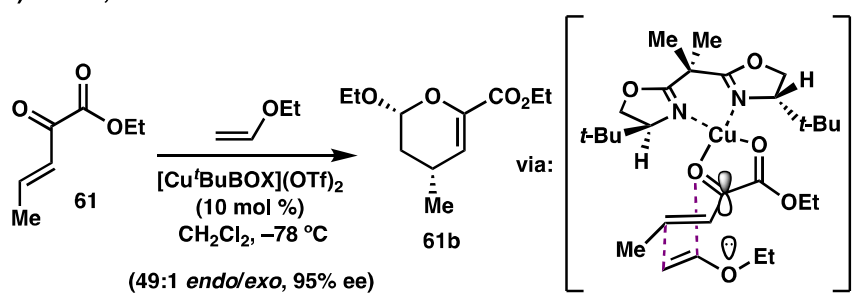

b) This work: attempted auxiliary-directed cycloaddition

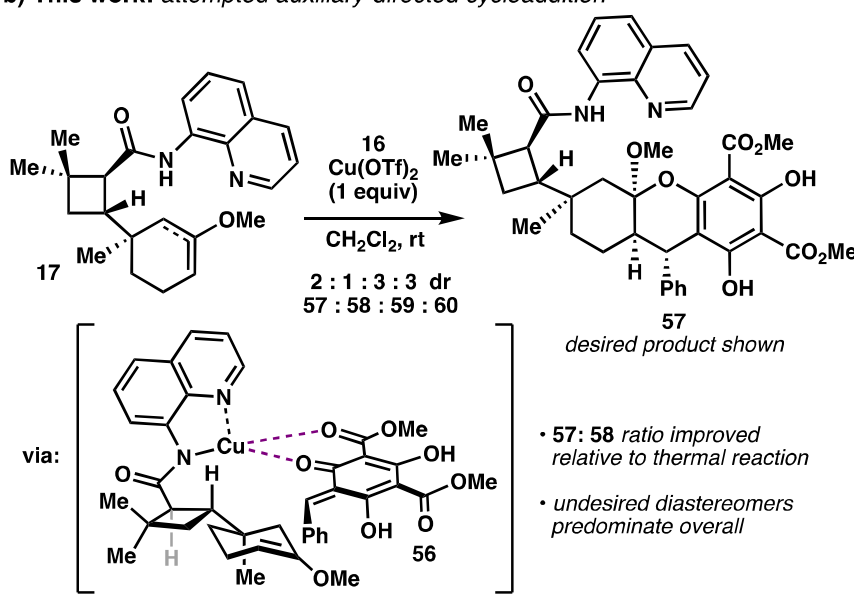

Unfortunately, exposure of ketal 65 to a variety of Lewis acids led to hydrolysis, yielding ketone $\mathbf{6 7}$ in nearly all cases. The use of $\mathrm{InCl}_{3},{ }^{36}$ however, delivered the desired Prins product 66 in 11\% yield. Formation of the 7-membered ring was confirmed by a key HMBC correlation between the C12 axial proton and the distinct $\mathrm{sp}^{2} \mathrm{C} 7$ signal at $\delta 140 \mathrm{ppm}$. Although the formation of the seven-membered ring through a Prins cyclization was promising, our excitement was tempered by the fact that $\mathbf{6 6}$ was obtained in poor yield and challenges were encountered with reproducibility. Taken together with the significant diastereoselectivity issues plaguing the 0 QMHDA reaction, we revised our retrosynthetic analysis.
Scheme 7. Model studies toward Prins cyclization.

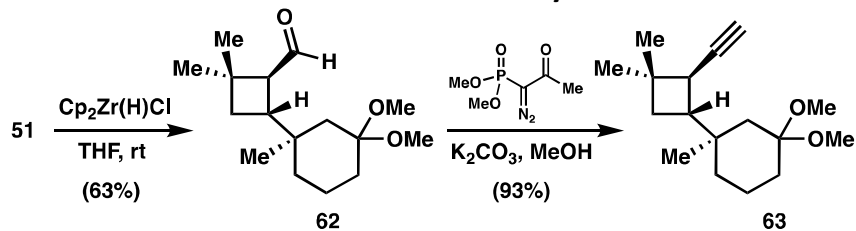
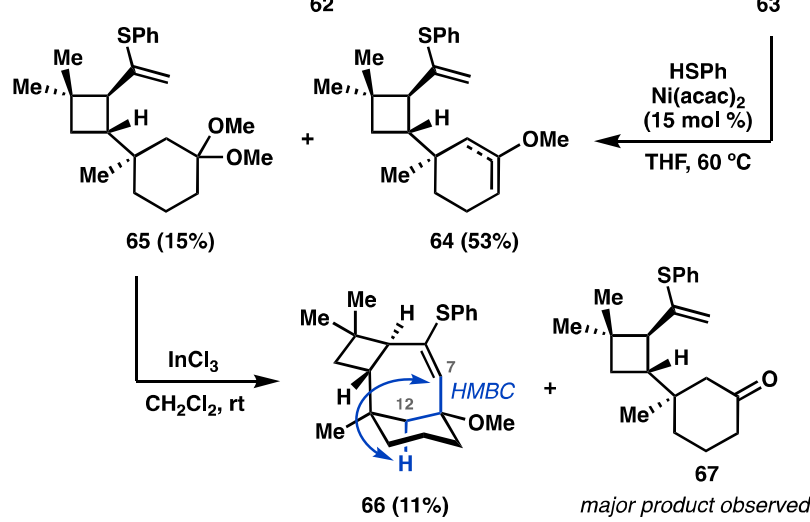

\section{SECOND GENERATION STRATEGY}

In our revised retrosynthesis, we envisioned that the chroman substructure could be constructed via a modified Norrish-Yang cyclization, ${ }^{37}$ revealing 68 as a key intermediate (Figure 3a). Benzophenones such as $\mathbf{6 8}$ are known to undergo photoexcitation upon irradiation with UV light ${ }^{38}$ to give triplet species (i.e. 68*) that can engage in Norrish type-II 1,5hydrogen atom abstraction and subsequent radical recombination. ${ }^{37,39}$ In the absence of any available $\gamma$ or $\delta$-hydrogens, it was hypothesized that $68^{*}$ could abstract a hydrogen atom from C9 to generate diradical $72 .{ }^{40}$ Recombination of the carbon-centered radicals would furnish the core of $\mathbf{3}$. We recognized that achieving the desired regioselectivity could prove challenging since the $\mathrm{C} 7$ and $\mathrm{C} 12$ methylenes in $68^{*}$ were also within range for $1,7-\mathrm{H}$-atom abstraction (Figure $3 \mathrm{~b}$ ). Although the outcome of this transformation was uncertain, conformational analysis suggested that the product resulting from hydrogen atom abstraction at C9 would produce the least sterically encumbered chroman product. Moreover, this strategy was particularly appealing since it was expected that $\mathbf{6 8}$ could be assembled in an expedient and convergent fashion. Benzophenone $\mathbf{6 8}$ was envisioned to be accessible from tertiary alcohol 70 via an intermolecular $O$-arylation reaction with aryl bromide $69 .{ }^{41}$ We reasoned that the strained 7-membered ring in $\mathbf{7 0}$ could be formed by ring-closing metathesis, ${ }^{42}$ leading back to vinyl ketone 71, which could in turn be synthesized from known intermediates prepared during our studies of the $\mathrm{C}\left(\mathrm{sp}^{3}\right)-\mathrm{H}$ alkenylation/asymmetric Wolff rearrangement.

With this revised retrosynthetic plan, we set out to prepare vinyl ketone 71, and to also address two key challenges identified in the first generation approach: 1) to lower the catalyst loading in the conjugate addition reaction used to set the $\mathrm{C} 1$ quaternary center, and 2) to develop an epimerization sequence to prepare vinyl ketone $\mathbf{7 1}$ in the correct enantiomeric series from quinolinamide (-)-18. In terms of the latter challenge, we anticipated that the desired enantiomeric se- 
ries could be accessed by epimerization of compounds derived from 18 (e.g. 46) at C5 instead of C2 (Scheme 8). A straightforward approach would involve disfavoring $\gamma$ deprotonation at $\mathrm{C} 2$ by masking the ketone of $\mathbf{4 6}$ in order to advance to a C5 epimerization substrate. Unfortunately, these efforts proved unfruitful, as ketalization of $\mathbf{4 6}$ under a variety of conditions always resulted in rapid epimerization at C2 to furnish trans-cyclobutane $\mathbf{7 7}$ in low yields. ${ }^{43}$

a) Revised retrosynthetic analysis

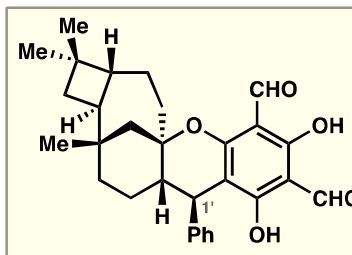

(+)-psiguadial B (3)

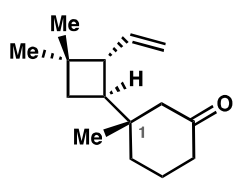

71

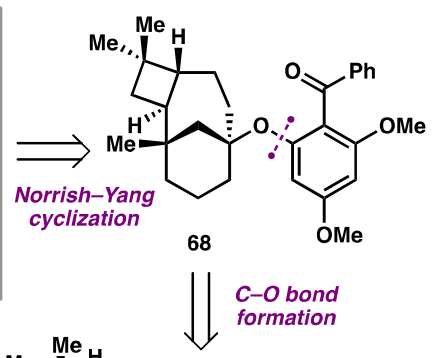

70

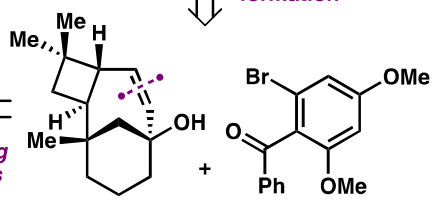

b) Regioselectivity considerations for Norrish-Yang cyclization

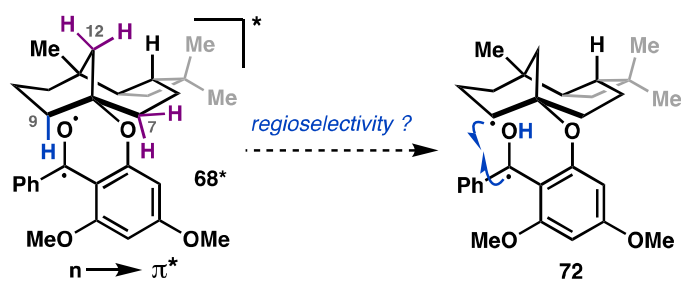

Figure 3. Second-generation retrosynthetic analysis.
Instead, it was recognized that $\mathbf{7 4}$ could be accessed directly by coupling 18 with vinyl iodide $73 .{ }^{44}$ To our delight, the $\mathrm{Pd}$-catalyzed coupling with vinyl iodide $\mathbf{7 3}$ performed even better than its enone counterpart (19), requiring only 2 equiv of $\mathbf{7 3}$ to furnish $\mathbf{7 4}$ in $\mathbf{7 2 \%}$ yield on a gram scale. Exposure of 74 to Schwartz's reagent effected reduction to the corresponding cis-aldehyde, which was epimerized at $\mathrm{C} 5$ by treatment with $\mathrm{KOH}$ in methanol to give trans-aldehyde $\mathbf{7 5}$ in $70 \%$ yield over the two steps. Gratifyingly, Wittig methylenation and hydrolysis provided (+)-76, the required enantiomer for synthesis of natural psiguadial B (3). In addition, crosscoupling of $\mathbf{7 3}$ eliminated a linear protection step and substantially improved the material throughput. ${ }^{45}$

To demonstrate that either enantiomer of 76 can be prepared using a single enantiomer of organocatalyst, an alternative sequence was also developed. Epimerization of $\mathbf{4 6}$ to the trans-cyclobutane under the previously developed conditions, followed by ketalization provided 77. Reductive cleavage of the aminoquinoline auxiliary gave the corresponding aldehyde (ent-75), which was telescoped through a Wittig olefination and hydrolysis as before to afford vinyl enone (-)-76 in 58\% yield over the two steps.

\section{Scheme 8. Development of enantiodivergent epimerization strategies.}

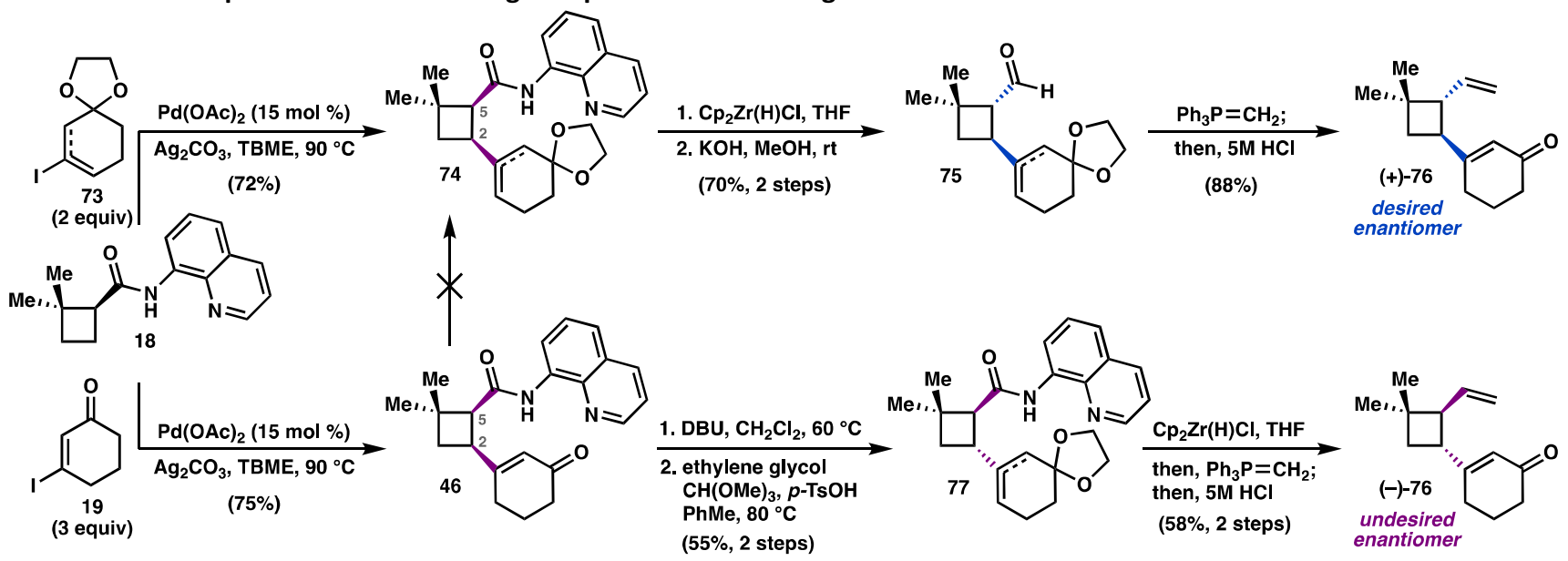

With the desired enantiomer of enone $\mathbf{7 6}$ in hand, attention turned to the installation of the C1 quaternary center using a catalytic asymmetric conjugate addition. In the absence of the aminoquinoline auxiliary, we were pleased to find that use of CUTC (15 mol \%) in conjunction with ligand ent-48 (30 mol \%) provided 71 in $94 \%$ yield and 19:1 dr
(Scheme 9). Addition of vinyl Grignard to ketone $\mathbf{7 1}$ proceeded uneventfully, providing alcohol $\mathbf{7 8}$ in excellent yield and diastereoselectivity. Gratifyingly, exposure of $\mathbf{7 8}$ to secondgeneration Hoveyda-Grubbs catalyst at elevated temperature delivered bridged bicycle $\mathbf{7 0}$ in $\mathbf{9 3 \%}$ yield. Subsequent hydrogenation under standard conditions led to tertiary alcohol $\mathbf{7 9 .}$ 
After some experimentation, we found that the combination of $\mathrm{Pd}(\mathrm{OAc})_{2}$ and dppf catalyzed the intermolecular $\mathrm{O}$-arylation between 79 and aryl bromide 69, affording aryl ether 68 in $45 \%$ yield. Unfortunately, the reproducibility of this transformation proved capricious, and attempts to improve the yield through further optimization were unsuccessful. Nevertheless, a sufficient amount of $\mathbf{6 8}$ was obtained to evaluate the key Norrish-Yang cyclization.

Scheme 9. Elaboration to Norrish-Yang benzophenone.
$(+)-76$
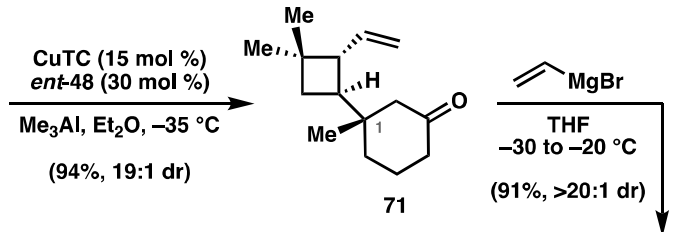

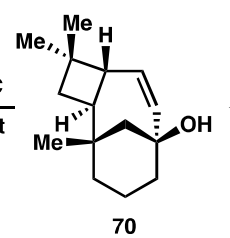

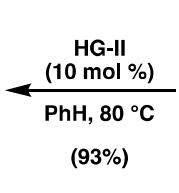

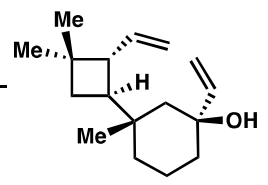

78

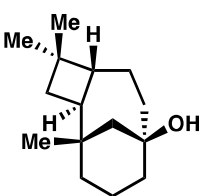

79

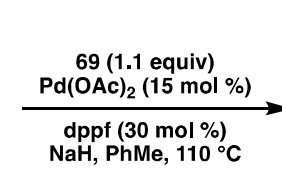

$(45 \%)$

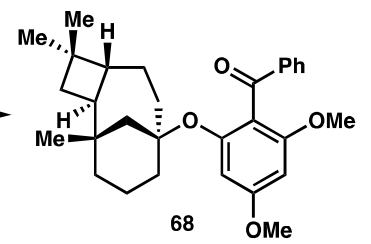

In the event, irradiation of $\mathbf{6 8}$ with $254 \mathrm{~nm}$ light in rigorously deoxygenated dioxane led to complete consumption of starting material within 1 hour and produced a complex mixture of several new products. ${ }^{46}$ The formation of the undesired Norrish-Yang product $\mathbf{8 0}$ was confirmed by 2D NMR spectroscopy; a prominent $\mathrm{HMBC}$ correlation was apparent between $\mathrm{C} 5$ and the newly formed methine proton at $\mathrm{C} 7$, and several key NOE signals were consistent with the stereochemical assignment (Scheme 10). Thus, while the anticipated reactivity was observed, $\mathbf{8 0}$ results from the wrong regioselectivity, and was isolated in a mere $6.5 \%$ yield-a result that would likely be difficult to substantially improve through reaction optimization.
Scheme 10. Evaluation of the Norrish-Yang cyclization.

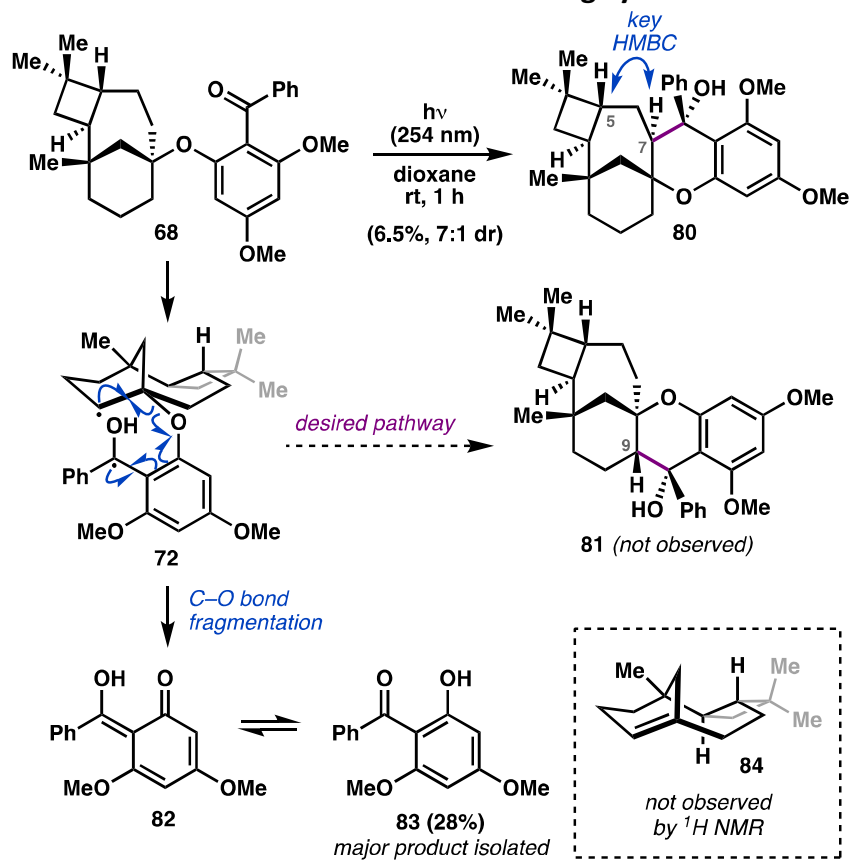

Notably, the major compound isolated from this reaction is phenol $83,{ }^{47}$ which was obtained in $28 \%$ yield. This side product presumably arises by fragmentation of diradical species $\mathbf{7 2}$ (or the diradical resulting from $\mathrm{H}$-atom abstraction at $\mathrm{C7}$ ), wherein $\mathrm{C}-\mathrm{O}$ bond cleavage expels enol tautomer 82; the resulting terpene-based fragment likely undergoes further decomposition, as alkene $\mathbf{8 4}$ or related compounds were not isolated. ${ }^{48}$ In an effort to investigate whether this competing pathway could be suppressed, we examined a number of different solvents and irradiation wavelengths in a model system, but observed rapid formation of phenol $\mathbf{8 3}$ in all cases. Having determined that the late-stage Norrish-Yang cyclization was an untenable strategy to complete the chroman core of $\mathbf{3}$, an alternative synthetic route was devised.

\section{THIRD GENERATION STRATEGY}

In our final revision of the retrosynthesis, we simplified 3 to 85 and elected to construct the C9-C1' bond at an earlier stage (Figure 4). Invoking a similar disconnection through the $\mathrm{C}-\mathrm{O}$ aryl bond as in our second-generation route, it was anticipated that an intramolecular ring closure would prove more reliable than the challenging intermolecular arylation employed previously (see Scheme 9). This bond scission revealed aryl bromide 86, which could be accessed using the established ring-closing metathesis, while the arene functionality at C9 could be installed via aldol condensation with vinyl ketone 71. 


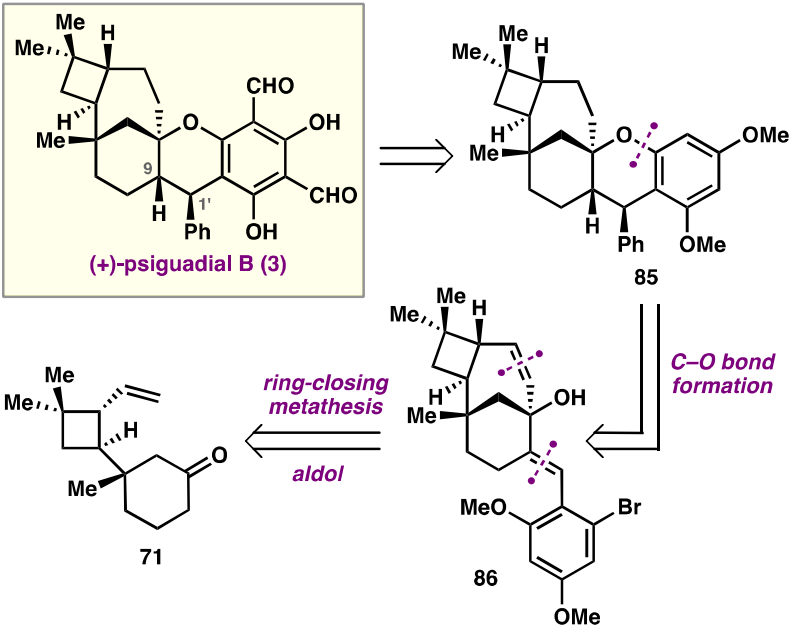

Figure 4. Third generation retrosynthetic analysis.

In the forward sense, a methanolic solution of vinyl ketone $\mathbf{7 1}$ and aldehyde $\mathbf{8 7}$ was treated with potassium hydroxide at elevated temperature to afford exo-enone $\mathbf{8 8}$ in $92 \%$ yield (Scheme 11). Attempts to incorporate the $\mathrm{C}^{\prime}$ ' phenyl group at this stage via conjugate addition were met with limited success, yielding only trace amounts of $\mathbf{9 0}$ as an inseparable mixture of diastereomers at $\mathrm{C} 9$ and $\mathrm{C}^{\prime}$. An alternative aldol condensation between 71 and benzophenone 69 (see Figure $\mathbf{3}$ for structure) failed to produce $\mathbf{8 9}$ under otherwise identical conditions or Mukaiyama aldol conditions. Given the inability to introduce the C1' phenyl substituent at this point, we elected to advanced $\mathbf{8 8}$ and attempt to install this group at a later stage in the synthesis.

In contrast to the previous system lacking substitution at C9 (i.e. 71), 1,2-addition into this more sterically hindered ketone proved challenging. Treatment of $\mathbf{8 8}$ with vinyl magnesium bromide under the conditions used previously led to incomplete conversion-presumably due to competitive $\alpha$ deprotonation-affording 91 (Scheme 12) in low yields and moderate diastereoselectivity. ${ }^{26}$ Attempts to improve conversion using Lewis acid activators gave higher yields of 91, but resulted in lower levels of diastereoselectivity $(<2: 1)$. Ultimately, the desired allylic alcohol was obtained in good yield with serviceable $d r$ by employing vinyllithium in THF at -78 ${ }^{\circ} \mathrm{C}$, allowing isolation of $\mathbf{9 1}$ as a single diastereomer in $54 \%$ yield. The ring-closing metathesis proceeded with equal efficiency on this new substrate to furnish 86 in $93 \%$ yield. With the strained sesquiterpene framework secured, both the diand trisubstituted olefins in $\mathbf{8 6}$ were hydrogenated in the presence of Crabtree's catalyst, which engaged in a hydroxyldirected reduction ${ }^{49}$ to establish the C9 stereogenic center with $16: 1 \mathrm{dr}$, providing 93 in excellent yield. The final ring of the psiguadial framework was formed by a Cu-catalyzed in- tramolecular $O$-arylation reaction, which furnished pentacycle 94 in $75 \%$ yield. ${ }^{50}$

Scheme 11. Installation of C9-C1' bond via aldol reaction.

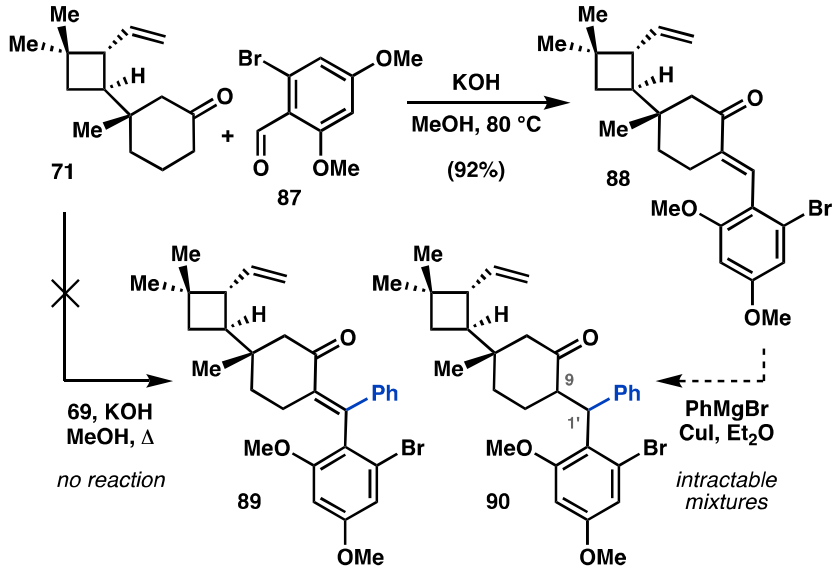

With the successful development of a scalable and highyielding route to 94 , the task of appending the $\mathrm{C}_{1}$ ' phenyl group was now at hand. Ideally, the electron rich arene in $\mathbf{9 4}$ would be engaged directly in a benzylic arylation reaction; a possible mechanism would involve benzylic oxidation at $\mathrm{C}^{\prime}$ followed by trapping with a phenyl nucleophile. Whereas a number of laboratories have shown that electron rich arenes can trap benzylic cations in simple systems, ${ }^{51}$ it was unclear whether an electronically neutral, unsubstituted phenyl group would be sufficiently reactive to engage as the nucleophile in this type of transformation. Nonetheless, we investigated this possibility with reagents commonly used in flavonoid chemistry (e.g. DDQ, ${ }^{51 a, d, 52}$ Chloranil, $\mathrm{Pb}_{3} \mathrm{O}_{4},{ }^{53}$ Oxone $/ \mathrm{CuSO}_{4}{ }^{54}$ and $\mathrm{NOBF}_{4}{ }^{55}$ ), followed by trapping with benzene, $\mathrm{PhMgBr}$, or $\mathrm{PhB}(\mathrm{OH})_{2}$, all without success. Efforts to apply Shi's $\mathrm{FeCl}_{2}$-catalyzed benzylic dehydrogenative arylation, ${ }^{56}$ or Muramatsu's $\mathrm{C}\left(\mathrm{sp}^{3}\right)-\mathrm{H}$ arylation using DDQ and PIFA $^{57}$ were also unfruitful.

Having failed to achieve a direct arylation, a stepwise protocol was employed. Oxidation with DDQ in the presence of ethoxyethanol ${ }^{52}$ afforded $95-$ a relatively stable productwhich could be isolated in modest yields. The remaining mass balance of the reaction consisted of side products suspected to result from over oxidation and elimination of the benzylic ether. A survey of reaction parameters revealed that adding acetonitrile as a co-solvent led to cleaner reaction profiles, albeit at the expense of conversion. Presumably, the acetonitrile solvent helps to stabilize the intermediate benzylic cation (i.e. 96), favoring more efficient trapping with ethoxyethanol over unproductive side reactions. Synthetically useful yields of 95 were obtained under these conditions by re-subjecting recovered $\mathbf{9 4}$ to the reaction conditions a second time.

Scheme 12. Synthesis of the core of (+)-psiguadial B. 


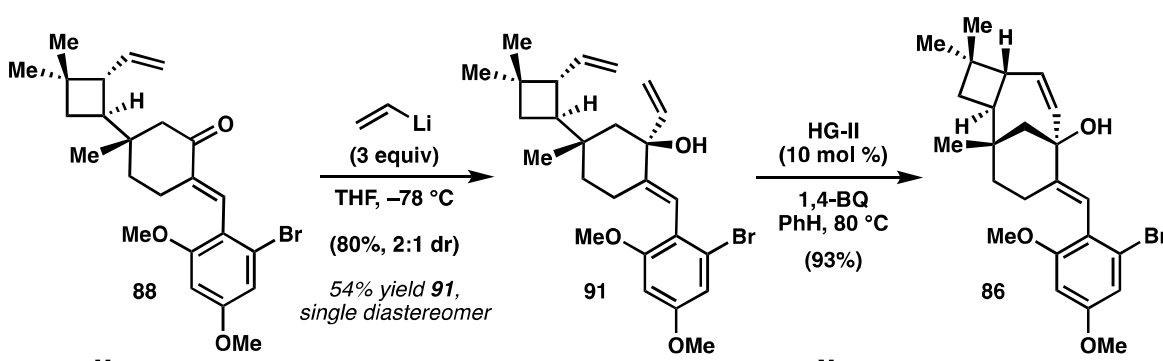

DDQ, $\mathrm{Pb}_{3} \mathrm{O}_{4}$, Chloranil, $\mathrm{NOBF}_{4}$ Oxone/CuSO ${ }_{4}, \mathrm{FeCl}_{2}$, PIFA

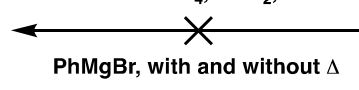

$\mathrm{PhMgBr}$, with and without $\Delta$

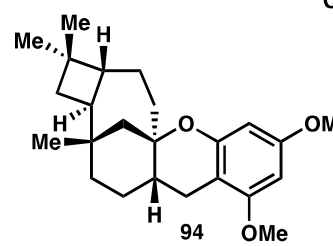

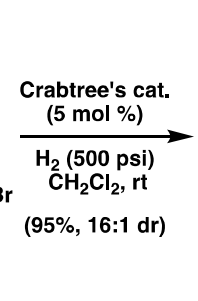

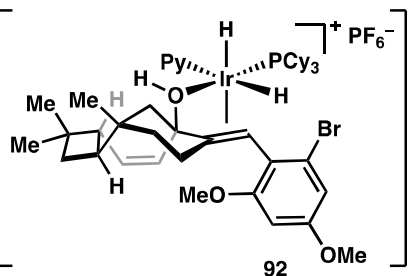

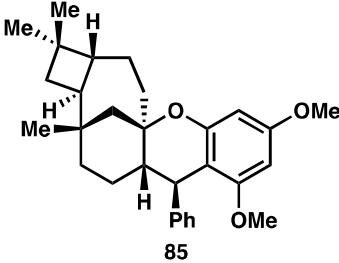
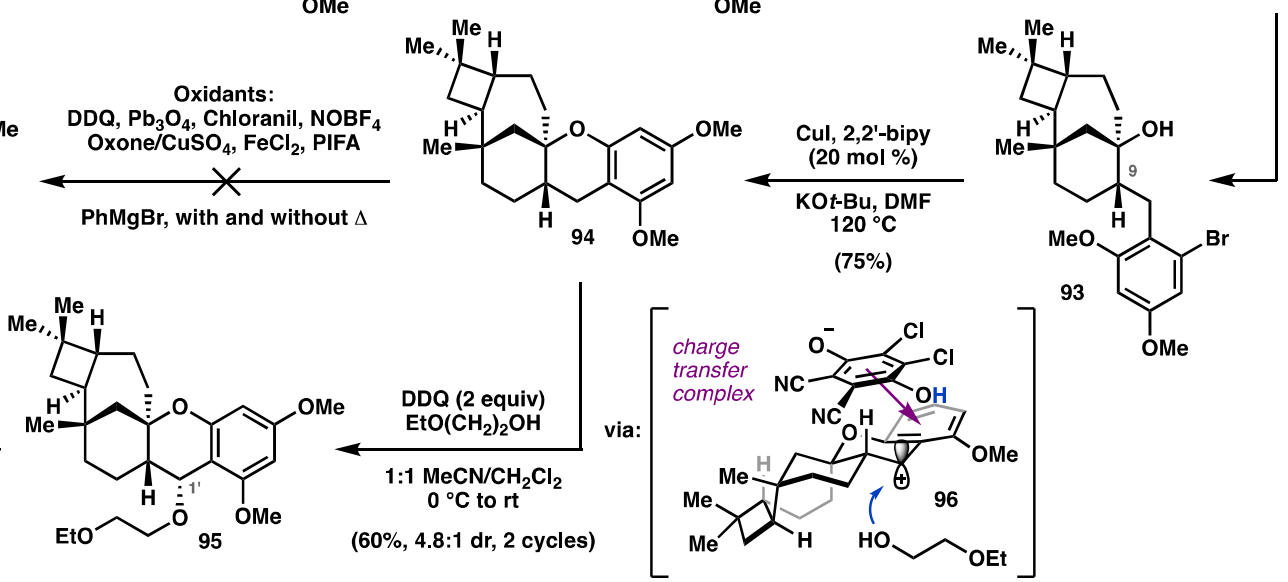

was iso-

With respect to the stereochemistry at $\mathrm{C}^{\prime}$ ', 95 was isolated as a 4.8:1 mixture of diastereomers, favoring the $\alpha$ disposed ether. Conformational analysis of $\mathbf{9 4}$ indicates that the 7-membered ring protrudes from the bottom face of the molecule, suggesting that $\mathrm{C}-\mathrm{O}$ bond formation appears to proceed with contrasteric selectivity. The observed stereochemical outcome might result from an overall double inversion process that proceeds by initial association of DDQ from the less hindered top face of $\mathbf{9 4}$ to form a tightly bound charge-transfer complex (i.e. 96). ${ }^{58}$ If this complex remains closely associated, ethoxyethanol would then attack from the bottom face, thus leading to $\alpha$-ether 95 as the major diastereomer.

With a functional handle installed at C1', TMSOTf was initially investigated as a Lewis acid to activate the ethoxyethyl benzyl ether, however, no phenylated product was obtained using $\mathrm{PhB}(\mathrm{OH})_{2}$, or $\mathrm{PhMgBr}$ as nucleophiles (Table 2, entries 1 and 2). ${ }^{52 b}$ Simple heating ${ }^{59}$ or nickel-catalyzed Kumada coupling with $\mathrm{PhMgBr}$ in $\mathrm{PhMe}^{60}$ yielded only eliminated products and complex reaction profiles (entries 3-5). Likewise, Bode's conditions for the addition of aryl trifluoroborates to oxonium ions, which use $\mathrm{BF}_{3} \bullet \mathrm{OEt}_{2}$ as the Lewis acid, failed to produce 85 (entries 6 and 7). ${ }^{61}$ We were therefore delighted to obtain a near quantitative yield of 85 (in 1.7:1 dr) by treating a mixture of $\mathbf{9 5}$ and lithium diphenylcyanocuprate with $\mathrm{BF}_{3} \bullet \mathrm{OEt}_{2}$ (entry 8). ${ }^{62}$ After some experimentation, it was found that the diastereoselectivity could be slightly improved to $2: 1$ by holding the reaction at $-45^{\circ} \mathrm{C}$ (entry 9). Although colder temperatures led to a further improvement in $\mathrm{dr}$, this was accompanied by a lower yield (entry 10).

As the $\mathrm{C} 1$ ' diastereomers of $\mathbf{8 5}$ were inseparable by silica gel chromatography, the mixture was subjected to pyridine hydrochloride at $200{ }^{\circ} \mathrm{C}$, which afforded the corresponding demethylated products in $92 \%$ combined yield (Scheme 13 ).
At this stage, the diastereomeric resorcinols were readily separable by column chromatography, providing 97 as a single diastereomer in $62 \%$ yield. Finally, the remaining two aryl aldehydes were simultaneously installed using Rieche formylation conditions, ${ }^{63}$ delivering (+)-psiguadial B (3) in $50 \%$ yield. Synthetic $\mathbf{3}$ was found to be spectroscopically identical in all respects to the natural sample reported by Shao et al. ${ }^{4}$

Table 2. Investigation of the $\mathrm{C1}^{\prime}$ Phenylation.

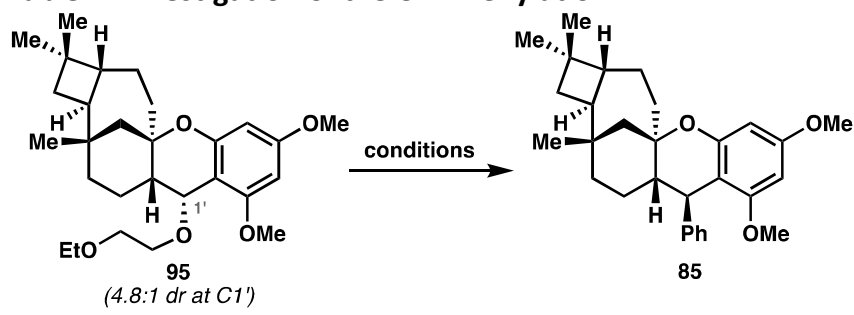

\begin{tabular}{cccccc}
\hline entry & $\begin{array}{c}\text { Lewis acid } \\
\text { or catalyst }\end{array}$ & nucleophile & solvent & $\mathrm{T}\left({ }^{\circ} \mathrm{C}\right)$ & $\begin{array}{c}\text { yield }(\%) \\
\mathbf{8 5}(\mathrm{dr})^{a}\end{array}$ \\
\hline 1 & $\mathrm{TMSOTf}$ & $\mathrm{PhB}(\mathrm{OH})_{2}$ & $\mathrm{THF}$ & -78 to 0 & 0 \\
2 & TMSOTf & $\mathrm{PhMgBr}$ & $\mathrm{THF}$ & -78 to 0 & 0 \\
3 & none & $\mathrm{PhMgBr}$ & $\mathrm{PhMe}$ & 110 & 0 \\
4 & $\mathrm{Ni}(\mathrm{dppe}) \mathrm{Cl}_{2}$ & $\mathrm{PhMgBr}$ & $\mathrm{PhMe}$ & 25 & 0 \\
5 & $\mathrm{Ni}\left(\mathrm{dppe}^{2} \mathrm{Cl}_{2}\right.$ & $\mathrm{PhMgBr}$ & $\mathrm{PhMe}$ & 25 & 0 \\
& $/ \mathrm{MgI}_{2}$ & & & & \\
6 & $\mathrm{BF}_{3} \cdot \mathrm{OEt}_{2}$ & $\mathrm{PhBF}_{3} \mathrm{~K}$ & $\mathrm{CH}_{2} \mathrm{Cl}_{2}$ & 0 to 25 & 0 \\
7 & $\mathrm{BF}_{3} \cdot \mathrm{OEt}_{2}$ & $\mathrm{PhBF}_{3} \mathrm{~K}$ & $\mathrm{MeCN}^{2}$ & 0 to 25 & 0 \\
8 & $\mathrm{BF}_{3} \cdot \mathrm{OEt}_{2}$ & $\mathrm{Ph}_{2} \mathrm{Cu}(\mathrm{CN}) \mathrm{Li}$ & $\mathrm{Et}_{2} \mathrm{O}$ & -78 to 0 & $99(1.7: 1)$ \\
9 & $\mathrm{BF}_{3} \cdot \mathrm{OEt}_{2}$ & $\mathrm{Ph}_{2} \mathrm{Cu}(\mathrm{CN}) \mathrm{Li}$ & $\mathrm{Et}_{2} \mathrm{O}$ & -78 to -45 & $90(2.0: 1)$ \\
10 & $\mathrm{BF}_{3} \cdot \mathrm{OEt}_{2}$ & $\mathrm{Ph}_{2} \mathrm{Cu}(\mathrm{CN}) \mathrm{Li}$ & $\mathrm{Et}_{2} \mathrm{O}$ & -78 to -60 & $57(3.3: 1)$ \\
\hline
\end{tabular}

${ }^{a}$ Diastereomeric ratio obtained by ${ }^{1} \mathrm{H}$ NMR analysis of crude reaction mixture, provided in parenthesis. 
Scheme 13. Completion of the synthesis of (+)-psiguadial B.
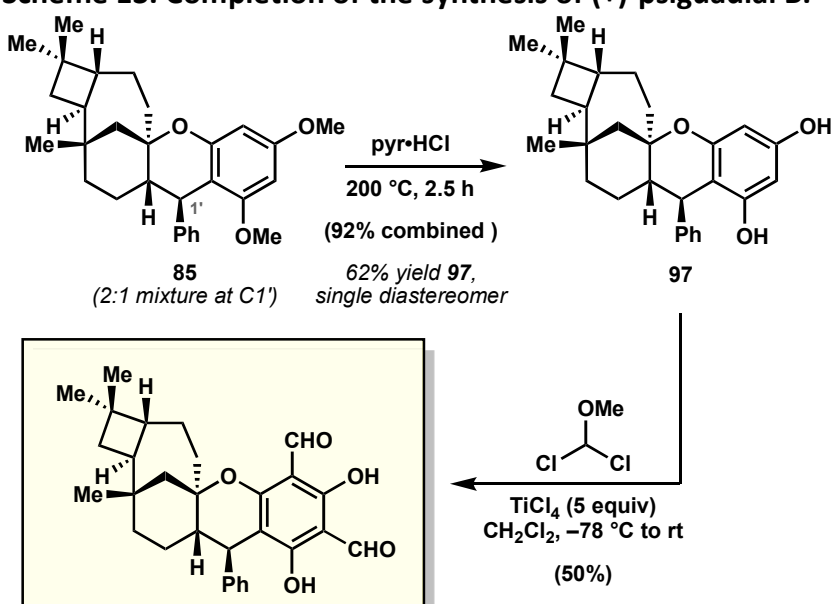

(+)-psiguadial B (3)

15 steps from diazoketone 20

\section{- CONCLUSION}

In summary, the first enantioselective total synthesis of the cytotoxic natural product, (+)-psiguadial B (3), was achieved in 15 steps from diazoketone 20 . The successful synthetic strategy was enabled by the implementation of a tandem photochemical Wolff rearrangement/asymmetric ketene addition reaction. Having developed a novel protocol for the enantioselective preparation of quinolinamide 18, a variety of substrates were evaluated and conditions were identified to prepare the corresponding 5- and 6-membered ring products. De novo construction of the trans-fused cyclobutane ring in $\mathbf{3}$ was accomplished using a strategic Pdcatalyzed $\mathrm{C}\left(\mathrm{sp}^{3}\right)-\mathrm{H}$ alkenylation reaction, followed by one of two distinct epimerization strategies, which permit access to both enantiomers of the natural product from a single enantiomer of organocatalyst.

In the course of this work, three different synthetic routes toward (+)-psiguadial B were investigated. These studies have led to the evaluation of several challenging transformations, including 1) an o-QMHDA cycloaddition between a highly functionalized enol ether and a phloroglucinolderived $o-Q M ; 2)$ a seven-membered ring-forming Prins cyclization; and 3) a modified Norrish-Yang cyclization. Ultimately, the strained sesquiterpene core was built using a remarkably efficient ring-closing metathesis, and elaborated through a short sequence to afford the natural product in $1.3 \%$ overall yield. We believe that the development of this route to $\mathbf{3}$ may enable the synthesis of unnatural analogs of $\mathbf{3}$, that would be difficult to access through semi-synthetic methods. Application of the key strategy concepts described herein to the synthesis of other trans-cyclobutane-containing natural products are currently ongoing in our laboratory.

\section{- EXPERIMENTAL}

General Procedures: Unless otherwise stated, reactions were performed under a nitrogen atmosphere using freshly dried solvents. Tetrahydrofuran (THF), methylene chloride $\left(\mathrm{CH}_{2} \mathrm{Cl}_{2}\right)$, acetonitrile $(\mathrm{MeCN})$, benzene $(\mathrm{PhH}), 1,4-d i o x a n e$, and toluene $(\mathrm{PhMe})$ were dried by passing through activated alumina columns. Triethylamine $\left(\mathrm{Et}_{3} \mathrm{~N}\right)$ and methanol $(\mathrm{MeOH})$ were distilled over calcium hydride prior to use. Unless otherwise stated, chemicals and reagents were used as received. All reactions were monitored by thin-layer chromatography (TLC) using EMD/Merck silica gel 60 F254 pre-coated plates $(0.25$ $\mathrm{mm}$ ) and were visualized by UV, $p$-anisaldehyde, or 2,4dinitrophenylhydrazine staining. Flash column chromatography was performed either as described by Still et al. ${ }^{64}$ using silica gel (particle size 0.032-0.063) purchased from Silicycle or using pre-packaged RediSep ${ }^{\circledR} \mathrm{Rf}$ columns on a CombiFlash Rf system (Teledyne ISCO Inc.). Optical rotations were measured on a Jasco P-2000 polarimeter using a $100 \mathrm{~mm}$ path-length cell at $589 \mathrm{~nm} .{ }^{1} \mathrm{H}$ and ${ }^{13} \mathrm{C}$ NMR spectra were recorded on a Bruker Avance III HD with Prodigy cryoprobe (at $400 \mathrm{MHz}$ and $101 \mathrm{MHz}$ respectively), a Varian $400 \mathrm{MR}$ (at $400 \mathrm{MHz}$ and $101 \mathrm{MHz}$, respectively), a Varian Inova 500 (at $500 \mathrm{MHz}$ and 126 $\mathrm{MHz}$, respectively), or a Varian Inova 600 (at $600 \mathrm{MHz}$ and $150 \mathrm{MHz}$, respectively), and are reported relative to internal $\mathrm{CHCl}_{3}\left({ }^{1} \mathrm{H}, \delta=\right.$ 7.26) and $\mathrm{CDCl}_{3}\left({ }^{13} \mathrm{C}, \delta=77.1\right), \mathrm{C}_{6} \mathrm{H}_{5}\left({ }^{1} \mathrm{H}, \delta=7.16\right)$ and $\mathrm{C}_{6} \mathrm{D}_{6}\left({ }^{13} \mathrm{C}, \delta=\right.$ 128), or $d_{8}$-THF $\left({ }^{1} \mathrm{H}, \delta=3.58\right)$ and $\left({ }^{13} \mathrm{C}, \delta=67.6\right)$. Data for ${ }^{1} \mathrm{H}$ NMR spectra are reported as follows: chemical shift $(\delta \mathrm{ppm})$ (multiplicity, coupling constant $(\mathrm{Hz})$, integration). Multiplicity and qualifier abbreviations are as follows: $\mathrm{s}=$ singlet, $\mathrm{d}=$ doublet, $\mathrm{t}=$ triplet, $\mathrm{q}=$ quartet, $\mathrm{m}=$ multiplet, $\mathrm{br}=$ broad, $\mathrm{app}=$ apparent. IR spectra were recorded on a Perkin Elmer Paragon 1000 spectrometer and are reported in frequency of absorption $\left(\mathrm{cm}^{-1}\right)$. HRMS were acquired using an $\mathrm{Ag}$ ilent 6200 Series TOF with an Agilent G1978A Multimode source in electrospray ionization (ESI), atmospheric pressure chemical ionization (APCI), or mixed (MM) ionization mode. Analytical SFC was performed with a Mettler SFC supercritical $\mathrm{CO}_{2}$ analytical chromatography system with a Chiralcel AD-H column $(4.6 \mathrm{~mm} \times 25 \mathrm{~cm})$.

Procedures and characterization data for compounds 3, 18, 20, $46,47,71,73,74,75,76,77,85,86,88,91,93,94,95,97$ were reported previously. ${ }^{12}$

Preparation of diazoketone $20:^{21,65}$ To each of two flame-dried $1 \mathrm{~L}$ round-bottom flasks was added $\mathrm{NaH}$ (60\% dispersion in mineral oil, $3.17 \mathrm{~g}, 79.2 \mathrm{mmol}, 1.20$ equiv) and the atmosphere was exchanged for $\mathrm{N}_{2}$ one time. Dry $\mathrm{Et}_{2} \mathrm{O}(30.0 \mathrm{~mL})$ was then added via syringe and the suspension cooled to $0{ }^{\circ} \mathrm{C}$. Ethyl formate $(12.4 \mathrm{~mL}$, $152 \mathrm{mmol}, 2.30$ equiv) was then added, followed by 2,2dimethylcyclopentanone $(7.40 \mathrm{~g}, 66.0 \mathrm{mmol})$ either neat, or as a 3.0 $\mathrm{M}$ solution in $\mathrm{Et}_{2} \mathrm{O}$. A catalytic amount of wet methanol $(\sim 100 \mu \mathrm{L})$ was then added and the reaction left to stir at $0{ }^{\circ} \mathrm{C} .{ }^{66}$ Upon completion, the reaction solidifies to a chunky, white solid that dissolved readily upon the addition of $\mathrm{DI} \mathrm{H}_{2} \mathrm{O}$. At this point, both reaction mixtures were combined for workup: after dilution with $\mathrm{Et}_{2} \mathrm{O}$, the layers were separated and the aqueous layer was washed with $\mathrm{Et}_{2} \mathrm{O} 3 \mathrm{x}$ to remove organic impurities and a small amount of unreacted starting material. The aqueous layer was then cooled to $0{ }^{\circ} \mathrm{C}$ and acidified to $\mathrm{pH}=3$ using $5 \mathrm{M} \mathrm{HCl}$. Et ${ }_{2} \mathrm{O}$ was then added and the acidified aqueous layer was extracted $6 x$. The combined organics were then dried over $\mathrm{Mg}_{2} \mathrm{SO}_{4}$, filtered, and concentrated in vacuo into a $500 \mathrm{~mL}$ roundbottom flask.

The crude $\alpha$-formyl ketone was taken up in $\mathrm{CH}_{2} \mathrm{Cl}_{2}(132 \mathrm{~mL})$ and the solution cooled to $-10{ }^{\circ} \mathrm{C}$. Triethylamine $(55.2 \mathrm{~mL}, 396 \mathrm{mmol}$, 5.00 equiv) was added, followed by solid $p-\mathrm{ABSA}^{67}(31.8 \mathrm{~g}, 132 \mathrm{mmol}$, 1.00 equiv) in three portions. The reaction was stirred for 3 hours and allowed to gradually reach $10{ }^{\circ} \mathrm{C}$, at which point an aqueous solution of $\mathrm{KOH}(55.0 \mathrm{~mL}, 4 \mathrm{M})$ was added. Additional $\mathrm{CH}_{2} \mathrm{Cl}_{2}$ and $\mathrm{H} 2 \mathrm{O}$ were added, the layers were separated and the aqueous layer extracted with $\mathrm{CH}_{2} \mathrm{Cl}_{2}$ until no product remains by TLC. The combined organics were dried over $\mathrm{Mg}_{2} \mathrm{SO}_{4}$, filtered, and concentrated in vacuo. The crude residue was purified by silica gel flash chromatography (20-30\% Et ${ }_{2} \mathrm{O} /$ pentane) to afford 20 (17.4 g, 95\% yield) as a bright yellow oil. ${ }^{1} \mathrm{H}$ NMR (400 MHz, $\left.\mathrm{CDCl}_{3}\right) \delta 2.88(\mathrm{t}, \mathrm{J}=7.0 \mathrm{~Hz}, 2 \mathrm{H}), 1.77(\mathrm{t}$, 
$J=7.2 \mathrm{~Hz}, 2 \mathrm{H}), 1.04(\mathrm{~d}, J=1.0 \mathrm{~Hz}, 6 \mathrm{H}) .{ }^{1} \mathrm{H}$ NMR $\left(400 \mathrm{MHz}, d_{8}-\mathrm{THF}\right) \delta$ $2.94(\mathrm{t}, J=7.0 \mathrm{~Hz}, 2 \mathrm{H}), 1.79(\mathrm{t}, J=7.2 \mathrm{~Hz}, 2 \mathrm{H}), 1.04(\mathrm{~s}, 6 \mathrm{H}) .{ }^{13} \mathrm{C}$ NMR $\left(101 \mathrm{MHz}, \mathrm{CDCl}_{3}\right) \delta 204.8,56.6,46.3,35.7,24.1,21.2 .{ }^{13} \mathrm{C}$ NMR (101 $\mathrm{MHz}, d_{8}$-THF) $\delta 203.6,56.1,46.9,36.6,24.5,21.9$. FTIR (NaCl, thin film) 3754, 3414, 3332, 2962, 2934, 2892, 2869, 2672, 2642, 2578, 2510, 2080, 1981, 1673, 1581, 1471, 1460, 1382, 1362, 1339, 1309, $1267,1245,1204,1133,1110,1058,1030,994,977,948,919,893$, $780,726,697 \mathrm{~cm}^{-1}$

Diazoketones 38-41 were prepared according to the procedure developed for 20. Spectroscopic data for $\mathbf{4 0}$ and $\mathbf{4 1}$ are consistent with that reported in the literature. ${ }^{68}$

(38): Yellow Oil, (1.76 g, 36\% yield over 2 steps). ${ }^{1} \mathbf{H}$ NMR (400 $\left.\mathrm{MHz}, \mathrm{CDCl}_{3}\right) \delta 2.71(\mathrm{t}, J=6.5 \mathrm{~Hz}, 2 \mathrm{H}), 1.82-1.73(\mathrm{~m}, 2 \mathrm{H}), 1.68-1.61$ $(\mathrm{m}, 2 \mathrm{H}), 1.15(\mathrm{~s}, 6 \mathrm{H}) .{ }^{13} \mathrm{C}$ NMR $\left(101 \mathrm{MHz}, \mathrm{CDCl}_{3}\right) \delta 200.1,62.6,42.0$, 37.5, 26.7, 22.9, 18.5. FTIR ( NaCl, thin film) 2943, 2864, 2082, 1626, $1472,1449,1381,1342,1317,1275,1261,1220,1201,1162,1122$, 1044, 1011, 910, 853, 738, $658 \mathrm{~cm}^{-1}$ HRMS (EI) calc'd for $\mathrm{C}_{8} \mathrm{H}_{12} \mathrm{~N}_{2} \mathrm{O}$ $[\mathrm{M}]^{+}$152.0950, found 152.0956 .

(39): Yellow Oil, $\left(400.0 \mathrm{mg}, 26 \%\right.$ yield over 2 steps) ${ }^{1} \mathbf{H}$ NMR $\left(400 \mathrm{MHz}, \mathrm{CDCl}_{3}\right) \delta 2.55$ (ddt, $\left.J=7.0,4.8,2.3 \mathrm{~Hz}, 2 \mathrm{H}\right), 1.75(\mathrm{dt}, \mathrm{J}=4.4$, $2.8 \mathrm{~Hz}, 4 \mathrm{H}$ ), 1.57 (ddt, $J=6.3,3.4,1.7 \mathrm{~Hz}, 2 \mathrm{H}$ ), 1.17 (s, 6H). ${ }^{13} \mathrm{C}$ NMR $\left(101 \mathrm{MHz}, \mathrm{CDCl}_{3}\right) \delta 202.2,68.3,47.0,37.9,29.5,25.8,25.7$, 25.6. FTIR ( $\mathrm{NaCl}$, thin film) 2981, 2966, 2927, 2858, 2083, 1704, 1617, 1474. $1448,1387.1364,1350,1324,1272,1251,1231,1203,1147,1113$, 1057, 1020, 980, 953, 871, 845, 736, $656 \mathrm{~cm} .^{-1}$ HRMS (El) calc'd for $\mathrm{C}_{9} \mathrm{H}_{14} \mathrm{~N}_{2} \mathrm{O}[\mathrm{M}]^{+}$166.1106, found 166.1095.

Small-scale screening protocol for enantioenriched amides 18, 42-45: Oven-dried quartz tubes were each charged with aminoquinoline ( $21.6 \mathrm{mg}, 0.150 \mathrm{mmol}, 3.00$ equiv) and catalyst (50 mol \%). Inside a $\mathrm{N}_{2}$-filled glovebox, diazoketones $20,38-40$ (0.05 mmol) were then added to each as a solution in $0.500 \mathrm{~mL}$ THF (excluding diazoketone 41, which was added as a solid outside of the glovebox). The reactions were then sealed with a 19/38 rubber septum around the outside of each tube and sealed with electrical tape. The reactions were then brought out of the glovebox and placed in a bottomless test tube rack in front of a Honeywell $254 \mathrm{~nm}$ lamp. The reactions were irradiated with stirring at room temperature for 18 hours. The reactions were then concentrated in vacuo, and the crude reaction mixtures were analyzed by ${ }^{1} \mathrm{H}$ NMR with an added internal standard to determine $\%$ yield. The crude residues were purified by silica gel preparative $\mathrm{TLC}\left(2 \% \mathrm{Et}_{2} \mathrm{O} / \mathrm{CH}_{2} \mathrm{Cl}_{2}\right)$ to provide $18,42-45$ in varying yields and enantiopurities.

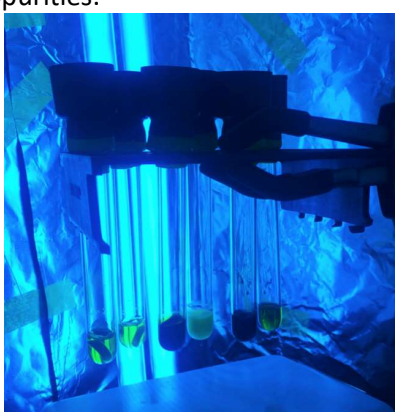

Large-scale protocol for enantioenriched amide 18:65 To a flame-dried, $1 \mathrm{~L}$ quartz flask was added 8-aminoquinoline (29) (12.9 g, $89.5 \mathrm{mmol}, 3.00$ equiv) and (+)-cinchonine (30) $(879 \mathrm{mg}, 2.99$ mmol, 0.100 equiv). The flask was evacuated and backfilled with $\mathrm{N}_{2}$ three times and dry THF $(600 \mathrm{~mL})$ was then added via cannula. Diazoketone 20 ( $4.12 \mathrm{~g}, 29.8 \mathrm{mmol}, 1.00$ equiv) was added last via syringe and the reaction was irradiated with stirring using a Honeywell $254 \mathrm{~nm}$ lamp at room temperature. Reaction progress was monitored by TLC (72-168 hours are typically required for complete conversion on this scale, and rotation of the flask every day provided faster conversion). ${ }^{69}$ Upon completion, the reaction mixture was concentrated in vacuo, the solids were taken up in $\mathrm{CH}_{2} \mathrm{Cl}_{2}$, and the suspension filtered. The filter cake was washed with $\mathrm{CH}_{2} \mathrm{Cl}_{2}$ three times and the filtrate was concentrated in vacuo to give a crude residue that was purified by silica gel flash chromatography (isocratic: $6 \%$ EtOAc/hexane) to provide $18(4.69 \mathrm{~g}, 62 \%)$ as a pale-yellow solid. The enantiomeric excess was determined to be $79 \%$ by chiral SFC analysis (AD-H, $2.5 \mathrm{~mL} / \mathrm{min}, 20 \% \mathrm{IPA}$ in $\mathrm{CO}_{2}, \lambda=254 \mathrm{~nm}$ ): $\mathrm{t}_{R}$ (major $)=4.23 \mathrm{~min}, \mathrm{t}_{R}$ (minor) $=5.64 \mathrm{~min} .[\alpha]_{D}^{25.0}=-66.0^{\circ}(\mathrm{c}=0.560$, $\mathrm{CHCl}_{3}$ ). Enantioenriched cyclobutane 18 was dissolved in a minimal amount of $\mathrm{CH}_{2} \mathrm{Cl}_{2}$ in a $100 \mathrm{~mL}$ round-bottom flask. An equal amount of hexanes was carefully layered on top of the $\mathrm{CH}_{2} \mathrm{Cl}_{2}$ to form a biphasic mixture. The layers were allowed to diffuse overnight to provide 18 as white, crystalline needles ( $\mathrm{mp}: 66-68^{\circ} \mathrm{C}$ ). The supernatant was concentrated under reduced pressure and this process was repeated again to provide additional 18 ( $3.50 \mathrm{~g}$ total, $83 \%$ recovery of theoretical total of the desired enantiomer, $46 \%$ overall from 20$)$ : $[\alpha]_{D}^{25.0}=-109^{\circ}\left(\mathrm{c}=0.720, \mathrm{CHCl}_{3}\right) .{ }^{1} \mathrm{H}$ NMR $\left(400 \mathrm{MHz}, \mathrm{CDCl}_{3}\right) \delta 9.68(\mathrm{~s}$, $1 \mathrm{H}), 8.80(\mathrm{t}, J=1.8 \mathrm{~Hz}, 1 \mathrm{H}), 8.79(\mathrm{dd}, J=13.6,1.6 \mathrm{~Hz}, 1 \mathrm{H}), 8.15$ (dd, $J$ $=8.3,1.7 \mathrm{~Hz}, 1 \mathrm{H}), 7.52(\mathrm{q}, J=8.2,7.5 \mathrm{~Hz}, 1 \mathrm{H}), 7.48(\mathrm{dd}, J=8.3,1.6 \mathrm{~Hz}$, $1 \mathrm{H}), 7.45$ (dd, $J=8.3,4.2 \mathrm{~Hz}, 1 \mathrm{H}$ ), 3.07 (ddd, $J=9.1,8.2,0.9 \mathrm{~Hz}, 1 \mathrm{H}$ ), $2.48(\mathrm{dq}, J=11.4,9.4 \mathrm{~Hz}, 1 \mathrm{H}), 2.06(\mathrm{dtd}, J=11.6,8.6,3.3 \mathrm{~Hz}, 1 \mathrm{H})$, $1.85(\mathrm{dt}, J=10.8,9.1 \mathrm{~Hz}, 1 \mathrm{H}$ ), 1.74 (dddd, $J=10.7,9.5,3.3,0.9 \mathrm{~Hz}$, $1 \mathrm{H}), 1.39(\mathrm{~s}, 3 \mathrm{H}), 1.14(\mathrm{~s}, 3 \mathrm{H}){ }^{13} \mathrm{C}$ NMR $\delta 171.8,148.3,138.6,136.4$, 134.7, 128.1, 127.6, 121.7, 121.3, 116.4, 51.0, 40.4, 32.3, 30.9, 23.4, 17.4. FTIR ( $\mathrm{NaCl}$, thin film) 3353, 3047, 2952, 2861, 1685, 1595, 1577, $1526,1485,1460,1424,1385,1324,1261,1239,1187,1169,1153$, $825,791,756 \mathrm{~cm}^{-1}$ HRMS (MM) calc'd for $\mathrm{C}_{16} \mathrm{H}_{19} \mathrm{~N}_{2} \mathrm{O}[\mathrm{M}+\mathrm{H}]^{+}$ 255.1492, found 255.1501 .

(42), $0.2 \mathrm{mmol}$ scale: Inside a $\mathrm{N}_{2}$ filled glovebox, an oven-dried quartz tube was charged with aminoquinoline (29) $(86.5 \mathrm{mg}, 0.600$ mmol, 3.00 equiv) and (34) $(32.5 \mathrm{mg}, 0.100 \mathrm{mmol}, 0.500$ equiv). Diazoketone (38) (33.2 $\mathrm{mg}, 0.200 \mathrm{mmol}, 1.00$ equiv) was added as a solution in $2.00 \mathrm{~mL}$ THF and the tube was sealed with a 19/38 rubber septum and secured with electrical tape. The reaction was removed from the glovebox and placed in a bottomless test tube rack in front of a Honeywell $254 \mathrm{~nm}$ lamp for 48 hours. The reaction mixture was then concentrated in vacuo. The crude residue was purified via silica gel flash chromatography (6\% EtOAc/hexanes) to afford $\mathbf{4 2}$ (37.5 mg, $77 \%$ yield) as a brown oil. The enantiomeric excess was determined to be $71 \%$ by chiral SFC analysis (AD-H, $2.5 \mathrm{~mL} / \mathrm{min}, 20 \%$ IPA in $\mathrm{CO}_{2}, \lambda$ $=254 \mathrm{~nm}): \mathrm{t}_{R}$ (major) $=4.28 \mathrm{~min}, \mathrm{t}_{R}($ minor $)=5.41 \mathrm{~min}$.

(42), $1 \mathrm{mmol}$ scale: Inside a $\mathrm{N}_{2}$ filled glovebox, an oven-dried quartz tube was charged with aminoquinoline (29) $(433 \mathrm{mg}, 3.00$ mmol, 3.00 equiv) and (34) (64.9 $\mathrm{mg}, 0.200 \mathrm{mmol}, 0.200$ equiv). Diazoketone (38) (166 mg, $1.00 \mathrm{mmol}, 1.00$ equiv) was added as a solution in $10.0 \mathrm{~mL}$ THF and the tube was sealed with a 19/38 rubber septum and secured with electrical tape. The reaction was removed from the glovebox and placed in a bottomless test tube rack in front of a Honeywell $254 \mathrm{~nm}$ lamp for 48 hours. The reaction mixture was then concentrated in vacuo. The crude residue was purified via silica gel flash chromatography (6\% EtOAc/hexanes) to afford $\mathbf{4 2}$ (215 mg, $80 \%$ yield) as a brown oil. The enantiomeric excess was determined to be $67 \%$ by chiral SFC analysis (AD-H, $2.5 \mathrm{~mL} / \mathrm{min}, 20 \%$ IPA in $\mathrm{CO}_{2}, \lambda$ $=254 \mathrm{~nm}): \mathrm{t}_{R}($ major $)=4.28 \mathrm{~min}, \mathrm{t}_{R}($ minor $)=5.41 \mathrm{~min} .[\alpha]_{D}^{25.0}=-$ $32.5^{\circ}\left(\mathrm{c}=2.075, \mathrm{CHCl}_{3}\right) .{ }^{1} \mathrm{H}$ NMR $\left(400 \mathrm{MHz}, \mathrm{CDCl}_{3}\right) \delta 9.80(\mathrm{~s}, 1 \mathrm{H}), 8.81$ $(\mathrm{d}, J=1.7 \mathrm{~Hz}, 1 \mathrm{H}), 8.80$ (dd, $J=3.0,1.7 \mathrm{~Hz}, 1 \mathrm{H}$ ), 8.16 (dd, $J=8.3,1.7$ $\mathrm{Hz}, 1 \mathrm{H}), 7.57-7.47(\mathrm{~m}, 2 \mathrm{H}), 7.45(\mathrm{dd}, J=8.3,4.2 \mathrm{~Hz}, 1 \mathrm{H}), 2.61(\mathrm{t}, J=$ $8.4 \mathrm{~Hz}, 1 \mathrm{H}), 2.38-2.22(\mathrm{~m}, 1 \mathrm{H}), 2.02(\mathrm{dtd}, J=13.2,8.5,4.4 \mathrm{~Hz}, 1 \mathrm{H})$, $1.95-1.82(\mathrm{~m}, 1 \mathrm{H}), 1.79-1.65(\mathrm{~m}, 2 \mathrm{H}), 1.63-1.57(\mathrm{~m}, 1 \mathrm{H}), 1.31(\mathrm{~s}$, $3 \mathrm{H}), 1.01(\mathrm{~s}, 3 \mathrm{H}) .{ }^{13} \mathrm{C}$ NMR $\left(101 \mathrm{MHz}, \mathrm{CDCl}_{3}\right) \delta 173.1,148.3,138.6$, 136.5, 134.8, 128.1, 127.6, 121.7, 121.3, 116.4, 58.1, 43.2, 42.1, 29.7, 27.9, 24.0, 22.5. FTIR (NaCl, thin film) 3362, 2957, 2924, 2854, 1729, $1690,1525,1486,1464,1424,1381,1325,1262,1164,1145,1132$, 
1072, 825, 791, $720 \mathrm{~cm} \cdot .^{-1}$ HRMS (MM) calc'd for $\mathrm{C}_{17} \mathrm{H}_{21} \mathrm{~N}_{2} \mathrm{O}[\mathrm{M}+\mathrm{H}]^{+}$ 269.1648, found 269.1645 .

(43), $0.2 \mathrm{mmol}$ scale: Inside a $\mathrm{N}_{2}$ filled glovebox, an oven-dried quartz tube was charged with 8 -aminoquinoline (29) $(86.5 \mathrm{mg}, 0.600$ mmol, 3.00 equiv) and (33) (32.5 mg, $0.100 \mathrm{mmol}, 0.500$ equiv). Diazoketone (39) $(31.0 \mathrm{mg}, 0.200 \mathrm{mmol}, 1.00$ equiv) was added as a solution in $2.00 \mathrm{~mL}$ THF and the tube was sealed with a 19/38 rubber septum and secured with electrical tape. The reaction was removed from the glovebox and placed in a bottomless test tube rack in front of a Honeywell $254 \mathrm{~nm}$ lamp for 48 hours. The reaction mixture was then concentrated in vacuo. The crude residue was purified via silica gel flash chromatography (6\% EtOAc/hexanes) to afford $\mathbf{4 3}$ (33.3 mg, $59 \%$ yield) as a brown oil. The enantiomeric excess was determined to be $71 \%$ by chiral SFC analysis (AD-H, $2.5 \mathrm{~mL} / \mathrm{min}, 12 \%$ IPA in $\mathrm{CO}_{2}, \lambda$ $=254 \mathrm{~nm}): \mathrm{t}_{R}$ (major) $=9.67 \mathrm{~min}, \mathrm{t}_{R}$ (minor) $=10.34 \mathrm{~min}$.

(43), $1 \mathrm{mmol}$ scale: Inside a $\mathrm{N}_{2}$ filled glovebox, an oven-dried quartz tube was charged with 8-aminoquinoline $(29)(433 \mathrm{mg}, 3.00$ mmol, 3.00 equiv) and (33) (64.9 $\mathrm{mg}, 0.200 \mathrm{mmol}, 0.200$ equiv). Diazoketone (39) (152 mg, $1.00 \mathrm{mmol}, 1.00$ equiv) was added as a solution in $10.0 \mathrm{~mL}$ THF and the tube was sealed with a 19/38 rubber septum and secured with electrical tape. The reaction was removed from the glovebox and placed in a bottomless test tube rack in front of a Honeywell $254 \mathrm{~nm}$ lamp for 48 hours. The reaction mixture was then concentrated in vacuo. The crude residue was purified via silica gel flash chromatography (6\% EtOAc/hexanes) to afford $\mathbf{4 3}$ (189 mg, $67 \%$ yield) as a brown oil. The enantiomeric excess was determined to be $65 \%$ by chiral SFC analysis (AD-H, $2.5 \mathrm{~mL} / \mathrm{min}, 12 \%$ IPA in $\mathrm{CO}_{2}, \lambda$ $=254 \mathrm{~nm}): \mathrm{t}_{R}$ (major) $=9.67 \mathrm{~min}, \mathrm{t}_{R}$ (minor) $=10.34 \mathrm{~min} .[\alpha]_{D}^{25.0}=-$ $17.3^{\circ}\left(\mathrm{c}=1.68, \mathrm{CHCl}_{3}\right) .{ }^{1} \mathrm{H}$ NMR $(400 \mathrm{MHz}, \mathrm{CDCl} 3) \delta 9.79(\mathrm{~s}, 1 \mathrm{H}), 8.82$ $(\mathrm{d}, J=1.7 \mathrm{~Hz}, 1 \mathrm{H}), 8.80(\mathrm{dd}, J=2.7,1.7 \mathrm{~Hz}, 1 \mathrm{H}), 8.16(\mathrm{dd}, J=8.3,1.7$ $\mathrm{Hz}, 1 \mathrm{H}), 7.57-7.47(\mathrm{~m}, 2 \mathrm{H}), 7.45$ (dd, $J=8.3,4.2 \mathrm{~Hz}, 1 \mathrm{H}), 2.30$ (dd, J $=11.8,3.5 \mathrm{~Hz}, 1 \mathrm{H}), 1.99-1.78(\mathrm{~m}, 3 \mathrm{H}), 1.55-1.47(\mathrm{~m}, 2 \mathrm{H}), 1.39-$ $1.27(\mathrm{~m}, 3 \mathrm{H}), 1.13(\mathrm{~s}, 3 \mathrm{H}), 1.10(\mathrm{~s}, 3 \mathrm{H}) .{ }^{13} \mathrm{C} \mathrm{NMR}\left(101 \mathrm{MHz}, \mathrm{CDCl}_{3}\right) \delta$ 173.6, 148.3, 138.6, 136.5, 134.7, 128.1, 127.6, 121.7, 121.3, 116.5, 56.5, 41.6, 33.4, 31.5, 25.7, 25.7, 22.1, 21.2. FTIR ( NaCl, thin film) $3364,2956,2923,2852,1729,1691,1523,1486,1462,1424,1378$, 1326, 1273, 1129, 1072, 825, $790 \mathrm{~cm}^{-1}$ HRMS (MM) calc'd for $\mathrm{C}_{18} \mathrm{H}_{23} \mathrm{~N}_{2} \mathrm{O}[\mathrm{M}+\mathrm{H}]^{+}$283.1805, found 283.1796.

(44): Inside a $\mathrm{N}_{2}$ filled glovebox, an oven-dried quartz tube was charged with aminoquinoline (29) $(86.5 \mathrm{mg}, 0.600 \mathrm{mmol}, 3.00$ equiv) and (37) ( $85.7 \mathrm{mg}, 0.100 \mathrm{mmol}, 0.500$ equiv). Diazoketone (40) (31.6 $\mathrm{mg}, 0.200 \mathrm{mmol}, 1.00$ equiv) was added as a solution in $2.00 \mathrm{~mL}$ THF and the tube was sealed with a 19/38 rubber septum and secured with electrical tape. The reaction was removed from the glovebox and placed in a bottomless test tube rack in front of a Honeywell 254 $\mathrm{nm}$ lamp for 48 hours. The reaction mixture was then concentrated in vacuo. The crude residue was purified via silica gel flash chromatography (5-50\% EtOAc/hexanes followed by $0-1 \% \mathrm{Et}_{2} \mathrm{O} / \mathrm{CH}_{2} \mathrm{Cl}_{2}$ ) to afford 44 (16.8 mg, 31\% yield). The enantiomeric excess was determined to be $34 \%$ by chiral SFC analysis (AD-H, $2.5 \mathrm{~mL} / \mathrm{min}, 30 \%$ IPA in $\left.\mathrm{CO}_{2}, \lambda=254 \mathrm{~nm}\right): \mathrm{t}_{R}$ (major) $=5.06 \mathrm{~min}, \mathrm{t}_{R}($ minor $)=6.89 \mathrm{~min} .[\alpha]_{D}^{25.0}$ $=-4.1^{\circ}\left(\mathrm{c}=0.565, \mathrm{CHCl}_{3}\right) .{ }^{1} \mathrm{H} \mathrm{NMR}\left(400 \mathrm{MHz}, \mathrm{CDCl}_{3}\right) \delta 10.21(\mathrm{~s}, 1 \mathrm{H})$, $8.79(\mathrm{dd}, J=11.5,1.7 \mathrm{~Hz}, 1 \mathrm{H}), \delta 8.78(\mathrm{~d}, J=1.7 \mathrm{~Hz}, 1 \mathrm{H}), 8.15(\mathrm{dd}, J=$ 8.3, $1.7 \mathrm{~Hz}, 1 \mathrm{H}), 7.54(\mathrm{dd}, J=8.3,7.2 \mathrm{~Hz}, 1 \mathrm{H}), 7.50(\mathrm{dd}, J=8.3,1.8 \mathrm{~Hz}$, $1 \mathrm{H}), 7.46-7.41(\mathrm{~m}, 2 \mathrm{H}), 7.38-7.29(\mathrm{~m}, 2 \mathrm{H}), 7.22-7.16(\mathrm{~m}, 1 \mathrm{H})$, 4.56 (ddt, $J=5.8,2.9,0.8 \mathrm{~Hz}, 1 \mathrm{H}$ ), 3.69 (ddd, $J=14.2,5.7,0.7 \mathrm{~Hz}, 1 \mathrm{H}$ ), 3.60 (ddd, $J=14.2,2.9,0.8 \mathrm{~Hz}, 1 \mathrm{H}) .{ }^{13} \mathrm{C}$ NMR $(101 \mathrm{MHz}, \mathrm{CDCl} 3) \delta$ 170.6, 148.4, 144.7, 142.9, 138.7, 136.4, 134.5, 128.6, 128.0, 127.8, 127.5, 123.5, 122.7, 121.7, 121.7, 116.5, 49.3, 35.2. FTIR ( $\mathrm{NaCl}$, thin film) 3347, 3066, 2928, 2851, 1680, 1596, 1578, 1526, 1485, 1458, $1424,1386,1328,1262,1240,1202,1162,1132,869,826,791,759$, 734, 707, $679 \mathrm{~cm}^{-1}$ HRMS (MM) calc'd for $\mathrm{C}_{18} \mathrm{H}_{15} \mathrm{~N}_{2} \mathrm{O}[\mathrm{M}+\mathrm{H}]^{+}$ 275.1179 , found 275.1178 .
(45): An oven-dried quartz tube was charged with diazoketone (41) (34.4 mg, $0.200 \mathrm{mmol}, 1.00$ equiv). The tube was brought into a $\mathrm{N}_{2}$ filled glovebox, and subsequently charged with aminoquinoline (29) $(86.5 \mathrm{mg}, 0.600 \mathrm{mmol}, 3.00$ equiv) and (36) $(88.1 \mathrm{mg}, 0.100$ mmol, 0.500 equiv). The mixture was suspended in $2.00 \mathrm{~mL}$ THF and the tube was sealed with a 19/38 rubber septum and secured with electrical tape. The reaction was removed from the glovebox and placed in a bottomless test tube rack in front of a Honeywell $254 \mathrm{~nm}$ lamp for 48 hours. The reaction mixture was then concentrated in vacuo. The crude residue was purified via silica gel flash chromatography (5-10\% EtOAc/hexanes) to afford 45 ( $24.1 \mathrm{mg}, 42 \%$ yield) as a brown oil. The enantiomeric excess was determined to be $75 \%$ by chiral SFC analysis (AD-H, $2.5 \mathrm{~mL} / \mathrm{min}, 30 \%$ IPA in $\left.\mathrm{CO}_{2}, \lambda=254 \mathrm{~nm}\right): \mathrm{t}_{R}$ $($ major $)=5.73 \mathrm{~min}, \mathrm{t}_{R}($ minor $)=4.86 \mathrm{~min} .[\alpha]_{D}^{25.0}=65.0^{\circ}(\mathrm{c}=0.91$, $\left.\mathrm{CHCl}_{3}\right) .{ }^{1} \mathrm{H}$ NMR $\left(400 \mathrm{MHz}, \mathrm{CDCl}_{3}\right) \delta 10.06(\mathrm{~s}, 1 \mathrm{H}), 8.79$ (dd, $J=7.1,1.9$ $\mathrm{Hz}, 1 \mathrm{H}), 8.75(\mathrm{dd}, J=4.2,1.7 \mathrm{~Hz}, 1 \mathrm{H}), 8.15(\mathrm{dd}, J=8.3,1.7 \mathrm{~Hz}, 1 \mathrm{H})$, $7.56-7.46(\mathrm{~m}, 3 \mathrm{H}), 7.44$ (dd, $J=8.3,4.2 \mathrm{~Hz}, 1 \mathrm{H}), 7.33(\mathrm{~d}, J=7.2 \mathrm{~Hz}$, $1 \mathrm{H}), 7.31-7.18(\mathrm{~m}, 2 \mathrm{H}), 4.27(\mathrm{dd}, J=8.4,6.1 \mathrm{~Hz}, 1 \mathrm{H}), 3.23(\mathrm{dt}, J=$ 15.2, 7.4 Hz, 1H), $3.09-2.95(\mathrm{~m}, 1 \mathrm{H}), 2.69-2.48(\mathrm{~m}, 2 \mathrm{H}) .{ }^{13} \mathrm{C}$ NMR $\left(101 \mathrm{MHz} \mathrm{CDCl}_{3}\right) \delta 172.7,148.4,144.8,141.5,138.7,136.4,134.7$, $128.0,127.9,127.53,126.9,125.1,125.0,121.7,121.7,116.6,54.0$, 32.1, 30.4. FTIR ( $\mathrm{NaCl}$, thin film) 3347, 2957, 2923, 2852, 1728, 1689, $1524,1484,1461,1424,1380,1325,1272,1163,1132,1072,826$, 791, $743 \mathrm{~cm}^{-1}$ HRMS (MM) calc'd for $\mathrm{C}_{19} \mathrm{H}_{17} \mathrm{~N}_{2} \mathrm{O}[\mathrm{M}+\mathrm{H}]^{+}$289.1335, found 289.1334 .

(50): To a flame-dried $100 \mathrm{~mL}$ flask was added copper (I) iodide (1.48 g, $7.75 \mathrm{mmol}, 5.00$ equiv) and $\mathrm{Et}_{2} \mathrm{O}(15.5 \mathrm{~mL})$. The resulting suspension was cooled to $-40{ }^{\circ} \mathrm{C}$ and methyllithium (1.6 $\mathrm{M}$ in $\mathrm{Et}_{2} \mathrm{O}$; $9.68 \mathrm{~mL}, 15.5 \mathrm{mmol}, 10$ equiv) was added dropwise. The reaction mixture was stirred at $-40{ }^{\circ} \mathrm{C}$ for 2 hours before 47 (540 mg, 1.55 mmol) was added dropwise as a solution in $5: 2 \mathrm{CH}_{2} \mathrm{Cl}_{2} / \mathrm{Et}_{2} \mathrm{O}$. The reaction mixture was gradually warmed to $0{ }^{\circ} \mathrm{C}$ over 4 hours, then quenched with saturated aqueous $\mathrm{NH}_{4} \mathrm{Cl}(10 \mathrm{~mL})$ and diluted with EtOAc. $\mathrm{NH}_{4} \mathrm{OH}$ was added until all of the solid copper salts were sequestered and two homogenous layers remained. The aqueous layer was extracted with EtOAc $(3 \times 20 \mathrm{~mL})$ and the combined organics dried over $\mathrm{MgSO}_{4}$, filtered, and concentrated in vacuo. The crude residue was purified by silica gel flash chromatography (isocratic: $20 \%$ EtOAc/Hexane) to afford a 2.5:1 mixture of $\mathbf{4 9}$ and $\mathbf{5 0}$ (543 mg, $96 \%$ yield), respectively as a white amorphous solid. Subsequent purification by reverse-phase HPLC using two Agilent Eclipse XDB-C8 5 um $9.4 \times 250 \mathrm{~mm}$ columns connected in series (gradient: 77$85 \% \mathrm{MeCN} / \mathrm{H}_{2} \mathrm{O}$ ) afforded analytically pure samples of each diastereomer, from which $\mathbf{5 0}$ was crystallized for X-Ray analysis ${ }^{26}$ ( $\mathrm{mp}$ : 80-83 ${ }^{\circ} \mathrm{C}$ ). Data for minor diastereomer 50: $[\alpha]_{D}^{25.0}=-25.5^{\circ}$ (c = 1.50, $\left.\mathrm{CHCl}_{3}\right) .{ }^{1} \mathrm{H}$ NMR $\left(500 \mathrm{MHz}, \mathrm{CDCl}_{3}\right) \delta 9.64(\mathrm{~s}, 1 \mathrm{H}), 8.82(\mathrm{dd}, J=4.2,1.7$ $\mathrm{Hz}, 1 \mathrm{H}), 8.75(\mathrm{dd}, J=7.4,1.6 \mathrm{~Hz}, 1 \mathrm{H}), 8.17(\mathrm{dd}, J=8.3,1.7 \mathrm{~Hz}, 1 \mathrm{H})$, $7.56-7.48(\mathrm{~m}, 2 \mathrm{H}), 7.46(\mathrm{dd}, J=8.2,4.2 \mathrm{~Hz}, 1 \mathrm{H}), 2.89-2.77(\mathrm{~m}, 2 \mathrm{H})$, $2.35-2.26(\mathrm{~m}, 2 \mathrm{H}), 2.24(\mathrm{~d}, J=13.3 \mathrm{~Hz}, 1 \mathrm{H}), 2.09(\mathrm{~d}, J=13.4 \mathrm{~Hz}, 1 \mathrm{H})$, $2.07-1.99(\mathrm{~m}, 1 \mathrm{H}), 1.88-1.77(\mathrm{~m}, 1 \mathrm{H}), 1.72-1.61(\mathrm{~m}, 3 \mathrm{H}), 1.55-$ $1.48(\mathrm{~m}, 1 \mathrm{H}), 1.35(\mathrm{~s}, 3 \mathrm{H}), 1.13(\mathrm{~s}, 3 \mathrm{H}), 0.92(\mathrm{~s}, 3 \mathrm{H}) .{ }^{13} \mathrm{C}$ NMR $(126$ $\left.\mathrm{MHz}, \mathrm{CDCl}_{3}\right) \delta 212.4,170.6,148.4,138.5,136.5,134.6,128.1,127.6$, $121.7,121.4,116.4,51.5,50.8,41.2,39.8,39.6,35.2,34.1,33.0$, 30.8, 23.7, 22.2, 21.3. FTIR ( NaCl, thin film) 3349, 3044, 2952, 2863, $1706,1687,1595,1577,1523,1484,1460,1424,1383,1325,1238$, $1228,1163,827,792 \mathrm{~cm}^{-1}$ HRMS (MM) calc'd for $\mathrm{C}_{23} \mathrm{H}_{29} \mathrm{~N}_{2} \mathrm{O}_{2}[\mathrm{M}+\mathrm{H}]^{+}$ 365.2224, found 365.2261. XRCD: A suitable crystal of $\mathrm{C}_{23} \mathrm{H}_{28} \mathrm{~N}_{2} \mathrm{O}_{2}$ (50) was selected for analysis. Low-temperature diffraction data ( $\phi$ and $\omega$-scans) were collected on a Bruker AXS D8 VENTURE KAPPA diffractometer coupled to a PHOTON $100 \mathrm{CMOS}$ detector with $\mathrm{Cu}-\mathrm{K \alpha}$ radiation ( $\lambda=1.54178 \AA$ ) from a I $\mu \mathrm{S}$ HB micro-focus sealed X-ray tube. All diffractometer manipulations, including data collection, integration, and scaling were carried out using the Bruker APEXII software. ${ }^{70}$ 
(49): Inside a $\mathrm{N}_{2}$-filled glovebox, $[\mathrm{Cu}(\mathrm{OTf})]_{2} \bullet \mathrm{PhMe}(72.4 \mathrm{mg}$, $0.140 \mathrm{mmol}, 0.25$ equiv) and $(S, R, R)$ ligand $48^{71}(302 \mathrm{mg}, 0.560 \mathrm{mmol}$, 1.00 equiv) were added to a $25 \mathrm{~mL}$ flask. The reagents were suspended in $\mathrm{Et}_{2} \mathrm{O}(5.60 \mathrm{~mL})$ and stirred at room temperature for 30 mins before trans-cyclobutane $47(195 \mathrm{mg}, 0.560 \mathrm{mmol})$ was added as a solid, in one portion. The reaction was sealed under $\mathrm{N}_{2}$, removed from the glovebox and cooled to $-30{ }^{\circ} \mathrm{C}$ under argon using a cryocool unit to control the temperature. $\mathrm{Me}_{3} \mathrm{Al}(2.0 \mathrm{M}$ in heptane; $560 \mu \mathrm{L}$, $1.12 \mathrm{mmol}, 2.00$ equiv) was then added dropwise, taking care to avoid an exotherm and the reaction mixture stirred vigorously at -30 ${ }^{\circ} \mathrm{C}$ for 16 hours. $\mathrm{MeOH}(1.00 \mathrm{~mL})$ was then added to quench excess $\mathrm{Me}_{3} \mathrm{Al}$ and then the reaction was warmed to room temperature. The mixture was diluted with EtOAc and $\mathrm{H}_{2} \mathrm{O}$, then the organic layer was separated. The aqueous layer was extracted with EtOAc $(3 \times 5 \mathrm{~mL})$ and the combined organics dried over $\mathrm{MgSO}_{4}$, filtered, and concentrated in vacuo. The crude residue was purified by silica gel flash chromatography $\left(2 \% \mathrm{Et}_{2} \mathrm{O} / \mathrm{CH}_{2} \mathrm{Cl}_{2}\right.$ until ligand/impurities elute, then $4 \% \mathrm{Et}_{2} \mathrm{O} / \mathrm{CH}_{2} \mathrm{Cl}_{2}$ ) to afford a $30: 1$ mixture of $\mathbf{4 9}$ and $\mathbf{5 0}(126 \mathrm{mg}, 62 \%$ yield), respectively as a white solid: $[\alpha]_{D}^{25.0}=-84.7^{\circ}(\mathrm{c}=0.600$, $\mathrm{CHCl}_{3}$ ). ${ }^{1} \mathrm{H}$ NMR $\left(400 \mathrm{MHz}, \mathrm{CDCl}_{3}\right) \delta 9.64(\mathrm{~s}, 1 \mathrm{H}), 8.81(\mathrm{dd}, J=4.2,1.7$ $\mathrm{Hz}, 1 \mathrm{H}), 8.75$ (dd, $J=7.2,1.8 \mathrm{~Hz}, 1 \mathrm{H}), 8.16(\mathrm{dd}, J=8.3,1.7 \mathrm{~Hz}, 1 \mathrm{H})$, $7.56-7.47(\mathrm{~m}, 2 \mathrm{H}), 7.45(\mathrm{dd}, J=8.3,4.2 \mathrm{~Hz}, 1 \mathrm{H}), 2.89-2.76(\mathrm{~m}, 2 \mathrm{H})$, $2.36-2.28(\mathrm{~m}, 2 \mathrm{H}), 2.25(\mathrm{ddd}, J=12.5,6.6,1.1 \mathrm{~Hz}, 1 \mathrm{H}), 2.04(\mathrm{dt}, J=$ 13.4, $2.0 \mathrm{~Hz}, 1 \mathrm{H}), 1.96(\mathrm{ddq}, J=13.7,7.0,3.6 \mathrm{~Hz}, 1 \mathrm{H}), 1.81(\mathrm{dtt}, J=$ 13.7, 12.0, $5.0 \mathrm{~Hz}, 1 \mathrm{H}), 1.68-1.62(\mathrm{~m}, 2 \mathrm{H}), 1.62-1.51(\mathrm{~m}, 2 \mathrm{H}), 1.35$ $(\mathrm{s}, 3 \mathrm{H}), 1.13(\mathrm{~s}, 3 \mathrm{H}), 0.89(\mathrm{~s}, 3 \mathrm{H}) .{ }^{13} \mathrm{C}$ NMR $\left(101 \mathrm{MHz}, \mathrm{CDCl}_{3}\right) \delta 212.4$, 170.6, 148.3, 138.5, 136.5, 134.6, 128.1, 127.5, 121.7, 121.4, 116.4, 51.5, 50.4, 41.3, 40.9, 39.5, 35.2, 33.8, 32.6, 30.8, 23.7, 22.1, 20.8. FTIR ( $\mathrm{NaCl}$, thin film) 3351, 3047, 2954, 2870, 1708, 1688, 1524, $1485,1460,1424,1384,1325,1281,1259,1240,1228,1163,919$, 827, 792, 757, $732 \mathrm{~cm}^{-1}$ HRMS (MM) calc'd for $\mathrm{C}_{23} \mathrm{H}_{29} \mathrm{~N}_{2} \mathrm{O}_{2}[\mathrm{M}+\mathrm{H}]^{+}$ 365.2224, found 365.2228 .

(51): To a flame-dried $15 \mathrm{~mL}$ flask was added ketone 49 (100 $\mathrm{mg}, 0.274 \mathrm{mmol}$ ) and dissolved in freshly distilled $\mathrm{MeOH}(2.7 \mathrm{~mL})$. Trimethylorthoformate $(150 \mu \mathrm{L}, 1.37 \mathrm{mmol}, 5.00$ equiv) was then added, followed by $p$-toluenesulfonic acid monohydrate $(2.60 \mathrm{mg}$, $0.014 \mathrm{mmol}, 0.05$ equiv). The reaction was topped with a reflux condenser and heated to $65^{\circ} \mathrm{C}$ for 1 hour, then quenched with saturated aqueous $\mathrm{NaHCO}_{3}$. The aqueous layer was extracted with EtOAc ( $3 \times 5$ $\mathrm{mL}$ ), and the combined organics were dried over $\mathrm{MgSO}_{4}$, filtered, and concentrated in vacuo. The crude residue was purified by Florisil $^{\circ}$ flash chromatography (isocratic: $\mathbf{1 0 \%}$ EtOAc/Hexane) to afford $\mathbf{5 1}$ (106 mg, 94\% yield) as a white, foamy solid: $[\alpha]_{D}^{25.0}=-83.3^{\circ}(\mathrm{c}=1.60$, $\left.\mathrm{CHCl}_{3}\right) .{ }^{1} \mathrm{H}$ NMR $\left(400 \mathrm{MHz}, \mathrm{CDCl}_{3}\right) \delta 9.66(\mathrm{~s}, 1 \mathrm{H}), 8.81$ (dd, $J=4.3,1.7$ $\mathrm{Hz}, 1 \mathrm{H}), 8.78$ (dd, $J=7.4,1.6 \mathrm{~Hz}, 1 \mathrm{H}), 8.14(\mathrm{dd}, J=8.3,1.7 \mathrm{~Hz}, 1 \mathrm{H})$, $7.56-7.46(\mathrm{~m}, 2 \mathrm{H}), 7.44(\mathrm{dd}, J=8.3,4.2 \mathrm{~Hz}, 1 \mathrm{H}), 3.16(\mathrm{~s}, 3 \mathrm{H}), 3.13(\mathrm{~s}$, $3 \mathrm{H}), 2.80(\mathrm{~d}, J=10.0 \mathrm{~Hz}, 1 \mathrm{H}$ ), $2.69(\mathrm{q}, J=9.7 \mathrm{~Hz}, 1 \mathrm{H}$ ), 2.01 (ddd, $J=$ 13.2, 3.5, $1.6 \mathrm{~Hz}, 1 \mathrm{H}), 1.74(\mathrm{dt}, J=14.0,2.4 \mathrm{~Hz}, 1 \mathrm{H}), 1.70-1.50(\mathrm{~m}$, 4H), $1.31(\mathrm{~s}, 3 \mathrm{H}), 1.28-1.13(\mathrm{~m}, 4 \mathrm{H}), 1.11(\mathrm{~s}, 3 \mathrm{H}), 1.01(\mathrm{~s}, 3 \mathrm{H}) .{ }^{13} \mathrm{C}$ NMR $\left(101 \mathrm{MHz} \mathrm{CDCl}_{3}\right) \delta 171.0,148.3,138.5,136.4,134.7,128.0$, 127.6, 121.6, 121.2, 116.4, 100.8, 51.3, 47.9, 47.3, 42.3, 38.6, 34.8, $34.7,34.0,33.3,32.5,30.7,23.9,21.4,18.8$. FTIR ( $\mathrm{NaCl}$, thin film) $3356,3048,2950,2867,2828,1690,1525,1485,1460,1424,1384$, $1368,1325,1288,1276,1261,1242,1155,1108,1096,1048,946$, 927, 826, 792, 756, 690, $666 \mathrm{~cm}^{-1}$ HRMS (MM) calc'd for $\mathrm{C}_{24} \mathrm{H}_{31} \mathrm{~N}_{2} \mathrm{O}_{2}$ $\left[\mathrm{M}-\mathrm{OCH}_{3}\right]^{+}$379.2380, found 379.2376 .

(17): To a $15 \mathrm{~mL}$ thick-walled, screw top pressure vessel were added dimethyl ketal $\mathbf{5 1}(59.8 \mathrm{mg}, 0.146 \mathrm{mmol})$ and PhMe $(5.0 \mathrm{~mL})$. The tube sealed under a stream of $\mathrm{N}_{2}$. The reaction was heated to $170{ }^{\circ} \mathrm{C}$ in a preheated oil bath for 3.5 hours. The reaction was then cooled to room temperature and concentrated in vacuo to afford $\mathbf{1 7}$ (55.1 mg, quantitative yield), an inseparable $\sim 1: 1$ mixture of enol ether isomers, as a foamy colorless gum: $[\alpha]_{D}^{25.0}=-78.8^{\circ}(\mathrm{c}=1.25$, $\left.\mathrm{CHCl}_{3}\right) .{ }^{1} \mathrm{H}$ NMR $\left(400 \mathrm{MHz}, \mathrm{CDCl}_{3}\right) \delta 9.70(\mathrm{~s}, 1 \mathrm{H}), 8.90-8.72(\mathrm{~m}, 2 \mathrm{H})$, $8.15(\mathrm{dd}, J=8.2,1.5 \mathrm{~Hz}, 1 \mathrm{H}), 7.57-7.40(\mathrm{~m}, 3 \mathrm{H}), 4.48(\mathrm{~s}, 1 \mathrm{H}), 3.48(\mathrm{~s}$, $3 \mathrm{H}), 2.87-2.74(\mathrm{~m}, 2 \mathrm{H}), 2.12-1.93(\mathrm{~m}, 2 \mathrm{H}), 1.74-1.57(\mathrm{~m}, 4 \mathrm{H})$, $1.48-1.36(\mathrm{~m}, 1 \mathrm{H}), 1.33(\mathrm{~s}, 3 \mathrm{H}), 1.31-1.27(\mathrm{~m}, 1 \mathrm{H}), 1.12(\mathrm{~s}, 3 \mathrm{H})$, 0.97 (s, 3H). ${ }^{13} \mathrm{C}$ NMR $\left(101 \mathrm{MHz}, \mathrm{CDCl}_{3}\right) \delta 171.6,171.0,156.3,154.3$, $148.3,148.3,138.6,138.5,136.4,136.4,134.8,134.7,128.5,128.1$, $128.1,127.6,126.9,126.8,121.7,121.6,121.2,121.2,116.4,116.3$, 99.4, 92.1, 54.1, 53.9, 52.6, 51.5, 40.9, 40.1, 36.4, 35.4, 35.2, 34.0, $33.5,33.0,32.6,30.9,30.8,30.7,29.9,28.2,26.1,25.1,24.1,23.9$, 21.2, 20.7, 19.5. FTIR ( $\mathrm{NaCl}$, thin film) 3354, 3051, 2949, 2930, 2862, $1690,1668,1524,1484,1461,1424,1384,1368,1326,1238,1215$, 1162, 1147, 1026, 826, 791, 756, $694 \mathrm{~cm}^{-1}$ HRMS (MM) calc'd for $\mathrm{C}_{24} \mathrm{H}_{31} \mathrm{~N}_{2} \mathrm{O}_{2}[\mathrm{M}+\mathrm{H}]^{+}$379.2380, found 379.2395 .

(55): To a flame-dried $100 \mathrm{~mL}$ round-bottom flask were added phloroglucinol $54^{72}(1.00 \mathrm{~g}, 4.13 \mathrm{mmol})$, followed by freshly distilled $\mathrm{MeOH}$ (41.0 mL). Benzaldehyde (421 $\mu \mathrm{L}, 4.13 \mathrm{mmol}, 1.00$ equiv), morpholine ( $361 \mu \mathrm{L}, 4.13 \mathrm{mmol}, 1.00$ equiv), and triethylamine ( 576 $\mu \mathrm{L}, 4.13 \mathrm{mmol}, 1.00$ equiv) were then added successively via syringe and the reaction stirred at room temperature for 24 hours. The precipitate thus formed was collected by vacuum filtration and washed with $\mathrm{MeOH}(20 \mathrm{~mL})$ and dried under high vacuum to afford analytically pure 55 (1.19 g, 69\% yield) as a white powder. ${ }^{1} \mathbf{H}$ NMR (400 $\left.\mathrm{MHz}, \mathrm{CDCl}_{3}\right) \delta 15.34(\mathrm{~s}, 1 \mathrm{H}), 13.16(\mathrm{~s}, 1 \mathrm{H}), 12.53(\mathrm{~s}, 1 \mathrm{H}), 7.45(\mathrm{~d}, J=$ $7.2 \mathrm{~Hz}, 2 \mathrm{H}), 7.34-7.20(\mathrm{~m}, 3 \mathrm{H}), 4.88(\mathrm{~s}, 1 \mathrm{H}), 3.99(\mathrm{~s}, 3 \mathrm{H}), 3.91(\mathrm{~s}, 3 \mathrm{H})$, $3.90-3.40$ (br m, 4H), 3.08 (br s, $1 \mathrm{H}), 2.46$ (ddd, $J=11.9,6.2,3.1 \mathrm{~Hz}$, 2H), 2.18 (br s, 1H). ${ }^{13} \mathrm{C}$ NMR (101 MHz, CDCl $) \delta 171.7,166.2,165.6$, 165.1, 138.2, 128.9, 128.4, 103.8, 96.5, 94.2, 69.0, 66.6, 52.7, 52.6. FTIR ( $\mathrm{NaCl}$, thin film) 3404 (br), 3062, 3030, 2955, 2894, 2854, 2716, 2562 (br), 2252, 1953 (br), 1731, 1654, 1603, 1494, 1454, 1431, $1403,1326,1290,1250,1205,1169,1121,1080,1029,1006,986$, $942,915,878,843,825,808,761,732,700,648 \mathrm{~cm}^{-1}$ HRMS (MM) calc'd for $\mathrm{C}_{21} \mathrm{H}_{24} \mathrm{NO}_{8}[\mathrm{M}+\mathrm{H}]^{+} 418.1496$, found 418.1515 .

(16): To a $50 \mathrm{~mL}$ round-bottom flask was added benzhydryl morpholine 55 (200 mg, $0.479 \mathrm{mmol})$, followed by a 1:1 mixture of $\mathrm{THF} / \mathrm{H}_{2} \mathrm{O}$ (9.6 mL). p-Toluenesulfonic acid monohydrate $(91.1 \mathrm{mg}$, $0.479 \mathrm{mmol}, 1.00$ equiv) was then added in one portion and the reaction was heated to $60^{\circ} \mathrm{C}$ for 4 hours. Note: it is best to monitor this reaction closely by TLC to mitigate degradation of the product to $\mathbf{5 4}$, presumably via acid-mediated retro aldol. Upon completion, the reaction was cooled to room temperature and quenched with saturated aqueous $\mathrm{NaHCO}_{3}$. The reaction was diluted with EtOAc and the organic layer separated. The aqueous layer was extracted with EtOAc $(2 \times 5 \mathrm{~mL})$ and the combined organic layers were dried over $\mathrm{MgSO}_{4}$, filtered, and concentrated in vacuo. The crude residue was purified by silica gel flash chromatography (isocratic: $5 \% \mathrm{EtOAc} / \mathrm{CH}_{2} \mathrm{Cl}_{2}+0.5 \%$ $\mathrm{AcOH}$, necessary to avoid streaking on the column). Fractions containing pure product were combined, washed with saturated aqueous $\mathrm{NaHCO}_{3}$, dried over $\mathrm{MgSO}_{4}$, filtered, and concentrated in vacuo to afford 16 (82.0 mg, 49\% yield) as a white solid. ${ }^{1} \mathrm{H}$ NMR (400 MHz, $\left.\mathrm{CDCl}_{3}\right) \delta 11.89(\mathrm{~s}, 2 \mathrm{H}), 11.70(\mathrm{~s}, 1 \mathrm{H}), 7.46-7.39(\mathrm{~m}, 2 \mathrm{H}), 7.31(\mathrm{t}, \mathrm{J}=$ $7.4 \mathrm{~Hz}, 2 \mathrm{H}), 7.26-7.19(\mathrm{~m}, 1 \mathrm{H}), 6.38-6.23(\mathrm{~m}, 1 \mathrm{H}), 4.09(\mathrm{~d}, J=11.6$ $\mathrm{Hz}, 1 \mathrm{H}), 4.02(\mathrm{~s}, 6 \mathrm{H}) .{ }^{13} \mathrm{C}$ NMR $\left(101 \mathrm{MHz}, \mathrm{CDCl}_{3}\right) \delta 170.9,165.0,164.7$, 143.9, 128.2, 127.0, 125.6, 110.2, 94.5, 68.1, 53.2. FTIR ( $\mathrm{NaCl}$, thin film) 3563 (br), 3357 (br), 3085, 3058, 3028, 3006, 2956, 2851, 2749 (br), 1727, 1655, 1623, 1599, 1492, 1434, 1333, 1318, 1245, 1201, 1170, 1129, 1039, 1026, 972, 909, 836, 816, 733, 698, $622 \mathrm{~cm}^{-1}$ HRMS (MM) calc'd for $\mathrm{C}_{17} \mathrm{H}_{15} \mathrm{O}_{7}[\mathrm{M}-\mathrm{OH}]^{+} 331.0812$, found 331.0825 .

(57-60, thermal reaction): To a $15 \mathrm{~mL}$ thick-walled, screw top pressure vessel were added dimethyl ketal $\mathbf{5 1}(105 \mathrm{mg}, 0.256 \mathrm{mmol})$ and o-QM precursor 16 (98.0 mg, $0.281 \mathrm{mmol}, 1.10$ equiv). PhMe $(4.3 \mathrm{~mL})$ was then added and the tube sealed under a stream of argon. The reaction was heated to $170^{\circ} \mathrm{C}$ in a preheated oil bath for 21 hours. The reaction was then cooled to room temperature and concentrated in vacuo. The crude residue was first purified by silica gel flash chromatography to remove separable impurities $(4 \%$ 
EtOAc $/ \mathrm{CH}_{2} \mathrm{Cl}_{2}+0.5 \% \mathrm{AcOH}$ ) to afford a complex mixture of diastereomers, including 57-60 (109 mg, 68\% yield). Analytically pure samples of the four diastereomers produced in greatest abundance (i.e. 57-60) were obtained by subsequent reverse-phase HPLC purification using an Agilent XDB-C18 $5 \mu \mathrm{m} 30 \times 250 \mathrm{~mm}$ column (gradient: $\left.83-100 \% \mathrm{MeCN} / \mathrm{H}_{2} \mathrm{O}\right)$.

Data for 57 (peak 2): $[\alpha]_{D}^{25.0}=-32.2^{\circ}\left(\mathrm{c}=0.360, \mathrm{CHCl}_{3}\right.$ ) White Solid. ${ }^{1} \mathrm{H}$ NMR $\left(400 \mathrm{MHz}, \mathrm{CDCl}_{3}\right) \delta 12.81(\mathrm{~s}, 1 \mathrm{H}), 12.08(\mathrm{~s}, 1 \mathrm{H}), 9.65(\mathrm{~s}$, $1 \mathrm{H}), 8.78-8.74(\mathrm{~m}, 2 \mathrm{H}), 8.15(\mathrm{dd}, J=8.3,1.6 \mathrm{~Hz}, 1 \mathrm{H}), 7.53-7.46(\mathrm{~m}$, $2 \mathrm{H}), 7.43(\mathrm{dd}, J=8.3,4.2 \mathrm{~Hz}, 1 \mathrm{H}), 7.22(\mathrm{~d}, J=7.5 \mathrm{~Hz}, 2 \mathrm{H}), 7.14-7.07$ $(\mathrm{m}, 3 \mathrm{H}), 3.93(\mathrm{~s}, 3 \mathrm{H}), 3.93(\mathrm{~s}, 3 \mathrm{H}), 3.91(\mathrm{~d}, J=7.8 \mathrm{~Hz}, 1 \mathrm{H}), 3.39(\mathrm{~s}, 3 \mathrm{H})$, $2.82-2.76(\mathrm{~m}, 2 \mathrm{H}), 2.12(\mathrm{~s}, 1 \mathrm{H}), 1.86-1.73(\mathrm{~m}, 2 \mathrm{H}), 1.69-1.49(\mathrm{~m}$, $5 \mathrm{H}), 1.33(\mathrm{~s}, 3 \mathrm{H}), 1.25(\mathrm{~d}, J=9.6 \mathrm{~Hz}, 1 \mathrm{H}), 1.10(\mathrm{~s}, 3 \mathrm{H}), 1.05(\mathrm{~s}, 3 \mathrm{H}) .{ }^{13} \mathrm{C}$ NMR $\left(101 \mathrm{MHz}, \mathrm{CDCl}_{3}\right) \delta 171.4,170.8,169.9,166.0,164.7,158.9$, $148.3,145.9,138.5,136.5,134.7,128.1,128.1,127.8,127.6,126.0$, 121.7, 121.3, 116.3, 104.2, 104.1, 97.1, 95.7, 52.7, 52.7, 52.2, 49.0, 44.2, 41.7, 39.9, 37.7, 35.1, 35.1, 33.9, 30.8, 28.9, 24.0, 23.5, 22.8. FTIR ( $\mathrm{NaCl}$, thin film) 3412 (br), 3354 (br), 3059, 3022, 3006, 2951, 2928, 2864, 1731, 1686, 1654, 1648, 1643, 1594, 1524, 1484, 1459, $1426,1384,1338,1325,1249,1222,1201,1157,1122,1081,1092$, 1028, 976, 945, 936, 847, 826, 792, 755, 700, $667 \mathrm{~cm}^{-1}$ HRMS (MM) calc'd for $\mathrm{C}_{41} \mathrm{H}_{45} \mathrm{~N}_{2} \mathrm{O}_{9}[\mathrm{M}+\mathrm{H}]^{+} 709.3120$, found 709.3141 .

Data for 58 (peak 1): $[\alpha]_{D}^{25.0}=-13.8^{\circ}\left(\mathrm{c}=0.420, \mathrm{CHCl}_{3}\right)$ White Solid. ${ }^{1} \mathrm{H}$ NMR $\left(400 \mathrm{MHz}, \mathrm{CDCl}_{3}\right) \delta 12.22(\mathrm{~s}, 1 \mathrm{H}), 11.68(\mathrm{~s}, 1 \mathrm{H}), 9.65(\mathrm{~s}$, $1 \mathrm{H}), 8.81$ (dd, $J=4.2,1.7 \mathrm{~Hz}, 1 \mathrm{H}), 8.77(\mathrm{dd}, J=7.3,1.7 \mathrm{~Hz}, 1 \mathrm{H}), 8.16$ (dd, $J=8.3,1.7 \mathrm{~Hz}, 1 \mathrm{H}), 7.56-7.48(\mathrm{~m}, 2 \mathrm{H}), 7.46(\mathrm{dd}, J=8.3,4.2 \mathrm{~Hz}$, $1 \mathrm{H}), 7.24-7.16(\mathrm{~m}, 2 \mathrm{H}), 7.16-7.09(\mathrm{~m}, 1 \mathrm{H}), 7.09-7.02(\mathrm{~m}, 2 \mathrm{H})$, $3.96(\mathrm{~s}, 3 \mathrm{H}), 3.93(\mathrm{~s}, 3 \mathrm{H}), 3.91(\mathrm{~s}, 1 \mathrm{H}), 3.05(\mathrm{~s}, 3 \mathrm{H}), 2.82-2.67(\mathrm{~m}$, $2 \mathrm{H}), 2.16(\mathrm{dd}, J=12.4,3.5 \mathrm{~Hz}, 1 \mathrm{H}), 1.98(\mathrm{~d}, J=13.8 \mathrm{~Hz}, 1 \mathrm{H}), 1.76(\mathrm{dd}$, $J=13.3,4.1 \mathrm{~Hz}, 1 \mathrm{H}), 1.70-1.39(\mathrm{~m}, 6 \mathrm{H}), 1.32(\mathrm{~s}, 3 \mathrm{H}), 1.12(\mathrm{~s}, 3 \mathrm{H})$, 0.96 (s, 3H). ${ }^{13} \mathrm{C}$ NMR (101 MHz, $\left.\mathrm{CDCl}_{3}\right) \delta 171.0,170.8,169.9,165.0$, $163.1,157.2,148.3,145.6,138.5,136.5,134.7,128.1,127.8,127.6$, 127.3, 125.6, 121.7, 121.3, 116.4, 102.4, 102.1, 99.0, 95.3, 52.8, 52.5, 51.3, 47.8, 45.3, 41.9, 41.4, 40.1, 34.7, 34.6, 32.7, 32.6, 30.8, 27.4, 23.8, 22.3. FTIR (NaCl, thin film) 3410 (br), 3355 (br), 3055, 3021, 3000, 2950, 2864, 1734, 1686, 1654, 1643, 1599, 1524, 1484, 1460, $1426,1384,1336,1326,1279,1247,1225,1163,1142,1093,1063$, 988, 973, 949, 841, 826, 791, 754, 698, $667 \mathrm{~cm}^{-1}$ HRMS (MM) calc'd for $\mathrm{C}_{41} \mathrm{H}_{45} \mathrm{~N}_{2} \mathrm{O}_{9}[\mathrm{M}+\mathrm{H}]^{+} 709.3120$, found 709.3119.

Data for 59 (peak 3): $[\alpha]_{D}^{25.0}=-98.4^{\circ}\left(\mathrm{c}=0.206, \mathrm{CHCl}_{3}\right)$ White Solid. ${ }^{1} \mathbf{H}$ NMR $\left(400 \mathrm{MHz}, \mathrm{CDCl}_{3}\right) \delta 12.11(\mathrm{~s}, 1 \mathrm{H}), 11.61(\mathrm{~s}, 1 \mathrm{H}), 9.64(\mathrm{~s}$, $1 \mathrm{H}), 8.82(\mathrm{dd}, J=4.3,1.7 \mathrm{~Hz}, 1 \mathrm{H}), 8.76(\mathrm{dd}, J=7.3,1.7 \mathrm{~Hz}, 1 \mathrm{H}), 8.16$ (dd, $J=8.2,1.7 \mathrm{~Hz}, 1 \mathrm{H}), 7.57-7.43(\mathrm{~m}, 3 \mathrm{H}), 7.30$ (dd, $J=8.6,5.1 \mathrm{~Hz}$, $2 \mathrm{H}), 7.17(\mathrm{~s}, 2 \mathrm{H}), 6.81(\mathrm{~s}, 1 \mathrm{H}), 4.54(\mathrm{~d}, J=7.3 \mathrm{~Hz}, 1 \mathrm{H}), 3.94(\mathrm{~s}, 3 \mathrm{H})$, $3.92(\mathrm{~s}, 3 \mathrm{H}), 3.21(\mathrm{~s}, 3 \mathrm{H}), 2.74(\mathrm{q}, J=9.8 \mathrm{~Hz}, 2 \mathrm{H}), 2.10(\mathrm{~d}, J=13.7 \mathrm{~Hz}$, $1 \mathrm{H}), 1.97-1.83(\mathrm{~m}, 1 \mathrm{H}), 1.62(\mathrm{~d}, J=8.9 \mathrm{~Hz}, 2 \mathrm{H}), 1.45(\mathrm{~d}, J=13.8 \mathrm{~Hz}$, 1H), $1.32(\mathrm{~s}, 3 \mathrm{H}), 1.29-1.24(\mathrm{~m}, 1 \mathrm{H}), 1.18(\mathrm{~d}, J=13.2 \mathrm{~Hz}, 1 \mathrm{H}), 1.11(\mathrm{~s}$, $3 \mathrm{H}), 1.10-1.06(\mathrm{~m}, 1 \mathrm{H}), 1.04(\mathrm{~s}, 3 \mathrm{H}), 0.76(\mathrm{dd}, J=13.1,3.9 \mathrm{~Hz}, 1 \mathrm{H})$. ${ }^{13} \mathrm{C}$ NMR $\left(101 \mathrm{MHz}, \mathrm{CDCl}_{3}\right) \delta 171.0,170.9,169.7,164.9,162.7,158.0$, $148.3,142.2,138.5,136.5,134.7,128.5,128.1,127.7,127.6,125.9$, 121.7, 121.3, 116.4, 104.2, 102.2, 99.3, 95.5, 52.8, 52.5, 51.3, 49.0, 43.7, 42.2, 40.3, 38.5, 34.8, 34.4, 33.0, 32.6, 30.8, 23.8, 22.1, 21.7. FTIR (NaCl, thin film) 3408 (br), 3354 (br), 3059, 3022, 3009, 2952, $2868,1738,1732,1682,1658,1652,1645,1599,1525,1485,1462$, 1455, 1426, 1385, 1327, 1281, 1251, 1225, 1165, 1133, 1090, 1077, $1031,991,946,872,826,792,755,703 \mathrm{~cm} \cdot .^{-1}$ HRMS (MM) calc'd for $\mathrm{C}_{41} \mathrm{H}_{45} \mathrm{~N}_{2} \mathrm{O}_{9}[\mathrm{M}+\mathrm{H}]^{+}$709.3120, found 709.3133.

Data for 60 (peak 4): $[\alpha]_{D}^{25.0}=-13.4^{\circ}\left(\mathrm{c}=0.226, \mathrm{CHCl}_{3}\right)$ White Solid. ${ }^{1} \mathrm{H}$ NMR $\left(400 \mathrm{MHz}, \mathrm{CDCl}_{3}\right) \delta 11.95(\mathrm{~s}, 1 \mathrm{H}), 11.23(\mathrm{~s}, 1 \mathrm{H}), 9.66(\mathrm{~s}$, $1 \mathrm{H}), 8.81(\mathrm{dd}, J=4.2,1.7 \mathrm{~Hz}, 1 \mathrm{H}), 8.76(\mathrm{dd}, J=7.3,1.7 \mathrm{~Hz}, 1 \mathrm{H}), 8.16$ (dd, $J=8.3,1.7 \mathrm{~Hz}, 1 \mathrm{H}), 7.55-7.42(\mathrm{~m}, 3 \mathrm{H}), 7.22(\mathrm{dd}, J=7.9,6.5 \mathrm{~Hz}$, $2 \mathrm{H}), 7.18-7.13(\mathrm{~m}, 1 \mathrm{H}), 7.10(\mathrm{~d}, J=7.4 \mathrm{~Hz}, 2 \mathrm{H}), 3.90(\mathrm{~s}, 3 \mathrm{H}), 3.87(\mathrm{~s}$, $3 \mathrm{H}), 3.67(\mathrm{~d}, J=11.0 \mathrm{~Hz}, 1 \mathrm{H}), 3.16(\mathrm{~s}, 3 \mathrm{H}), 2.81-2.66(\mathrm{~m}, 2 \mathrm{H}), 2.10$ $(\mathrm{dd}, J=14.2,1.6 \mathrm{~Hz}, 1 \mathrm{H}), 1.71(\mathrm{td}, J=10.8,5.3 \mathrm{~Hz}, 1 \mathrm{H}), 1.64(\mathrm{dd}, J=$
9.2, $2.6 \mathrm{~Hz}, 2 \mathrm{H}), 1.56-1.48(\mathrm{~m}, 2 \mathrm{H}), 1.45(\mathrm{~d}, J=14.3 \mathrm{~Hz}, 1 \mathrm{H}), 1.38-$ $1.32(\mathrm{~m}, 1 \mathrm{H}), 1.31(\mathrm{~s}, 3 \mathrm{H}), 1.21-1.14(\mathrm{~m}, 1 \mathrm{H}), 1.12(\mathrm{~s}, 3 \mathrm{H}), 1.08(\mathrm{~s}$, 3H). ${ }^{13} \mathrm{C}$ NMR $\left(101 \mathrm{MHz}, \mathrm{CDCl}_{3}\right) \delta 170.8,170.8,169.5,164.0,162.4$, $157.4,148.3,145.4,138.5,136.5,134.7,128.1,128.1,127.6,125.9$, 121.7, 121.3, 116.4, 108.0, 101.7, 99.6, 95.5, 52.7, 52.5, 51.2, 49.4, 49.0, 42.0, 41.1, 36.2, 35.3, 34.8, 33.3, 32.6, 30.8, 23.8, 22.5, 21.1. FTIR ( $\mathrm{NaCl}$, thin film) 3412 (br), 3354 (br), 3055, 3023, 3003, 2950, 2866, 1732, 1688, 1656, 1598, 1524, 1484, 1453, 1426, 1384, 1327, $1277,1248,1225,1165,1062,993,954,925,826,792,755,702 \mathrm{~cm}$. 1 HRMS (MM) calc'd for $\mathrm{C}_{41} \mathrm{H}_{45} \mathrm{~N}_{2} \mathrm{O}_{9}[\mathrm{M}+\mathrm{H}]^{+}$709.3120, found 709.3139 .

(57-60, Cu-mediated reaction): Inside a $\mathrm{N}_{2}$-filled glovebox, methyl enol ether 17 (17.0 mg, $0.045 \mathrm{mmol})$ and o-QM precursor 16 ( $16.4 \mathrm{mg}, 0.047 \mathrm{mmol}, 1.05$ equiv) were added to a $1 \mathrm{dram}$ vial and dissolved in $\mathrm{CH}_{2} \mathrm{Cl}_{2}(400 \mu \mathrm{L})$. $\mathrm{Cu}(\mathrm{OTf})_{2}$ was then added as a solid in one portion and the reaction immediately turns a light green color, then yellow-brown within the first 5 minutes. The reaction was stirred at room temperature for 1 hour, then quenched with saturated aqueous $\mathrm{NaHCO}_{3}$ and diluted with $\mathrm{CHCl}_{3}$. The reaction mixture was extracted with $\mathrm{CHCl}_{3}(3 \times 1 \mathrm{~mL})$ and the organics filtered through a plug of $\mathrm{Na}_{2} \mathrm{SO}_{4}$ and concentrated in vacuo. The crude residue was analyzed by ${ }^{1} \mathrm{H}$ NMR and determined to contain 57, 58, 59, and 60 in an approximate ratio of $2: 1: 3: 3$, respectively.

(62): Inside a $\mathrm{N}_{2}$-filled glovebox, Schwartz's reagent (119 mg, $0.462 \mathrm{mmol}, 2.00$ equiv) was added to a $10 \mathrm{~mL}$ flask and sealed un$\operatorname{der} \mathrm{N}_{2}$. The flask was removed from the glovebox and THF $(1.2 \mathrm{~mL})$ was added via syringe. To the milky-white suspension was added ketal $51(94.8 \mathrm{mg}, 0.231 \mathrm{mmol})$ as a solution in THF $(1.2 \mathrm{~mL})$ in a quick drip. The reaction immediately beings to turn yellow, eventually becoming a darker orange color over 1 hour, at which time the reaction was quenched by the addition of saturated aqueous $\mathrm{NaHCO}_{3}$. The reaction was diluted with EtOAc and the organic layer separated. The aqueous layer was extracted with EtOAc $(2 \times 5 \mathrm{~mL})$ and the combined organic layers were dried over $\mathrm{MgSO}_{4}$, filtered, and concentrated in vacuo. The crude residue was purified by silica gel flash chromatography (isocratic: $5 \%$ EtOAc/hexane $+1 \% \mathrm{Et}_{3} \mathrm{~N}$ ) to afford 62 (36.9 mg, 62\% yield) as a pale yellow oil: $[\alpha]_{D}^{25.0}=-33.1^{\circ}(\mathrm{c}=0.500$, $\left.\mathrm{CHCl}_{3}\right) .{ }^{1} \mathrm{H}$ NMR $\left(400 \mathrm{MHz}, \mathrm{CDCl}_{3}\right) \delta 9.70(\mathrm{~d}, J=3.0 \mathrm{~Hz}, 1 \mathrm{H}), 3.14(\mathrm{~s}$, $3 \mathrm{H}), 3.09(\mathrm{~s}, 3 \mathrm{H}), 2.64(\mathrm{td}, J=9.7,8.5 \mathrm{~Hz}, 1 \mathrm{H}), 2.58(\mathrm{dd}, J=9.9,3.0 \mathrm{~Hz}$, $1 \mathrm{H}), 1.86$ (ddt, $J=13.6,4.2,2.6 \mathrm{~Hz}, 1 \mathrm{H}), 1.61(\mathrm{t}, J=10.3 \mathrm{~Hz}, 1 \mathrm{H}), 1.57$ $-1.44(\mathrm{~m}, 4 \mathrm{H}), 1.34-1.18(\mathrm{~m}, 2 \mathrm{H}), 1.16(\mathrm{~s}, 3 \mathrm{H}), 1.14(\mathrm{~s}, 3 \mathrm{H}), 1.13-$ $1.05(\mathrm{~m}, 2 \mathrm{H}), 0.89(\mathrm{~s}, 3 \mathrm{H}) .{ }^{13} \mathrm{C}$ NMR $\left(101 \mathrm{MHz}, \mathrm{CDCl}_{3}\right) \delta 204.7,100.5$, 55.2, 47.6, 47.1, 39.8, 39.3, 35.7, 34.4, 33.9, 33.0, 32.7, 31.1, 24.3, 21.7, 18.6. FTIR ( $\mathrm{NaCl}$, thin film) 2952, 2868, 2828, 2705, 1713, 1461, $1383,1368,1341,1288,1262,1246,1180,1166,1110,1098,1048$, 1009, 945, 924, 823, $828 \mathrm{~cm}^{-1}$ HRMS (FAB) calc'd for $\mathrm{C}_{15} \mathrm{H}_{25} \mathrm{O}_{2}$ [M$\left.\mathrm{OCH}_{3}\right]^{+}$237.1849, found 237.1855.

(63): To a $10 \mathrm{~mL}$ round bottom flask were added aldehyde 62 ( $36.0 \mathrm{mg}, 0.134 \mathrm{mmol}$ ) and $\mathrm{K}_{2} \mathrm{CO}_{3}(37.0 \mathrm{mg}, 0.268 \mathrm{mmol}, 2.00$ equiv). The flask was fitted with a septum and the atmosphere exchanged $2 x$ for $\mathrm{N}_{2}$. Freshly distilled $\mathrm{MeOH}(1.5 \mathrm{~mL})$ was then added via syringe and the solution cooled to $0{ }^{\circ} \mathrm{C}$. Dimethyl-1-diazo-2oxopropylphosphonate $^{73}$ (38.6 mg, $0.201 \mathrm{mmol}, 1.50$ equiv) was weighed into a tared syringe and added dropwise to the reaction, neat. The reaction was allowed to gradually warm to room temperature and stirred for 12 hours. The reaction was then diluted with $\mathrm{Et}_{2} \mathrm{O}$, saturated aqueous $\mathrm{NaHCO}_{3}$ was added, and the organic layer separated. The aqueous layer was extracted with $\mathrm{Et}_{2} \mathrm{O}(3 \times 5 \mathrm{~mL})$ and the combined organic layers were dried over $\mathrm{MgSO}_{4}$, filtered, and concentrated in vacuo. The crude residue was purified by Florisil ${ }^{\circ}$ flash chromatography (isocratic: $5 \% \mathrm{Et}_{2} \mathrm{O} /$ pentane) to afford 63 (32.9 $\mathrm{mg}, 93 \%$ yield) as a pale yellow oil: $[\alpha]_{D}^{25.0}=-43.6^{\circ}\left(\mathrm{c}=0.355, \mathrm{CHCl}_{3}\right)$. ${ }^{1} \mathrm{H}$ NMR (400 MHz, $\left.\mathrm{CDCl}_{3}\right) \delta 3.17(\mathrm{~s}, 3 \mathrm{H}), 3.13(\mathrm{~s}, 3 \mathrm{H}), 2.43(\mathrm{dd}, J=$ 10.1, $2.4 \mathrm{~Hz}, 1 \mathrm{H}), 2.16-2.05(\mathrm{~m}, 2 \mathrm{H}), 2.04-1.93(\mathrm{~m}, 1 \mathrm{H}), 1.69$ (ddd, 
$J=13.9,2.8,1.8 \mathrm{~Hz}, 1 \mathrm{H}), 1.59-1.50(\mathrm{~m}, 2 \mathrm{H}), 1.48(\mathrm{~d}, J=9.6 \mathrm{~Hz}, 2 \mathrm{H})$, $1.29-1.17(\mathrm{~m}, 5 \mathrm{H}), 1.16(\mathrm{~d}, J=2.7 \mathrm{~Hz}, 4 \mathrm{H}), 1.03(\mathrm{~s}, 3 \mathrm{H}), 0.97(\mathrm{~s}$, 3H). ${ }^{13} \mathrm{C}$ NMR $\left(101 \mathrm{MHz}, \mathrm{CDCl}_{3}\right) \delta 100.7,85.8,70.5,49.1,47.9,47.3$, 39.1, 35.2, 35.1, 34.0, 33.5, 33.2, 33.2, 29.9, 24.8, 21.1, 18.8. FTIR ( $\mathrm{NaCl}$, thin film) 3310, 3263, 2953, 2866, 2828, 1459, 1383, 1364, $1342,1323,1288,1266,1243,1180,1157,1106,1094,1048,945$, 926, 858, 830, 655, $621 \mathrm{~cm}^{-1}$ HRMS (MM) calc'd for $\mathrm{C}_{16} \mathrm{H}_{25} \mathrm{O}_{2}$ [M$\left.\mathrm{OCH}_{3}\right]^{+}$233.1900, found 233.1887.

(64-65): Inside a $\mathrm{N}_{2}$-filled glovebox, THF $(400 \mu \mathrm{L})$ was added to a 1 dram vial containing alkyne $63(12.4 \mathrm{mg}, 0.047 \mathrm{mmol})$, followed by $\mathrm{Ni}(\mathrm{acac})_{2}$ as a stock solution in THF $(0.10 \mathrm{M}, 70 \mu \mathrm{L}, 0.007 \mathrm{mmol}$, 0.15 equiv). The reaction was stirred for 10 minutes at room temperature before thiophenol ( $10 \mu \mathrm{L}, 0.094 \mathrm{mmol}, 2.00$ equiv) was added neat. The reaction was sealed with a Teflon cap and heated to $60^{\circ} \mathrm{C}$ in a preheated aluminum block inside the glovebox. After 3 hours, the reaction was cooled to room temperature and diluted with $\mathrm{CH}_{2} \mathrm{Cl}_{2}$. The reaction mixture was filtered over a small pad of celite, washed with $\mathrm{CH}_{2} \mathrm{Cl}_{2}$ until the filtrate runs colorless, and concentrated in vacuo. The crude residue was taken up in EtOAc and shaken with $5 \mathrm{M} \mathrm{NaOH}$ (to remove excess thiophenol). The organic layer was then filtered through a plug of $\mathrm{Na}_{2} \mathrm{SO}_{4}$, concentrated, and purified by silica gel preparative TLC ( $\left.5 \% \mathrm{EtOAc} / \mathrm{hexane}+1 \% \mathrm{Et}_{3} \mathrm{~N}\right)$ to afford $64(8.50$ $\mathrm{mg}, 53 \%$ yield) and $65(2.7 \mathrm{mg}, 15 \%$ yield $)$ each as colorless oils.

Data for 65: $[\alpha]_{D}^{25.0}=+12.3^{\circ}\left(\mathrm{c}=0.115, \mathrm{CHCl}_{3}\right)$. ${ }^{1} \mathrm{H}$ NMR $(400$ $\left.\mathrm{MHz}, \mathrm{CDCl}_{3}\right) \delta 7.42(\mathrm{dd}, J=8.1,1.6 \mathrm{~Hz}, 2 \mathrm{H}), 7.36-7.28(\mathrm{~m}, 3 \mathrm{H}), 5.17$ $(\mathrm{d}, J=1.3 \mathrm{~Hz}, 1 \mathrm{H}), 4.96(\mathrm{~s}, 1 \mathrm{H}), 3.17(\mathrm{~s}, 3 \mathrm{H}), 3.13(\mathrm{~s}, 3 \mathrm{H}), 2.51(\mathrm{~d}, J=$ $10.2 \mathrm{~Hz}, 1 \mathrm{H}$ ), 2.26 (q, J=9.7 Hz, 1H), $2.04-1.92(\mathrm{~m}, 1 \mathrm{H}$ ), 1.65 (ddd, $J$ $=13.8,2.8,1.6 \mathrm{~Hz}, 1 \mathrm{H}$ ), 1.50 (ddd, $J=9.6,7.0,3.7 \mathrm{~Hz}, 2 \mathrm{H}$ ), $1.45-1.39$ $(\mathrm{m}, 2 \mathrm{H}), 1.21-1.12(\mathrm{~m}, 4 \mathrm{H}), 1.11(\mathrm{~s}, 3 \mathrm{H}), 0.98(\mathrm{~s}, 3 \mathrm{H}), 0.91(\mathrm{~s}, 3 \mathrm{H}) .{ }^{13} \mathrm{C}$ NMR $\left(101 \mathrm{MHz}, \mathrm{CDCl}_{3}\right) \delta 145.9,133.8,133.4,129.2,127.9,111.6$, $100.8,49.4,47.9,47.3,45.1,39.7,35.6,34.8,34.6,33.2,32.4,30.6$, 23.2, 21.7, 18.9. FTIR ( $\mathrm{NaCl}$, thin film) 2950, 2863, 2827, 1610, 1583, $1476,1459,1439,1379,1364,1322,1274,1260,1247,1178,1145$, 1130, 1100, 1083, 1049, 1024, 946, 926, 856, 831, 822, 747, $691 \mathrm{~cm}$. 1 HRMS (MM) calc'd for $\mathrm{C}_{22} \mathrm{H}_{31} \mathrm{OS}\left[\mathrm{M}-\mathrm{OCH}_{3}\right]^{+}$343.2090, found 343.2073.

Data for 64: $[\alpha]_{D}^{25.0}=-11.0^{\circ}\left(\mathrm{c}=0.982, \mathrm{CHCl}_{3}\right) .{ }^{1} \mathbf{H}$ NMR $(400$ $\left.\mathrm{MHz}, \mathrm{CDCl}_{3}\right) \delta 7.46-7.36(\mathrm{~m}, 2 \mathrm{H}), 7.36-7.27(\mathrm{~m}, 3 \mathrm{H}), 5.23-4.84$ $(\mathrm{m}, 2 \mathrm{H}), 4.63-4.29(\mathrm{~m}, 1 \mathrm{H}), 3.40(\mathrm{~s}, 3 \mathrm{H}), 2.58-2.50(\mathrm{~m}, 1 \mathrm{H}), 2.40$ (dq, $J=34.9,9.5 \mathrm{~Hz}, 1 \mathrm{H}$ ), $2.11-1.91(\mathrm{~m}, 3 \mathrm{H}), 1.64$ (ddd, $J=15.0,5.9$, $2.4 \mathrm{~Hz}, 2 \mathrm{H}), 1.48-1.40(\mathrm{~m}, 2 \mathrm{H}), 1.39-1.30(\mathrm{~m}, 1 \mathrm{H}), 1.11(\mathrm{~d}, J=9.9$ $\mathrm{Hz}, 3 \mathrm{H}), 1.00(\mathrm{~d}, J=2.4 \mathrm{~Hz}, 3 \mathrm{H}), 0.83(\mathrm{~d}, J=21.0 \mathrm{~Hz}, 4 \mathrm{H}) .{ }^{13} \mathrm{C}$ NMR $\left(101 \mathrm{MHz}, \mathrm{CDCl}_{3}\right) \delta 155.3,154.4,146.0,145.9,133.8,133.5,133.4$, $133.3,129.2,129.1,127.9,127.7,112.3,111.1,100.6,92.0,54.1$, $53.9,50.2,49.5,43.5,40.9,37.7,36.1,35.1,35.1,34.5,34.1,32.9$, 32.6, 31.6, 30.6, 30.5, 28.2, 25.8, 23.3, 23.2, 22.0, 20.8, 19.4. FTIR ( $\mathrm{NaCl}$, thin film) 3061, 2991, 2950, 2930, 2862, 2843, 1667, 1609, $1583,1476,1460,1453,1440,1380,1366,1251,1215,1148,1066$, 1024, 940, 817, 747, $691 \mathrm{~cm}^{-1}$ HRMS (MM) calc'd for $\mathrm{C}_{22} \mathrm{H}_{31} \mathrm{OS}$ $[\mathrm{M}+\mathrm{H}]^{+} 343.2090$, found 343.2087 .

(66-67): Inside a $\mathrm{N}_{2}$-filled glovebox, $\mathrm{CH}_{2} \mathrm{Cl}_{2}$ was added to a 1 dram vial containing $65(9.30 \mathrm{mg}, 0.025 \mathrm{mmol})$, followed by $\mathrm{InCl}_{3}$ ( $5.49 \mathrm{mg}, 0.025 \mathrm{mmol}, 1.00$ equiv). The reaction was stirred at room temperature for 2 hours, then quenched with saturated aqueous $\mathrm{NaHCO}_{3}$ and diluted with $\mathrm{CH}_{2} \mathrm{Cl}_{2}$. The reaction was extracted with $\mathrm{CH}_{2} \mathrm{Cl}_{2}(3 \times 500 \mu \mathrm{L})$, the combined organics filtered a plug of $\mathrm{Na}_{2} \mathrm{SO}_{4}$, and concentrated in vacuo. The crude residue was purified by silica gel flash chromatography $\left(40-60 \% \mathrm{CH}_{2} \mathrm{Cl}_{2}\right.$ /hexane) to afford 66 ( $0.900 \mathrm{mg}, 11 \%$ yield) as a colorless oil, with the remaining mass balance accounted for by ketone 67 , as determined by crude ${ }^{1} \mathrm{H}$ NMR.

Data for 66: $[\alpha]_{D}^{25.0}=+58.2^{\circ}\left(\mathrm{c}=0.053, \mathrm{CHCl}_{3}\right) .{ }^{1} \mathrm{H}$ NMR $(400$ $\left.\mathrm{MHz}, \mathrm{CDCl}_{3}\right) \delta 7.40-7.36(\mathrm{~m}, 2 \mathrm{H}), 7.30$ (ddd, $J=8.3,7.1,0.8 \mathrm{~Hz}, 2 \mathrm{H}$ ), $7.24-7.18(\mathrm{~m}, 1 \mathrm{H}), 5.52(\mathrm{dd}, J=2.8,1.7 \mathrm{~Hz}, 1 \mathrm{H}), 3.18(\mathrm{~s}, 3 \mathrm{H}), 2.91-$ $2.81(\mathrm{~m}, 1 \mathrm{H}), 2.00-1.72(\mathrm{~m}, 5 \mathrm{H}), 1.66$ (ddd, $J=11.6,6.8,3.5 \mathrm{~Hz}, 1 \mathrm{H})$, $1.44-1.37(\mathrm{~m}, 2 \mathrm{H}), 1.35(\mathrm{dd}, J=12.3,1.7 \mathrm{~Hz}, 1 \mathrm{H}), 1.29(\mathrm{~m}, 1 \mathrm{H}), 1.28$ (s, 3H), 1.19 (dd, J = 14.1, 7.0 Hz, 1H), $1.00(\mathrm{~s}, 3 \mathrm{H}), 0.80(\mathrm{~s}, 3 \mathrm{H}) .{ }^{13} \mathrm{C}$ NMR $\left(101 \mathrm{MHz}, \mathrm{CDCl}_{3}\right) \delta 139.7,139.6,135.0,131.7,129.2,127.2$, 80.6, 52.4, 50.2, 49.2, 48.6, 40.1, 38.3, 36.2, 33.7, 31.3, 31.2, 28.9, 22.4, 21.2. FTIR ( $\mathrm{NaCl}$, thin film) 3062, 2945, 2927, 2860, 2820, 1734, $1718,1701,1654,1583,1560,1476,1458,1438,1370,1294,1254$, $1232,1151,1086,1066,1024,950,870,840,800,743,690 \mathrm{~cm}^{-1}$ HRMS (MM) calc'd for $\mathrm{C}_{22} \mathrm{H}_{31} \mathrm{OS}[\mathrm{M}+\mathrm{H}]^{+} 343.2090$, found 343.2077.

Data for 67: $[\alpha]_{D}^{25.0}=+31.6^{\circ}\left(\mathrm{c}=0.100, \mathrm{CHCl}_{3}\right) .{ }^{1} \mathbf{H}$ NMR $(400$ $\left.\mathrm{MHz}, \mathrm{CDCl}_{3}\right) \delta 7.46(\mathrm{dd}, J=8.1,1.6 \mathrm{~Hz}, 2 \mathrm{H}), 7.40-7.32(\mathrm{~m}, 3 \mathrm{H}), 5.13$ $(\mathrm{d}, J=1.3 \mathrm{~Hz}, 1 \mathrm{H}), 4.98(\mathrm{~s}, 1 \mathrm{H}), 2.53(\mathrm{~d}, J=10.1 \mathrm{~Hz}, 1 \mathrm{H}), 2.38(\mathrm{td}, J=$ 10.0, 8.9 Hz, 1H), $2.32-2.23(\mathrm{~m}, 2 \mathrm{H}), 2.17(\mathrm{~d}, J=13.6 \mathrm{~Hz}, 1 \mathrm{H}), 2.02$ (dt, $J=13.4,1.9 \mathrm{~Hz}, 1 \mathrm{H}), 1.93-1.90(\mathrm{~m}, 1 \mathrm{H}), 1.82$ (dddd, $J=9.7,8.1$, 3.9, $2.3 \mathrm{~Hz}, 1 \mathrm{H}), 1.57(\mathrm{q}, J=4.4 \mathrm{~Hz}, 1 \mathrm{H}), 1.49-1.44(\mathrm{~m}, 1 \mathrm{H}), 1.44-$ $1.33(\mathrm{~m}, 2 \mathrm{H}), 1.16(\mathrm{~s}, 3 \mathrm{H}), 1.03(\mathrm{~s}, 3 \mathrm{H}), 0.82(\mathrm{~s}, 3 \mathrm{H}) .{ }^{13} \mathrm{C}$ NMR (101 $\left.\mathrm{MHz}, \mathrm{CDCl}_{3}\right) \delta 212.6,145.5,134.1,133.0,129.3,128.2,111.4,51.1$, 49.8, 43.1, 41.3, 40.3, 35.1, 34.2, 32.5, 30.6, 23.1, 22.1, 21.8. FTIR ( $\mathrm{NaCl}$, thin film) 3059, 2953, 2927, 2860, 1711, 1680, 1611, 1583, $1476,1461,1440,1381,1364,1347,1311,1283,1253,1228,1151$, 1087, 1067, 1024, 890, 855, 749, $692 \mathrm{~cm}^{-1}$ HRMS (MM) calc'd for $\mathrm{C}_{21} \mathrm{H}_{29} \mathrm{OS}[\mathrm{M}+\mathrm{H}]^{+} 329.1934$, found 329.1943 .

(78): To a $15 \mathrm{~mL}$ round-bottom flask was added vinyl ketone $\mathbf{7 1}$ $(91.0 \mathrm{mg}, 0.413 \mathrm{mmol})$ and the atmosphere was exchanged $3 x$ for $\mathrm{N}_{2}$. Dry THF $(4.10 \mathrm{~mL})$ was then added via syringe and the reaction cooled to $-30{ }^{\circ} \mathrm{C}$ using a closely monitored acetone $/ \mathrm{CO}_{2}$ bath. Vinylmagnesium bromide ( $2.06 \mathrm{~mL}, 1.0 \mathrm{M}$ in THF, $2.06 \mathrm{mmol}, 5.00$ equiv) was then added dropwise. The reaction was maintained at $-30{ }^{\circ} \mathrm{C}$ for 30 minutes, then quenched at that temperature with saturated aqueous $\mathrm{NaH}_{2} \mathrm{PO}_{4}$. The reaction mixture was diluted with $\mathrm{Et}_{2} \mathrm{O}$ and the layers separated. The aqueous layer was extracted with $\mathrm{Et}_{2} \mathrm{O}(2 \mathrm{x}$ $5 \mathrm{~mL}$ ) and the combined organics were dried over $\mathrm{Mg}_{2} \mathrm{SO}_{4}$, filtered, and concentrated in vacuo. The crude residue was purified by silica gel flash chromatography (10\% EtOAc/hexane) to afford $78(92.7 \mathrm{mg}$, 91\% yield) as a colorless oil: $[\alpha]_{D}^{25.0}=+54.4^{\circ}\left(\mathrm{c}=1.75, \mathrm{CHCl}_{3}\right) .{ }^{1} \mathrm{H}$ NMR $\left(400 \mathrm{MHz}, \mathrm{CDCl}_{3}\right) \delta 5.88$ (dd, $\left.J=17.3,10.6 \mathrm{~Hz}, 1 \mathrm{H}\right), 5.75$ (ddd, J $=17.1,10.2,8.7 \mathrm{~Hz}, 1 \mathrm{H}), 5.18(\mathrm{dd}, J=17.3,1.3 \mathrm{~Hz}, 1 \mathrm{H}), 5.01-4.85$ $(\mathrm{m}, 3 \mathrm{H}), 2.32(\mathrm{t}, J=9.3 \mathrm{~Hz}, 1 \mathrm{H}), 1.92(\mathrm{q}, J=9.6 \mathrm{~Hz}, 1 \mathrm{H}), 1.82$ (qt, $J=$ 13.5, 3.4 Hz, 1H), 1.55 (dddd, J = 14.0, 5.3, 3.5, $1.9 \mathrm{~Hz}, 1 \mathrm{H}$ ), 1.48 (dq, J $=13.8,3.5 \mathrm{~Hz}, 1 \mathrm{H}), 1.45-1.39(\mathrm{~m}, 2 \mathrm{H}), 1.35(\mathrm{dd}, J=13.5,4.0 \mathrm{~Hz}, 1 \mathrm{H})$, $1.31-1.22(\mathrm{~m}, 3 \mathrm{H}), 1.16-1.11(\mathrm{~m}, 1 \mathrm{H}), 1.11(\mathrm{~s}, 1 \mathrm{H}), 1.06(\mathrm{~s}, 3 \mathrm{H})$, $0.97(\mathrm{~s}, 3 \mathrm{H}), 0.97(\mathrm{~s}, 3 \mathrm{H}) .{ }^{13} \mathrm{C} \mathrm{NMR}\left(101 \mathrm{MHz}, \mathrm{CDCl}_{3}\right) \delta$ 148.1, 140.6, 114.6, 110.5, 73.1, 49.0, 48.0, 45.0, 37.6, 34.6, 34.3, 33.9, 32.8, 30.1, 23.8, 22.7, 17.8. FTIR ( $\mathrm{NaCl}$, thin film) 3601, 3452 (br), 3077, 2996, 2950, 2932, 2865, 1635, 1459, 1441, 1413, 1380, 1367, 1343, 1291, $1275,1250,1200,1170,1081,1058,994,974,909,858,846,666$ $\mathrm{cm}^{-1}$ HRMS (ESI) calc'd for $\mathrm{C}_{17} \mathrm{H}_{27}[\mathrm{M}-\mathrm{OH}]^{+}$231.2107, found 231.2101

(70): A $50 \mathrm{~mL}$ round-bottom flask containing divinyl alcohol 78 ( $88.0 \mathrm{mg}, 0.355 \mathrm{mmol}$ ) was pumped into a $\mathrm{N}_{2}$-filled glovebox where Hoveyda-Grubbs second-generation catalyst $(22.2 \mathrm{mg}, 0.035 \mathrm{mmol}$, 0.100 equiv) was added. The flask was sealed under nitrogen, removed from the glovebox and dry $\mathrm{PhH}(17.7 \mathrm{~mL})$ was added via syringe. The green reaction mixture was heated to $80^{\circ} \mathrm{C}$ for 3.5 hours, then cooled to room temperature. Ethyl vinyl ether was added to inactivate the catalyst and stirred for 15 minutes before the reaction mixture was concentrated in vacuo. The crude residue was purified by silica gel flash chromatography (isocratic: $30 \% \mathrm{Et}_{2} \mathrm{O} /$ hexane) to afford allylic alcohol 70 (72.5 mg, 93\% yield) as a pale yellow oil and a single diastereomer at $\mathrm{C} 1:[\alpha]_{D}^{25.0}=-62.9^{\circ}\left(\mathrm{c}=2.67, \mathrm{CHCl}_{3}\right) .{ }^{1} \mathbf{H} \mathbf{~ N M R}$ $\left(400 \mathrm{MHz}, \mathrm{CDCl}_{3}\right) \delta 5.84$ (dd, $\left.J=10.9,2.5 \mathrm{~Hz}, 1 \mathrm{H}\right), 5.15$ (ddd, $J=11.0$, 2.9, $2.2 \mathrm{~Hz}, 1 \mathrm{H}), 2.41(\mathrm{dt}, J=11.6,2.7 \mathrm{~Hz}, 1 \mathrm{H}), 2.09(\mathrm{td}, J=11.5,10.7$, $7.9 \mathrm{~Hz}, 2 \mathrm{H}), 1.69$ (ddd, $J=13.0,3.2,1.1 \mathrm{~Hz}, 1 \mathrm{H}), 1.64(\mathrm{~s}, 1 \mathrm{H}), 1.63-$ $1.56(\mathrm{~m}, 2 \mathrm{H}), 1.54-1.41(\mathrm{~m}, 2 \mathrm{H}), 1.34-1.25(\mathrm{~m}, 2 \mathrm{H}), 1.15(\mathrm{dd}, J=$ 
12.8, 2.2 Hz, 1H), $1.12-1.06(\mathrm{~m}, 1 \mathrm{H}), 1.05(\mathrm{~s}, 3 \mathrm{H}), 1.03(\mathrm{~s}, 3 \mathrm{H}), 0.87$ (s, 3H). ${ }^{13} \mathrm{C}$ NMR (101 MHz, $\left.\mathrm{CDCl}_{3}\right) \delta 134.1,132.5,75.1,49.9,45.3$, $43.9,39.0,38.1,37.8,35.0,32.6,30.9,26.9,21.3,20.2$. FTIR $(\mathrm{NaCl}$, thin film) 3350 (br), 3004, 2948, 2930, 2866, 1460, 1443, 1369, 1380, 1366, 1329, 1270, 1256, 1238, 1175, 1106, 1044, 1030, 999, 973, 958, 925, 875, 864, 766, $723 \mathrm{~cm} .^{-1}$ HRMS (MM) calc'd for $\mathrm{C}_{15} \mathrm{H}_{23}[\mathrm{M}-$ $\mathrm{OH}]^{+}$203.1794, found 203.1790 .

(79): To a $100 \mathrm{~mL}$ round-bottom flask were added allylic alcohol 70 (107 mg, $0.486 \mathrm{mmol}$ ) and Pd/C (103 mg, 10\% by weight, 0.097 $\mathrm{mmol}, 0.200$ equiv). The flask was fitted with a septum and the atmosphere exchanged $1 x$ for $\mathrm{N}_{2}$. $\mathrm{MeOH}(9.7 \mathrm{~mL})$ was then added via syringe and the reaction placed under a balloon atmosphere of $\mathrm{H}_{2}$ (purged through a needle for 30 seconds). The reaction was stirred vigorously at room temperature for 2.5 hours, at which time the atmosphere was purged with argon. The reaction mixture was filtered over celite, washed thoroughly with $\mathrm{Et}_{2} \mathrm{O}$, and the filtrate concentrated in vacuo. The crude residue was purified by silica gel flash chromatography (isocratic: $40 \% \mathrm{Et}_{2} \mathrm{O} /$ pentane) to afford 79 (101 mg, $94 \%$ yield) as a colorless oil: $[\alpha]_{D}^{25.0}=+6.37^{\circ}\left(\mathrm{c}=0.800, \mathrm{CHCl}_{3}\right) .{ }^{1} \mathrm{H}$ NMR $\left(400 \mathrm{MHz}, \mathrm{CDCl}_{3}\right) \delta 1.97$ (ddd, $\left.J=11.8,10.7,7.9 \mathrm{~Hz}, 1 \mathrm{H}\right), 1.86-$ $1.78(\mathrm{~m}, 1 \mathrm{H}), 1.78-1.68(\mathrm{~m}, 3 \mathrm{H}), 1.67(\mathrm{~d}, J=0.8 \mathrm{~Hz}, 3 \mathrm{H}), 1.51-1.39$ $(\mathrm{m}, 2 \mathrm{H}), 1.34(\mathrm{dt}, J=3.5,2.0 \mathrm{~Hz}, 1 \mathrm{H}), 1.33-1.22(\mathrm{~m}, 4 \mathrm{H}), 1.15-1.04$ $(\mathrm{m}, 1 \mathrm{H}), 1.02(\mathrm{~d}, J=12.8 \mathrm{~Hz}, 1 \mathrm{H}), 0.97(\mathrm{~s}, 3 \mathrm{H}), 0.96(\mathrm{~s}, 3 \mathrm{H}), 0.80(\mathrm{~s}$, 3H). ${ }^{13} \mathrm{C}$ NMR $\left(101 \mathrm{MHz}, \mathrm{CDCl}_{3}\right) \delta 74.0,50.2,46.3,40.3,40.1,39.7$, 38.2, 36.4, 34.6, 32.8, 30.7, 27.1, 22.7, 20.9, 20.7. FTIR ( $\mathrm{NaCl}$, thin film) 3368 (br), 2948, 2927, 2863, 1460,1443, 1384, 1364, 1332, $1288,1249,1217,1183,1124,1102,1050,1022,993,976,936,918$, 873, $862 \mathrm{~cm} .^{-1}$ HRMS (ESI) calc'd for $\mathrm{C}_{15} \mathrm{H}_{25}[\mathrm{M}-\mathrm{OH}]^{+} 205.1951$, found 205.1951

(68): Inside a $\mathrm{N}_{2}$-filled glovebox, to a 1 dram vial containing tertiary alcohol 79 (14.4 mg, $0.065 \mathrm{mmol})$ were added $\mathrm{Pd}(\mathrm{OAc})_{2}(4.36$ $\mathrm{mg}, 0.019 \mathrm{mmol}, 0.300$ equiv), dppf $(21.6 \mathrm{mg}, 0.039 \mathrm{mmol}, 0.600$ equiv), and $\mathrm{NaH}(95 \%, 3.11 \mathrm{mg}, 0.130 \mathrm{mmol}, 2.00$ equiv). PhMe (650 $\mu \mathrm{L}$ ) was then added and the orange reaction mixture stirred at room temperature for 5 minutes before aryl bromide $69^{74}(22.8 \mathrm{mg}, 0.071$ mmol, 1.10 equiv) was added as a solid in one portion. The reaction was sealed with a Teflon cap and heated to $110{ }^{\circ} \mathrm{C}$ in a preheated aluminum block inside the glovebox. After 13.5 hours, the reaction was cooled to room temperature, diluted with EtOAc and saturated aqueous $\mathrm{Na}_{2} \mathrm{HPO}_{4}$ was added. The layers were separated and the aqueous layer was extracted with EtOAc until the organic layer was colorless. The combined organics were filtered over a plug of celite and $\mathrm{Na}_{2} \mathrm{SO}_{4}$. The filtrate was concentrated in vacuo and the crude residue purified by silica gel flash chromatography (isocratic: $30 \%$ hexane $/ \mathrm{CH}_{2} \mathrm{Cl}_{2}+1 \%$ EtOAc) to afford $68(13.4 \mathrm{mg}, 45 \%$ yield) as a milky white gum: $[\alpha]_{D}^{25.0}=+1.27^{\circ}\left(\mathrm{c}=0.345, \mathrm{CHCl}_{3}\right) .{ }^{1} \mathbf{H}$ NMR (400 $\left.\mathrm{MHz}, \mathrm{CDCl}_{3}\right) \delta 7.86-7.76(\mathrm{~m}, 2 \mathrm{H}), 7.51(\mathrm{tt}, J=7.5,2.7 \mathrm{~Hz}, 1 \mathrm{H}), 7.44-$ $7.35(\mathrm{~m}, 2 \mathrm{H}), 6.29(\mathrm{~d}, J=2.1 \mathrm{~Hz}, 1 \mathrm{H}), 6.23(\mathrm{~d}, J=2.1 \mathrm{~Hz}, 1 \mathrm{H}), 3.83(\mathrm{~s}$, $3 \mathrm{H}), 3.70(\mathrm{~s}, 3 \mathrm{H}), 1.90(\mathrm{ddd}, J=12.0,10.7,7.9 \mathrm{~Hz}, 1 \mathrm{H}), 1.78(\mathrm{~d}, J=2.3$ $\mathrm{Hz}, 1 \mathrm{H}), 1.73(\mathrm{t}, J=6.5 \mathrm{~Hz}, 2 \mathrm{H}), 1.68(\mathrm{dt}, J=13.0,2.3 \mathrm{~Hz}, 1 \mathrm{H}), 1.65-$ $1.57(\mathrm{~m}, 1 \mathrm{H}), 1.55-1.45(\mathrm{~m}, 2 \mathrm{H}), 1.45-1.35(\mathrm{~m}, 3 \mathrm{H}), 1.27-1.23(\mathrm{~m}$, $2 \mathrm{H}), 1.22-1.11(\mathrm{~m}, 2 \mathrm{H}), 1.04(\mathrm{~d}, J=12.9 \mathrm{~Hz}, 1 \mathrm{H}), 0.92(\mathrm{~s}, 3 \mathrm{H}), 0.91(\mathrm{~s}$, 3H), 0.69 (s, 3H). ${ }^{13} \mathrm{C}$ NMR $\left(101 \mathrm{MHz}, \mathrm{CDCl}_{3}\right) \delta 196.0,161.3,158.7$, $155.2,138.8,132.8,129.6,128.3,116.8,100.3,92.5,86.9,55.9,55.6$, 47.6, 45.6, 39.7, 37.5, 36.8, 36.2, 36.1, 34.6, 32.7, 30.7, 27.1, 22.5, 20.9, 20.5. FTIR (NaCl, thin film) 3059, 2948, 2930, 2861, 1671, 1601, $1582,1458,1451,1438,1420,1364,1335,1312,1266,1216,1199$, 1157, 1138, 1107, 1052, 1015, 998, 948, 917, 843, 819, 802, 721, 702, $689 \mathrm{~cm} .^{-1}$ HRMS (MM) calc'd for $\mathrm{C}_{30} \mathrm{H}_{38} \mathrm{NaO}_{4}[\mathrm{M}+\mathrm{Na}]^{+} 485.2662$, found 485.2672 .

(80): To a $13 \times 100$ quartz test tube was added benzophenone 68 (15.5 mg, $0.034 \mathrm{mmol}$ ). The tube was fitted with a 19/38 rubber septum and the atmosphere was exchanged $3 \times$ for $\mathrm{N}_{2}$. Rigorously degassed dioxane $(4.70 \mathrm{~mL}$, freeze-pump-thawed $3 \mathrm{x}$ ) was then add- ed via syringe and the tube was sealed with electrical tape. The reaction was then placed in a bottomless test tube rack in front of a Honeywell $254 \mathrm{~nm}$ lamp and irradiated for 1 hour at room temperature. The reaction mixture was transferred to a cone-bottom flask and concentrated in vacuo. The crude residue was purified by silica gel preparative TLC ( $30 \%$ hexane/ $\mathrm{CH}_{2} \mathrm{Cl}_{2}+1 \%$ EtOAc) to afford $83^{75}(2.4$ $\mathrm{mg}, 28 \%$ yield) as a white solid and $80(1.00 \mathrm{mg}, 6.5 \%$ yield $)$ as a colorless oil: $[\alpha]_{D}^{25.0}=+13.8^{\circ}\left(\mathrm{c}=0.050, \mathrm{CHCl}_{3}\right.$ ). Note: an additional $\sim 18 \%$ yield of a complex mixture of products is also isolated as a single band. Although this mixture generally appears similar to 80 by ${ }^{1} \mathrm{H}$ NMR, definitive characterization was not achieved. ${ }^{1} \mathbf{H}$ NMR (400 $\left.\mathrm{MHz}, \mathrm{CDCl}_{3}\right) \delta 7.34-7.26(\mathrm{~m}, 1 \mathrm{H}), 7.24-7.09(\mathrm{~m}, 4 \mathrm{H}), 6.11(\mathrm{dd}, J=$ 2.5, $1.1 \mathrm{~Hz}, 1 \mathrm{H}), 6.01(\mathrm{dd}, J=2.4,1.2 \mathrm{~Hz}, 1 \mathrm{H}), 3.95(\mathrm{~d}, J=1.1 \mathrm{~Hz}, 1 \mathrm{H})$, $3.78(\mathrm{~d}, J=1.2 \mathrm{~Hz}, 3 \mathrm{H}$ ), 3.35 (d, $J=1.1 \mathrm{~Hz}, 3 \mathrm{H}), 2.65$ (dd, $J=12.7,3.5$ $\mathrm{Hz}, 1 \mathrm{H}), 2.62-2.52(\mathrm{~m}, 1 \mathrm{H}), 2.40(\mathrm{t}, J=14.4 \mathrm{~Hz}, 1 \mathrm{H}), 2.26(\mathrm{q}, J=10.4$ $\mathrm{Hz}, 1 \mathrm{H}), 2.11-1.90(\mathrm{~m}, 1 \mathrm{H}), 1.86(\mathrm{~d}, J=13.0 \mathrm{~Hz}, 1 \mathrm{H}), 1.83-1.72(\mathrm{~m}$, $1 \mathrm{H}), 1.69-1.57(\mathrm{~m}, 1 \mathrm{H}), 1.43-1.34(\mathrm{~m}, 2 \mathrm{H}), 1.30-1.09(\mathrm{~m}, 4 \mathrm{H})$, $0.80(\mathrm{~s}, 3 \mathrm{H}), 0.78(\mathrm{~s}, 3 \mathrm{H}), 0.75(\mathrm{~s}, 3 \mathrm{H}), 0.50(\mathrm{dt}, J=14.5,4.2 \mathrm{~Hz}, 1 \mathrm{H})$. ${ }^{13} \mathrm{C}$ NMR $\left(101 \mathrm{MHz}, \mathrm{CDCl}_{3}\right) \delta 160.5,158.8,154.3,149.3,127.4,126.1$, $125.8,111.4,94.2,93.5,80.6,74.6,55.6,55.4,48.5,48.1,44.0,37.3$, 36.8, 35.7, 35.5, 34.6, 33.2, 30.5, 26.4, 25.0, 20.6, 20.4. FTIR ( $\mathrm{NaCl}$, thin film) 3542 (br), 3312, 3187 (br), 2960, 2924, 2854, 1738, 1726, $1710,1666,1614,1592,1492,1462,1453,1445,1423,1376,1366$, $1351,1332,1261,1215,1203,1150,1112,1045,1020,865,800$, 736, 702, $664 \mathrm{~cm}^{-1}$ HRMS (MM) calc'd for $\mathrm{C}_{30} \mathrm{H}_{37} \mathrm{O}_{3}[\mathrm{M}-\mathrm{OH}]^{+}$ 445.2737, found 445.2729 .

(+)-psiguadial B (3): ${ }^{76}$ To a 2-dram vial was added resorcinol 97 (15.4 $\mathrm{mg}, 0.037 \mathrm{mmol}$ ) and the atmosphere exchanged three times for $\mathrm{N}_{2} . \mathrm{CH}_{2} \mathrm{Cl}_{2}(1.30 \mathrm{~mL})$ was then added via syringe, followed by dichloromethyl methyl ether $(0.083 \mathrm{~mL}, 0.920 \mathrm{mmol}, 25.0$ equiv). The solution was cooled to $-78{ }^{\circ} \mathrm{C}$ and a freshly prepared stock solution of $\mathrm{TiCl}_{4}\left(0.190 \mathrm{~mL}, 0.912 \mathrm{M}\right.$ in $\mathrm{CH}_{2} \mathrm{Cl}_{2}, 0.173 \mathrm{mmol}, 4.68$ equiv) was added dropwise. The reaction immediately turns dark red. The reaction was stirred at $-78{ }^{\circ} \mathrm{C}$ for 5 minutes, then warmed to room temperature and stirred for an additional 3 hours and 40 minutes. DI $\mathrm{H}_{2} \mathrm{O}(2.00 \mathrm{~mL})$ was then added via syringe and the reaction stirred vigorously for 15 minutes before the layers were separated. The aqueous layer was extracted five times with $\mathrm{CH}_{2} \mathrm{Cl}_{2}$ and the combined organic layers were filtered over a plug of $\mathrm{Na}_{2} \mathrm{SO}_{4}$ and concentrated in vacuo. The crude residue was purified by silica gel flash chromatography (isocratic: $2 \%$ EtOAc/hexane $+1 \% \mathrm{AcOH}$ ) to afford (+)-psiguadial B (3) $(8.7 \mathrm{mg}, 50 \%)$ as an ivory solid. Note: $\mathbf{3}$ is streaky on $\mathrm{SiO}_{2}$ and after an initial concentrated band elutes, approximately $12 \%$ of the product is contained in the following very dilute fractions. The natural product is weakly UV active, but can also be visualized by TLC using 2,4-dinitrophenylhydrazine stain. $[\alpha]_{D}^{25.0}=+94.0^{\circ}$ (c $=$ $\left.0.265, \mathrm{CHCl}_{3}\right) .{ }^{1} \mathrm{H}$ NMR $\left(400 \mathrm{MHz}, \mathrm{CDCl}_{3}\right) \delta 13.51(\mathrm{~s}, 1 \mathrm{H}), 13.04(\mathrm{~s}, 1 \mathrm{H})$, 10.07 (s, 2H), 7.26 (dd, $J=14.6,1.5 \mathrm{~Hz}, 2 \mathrm{H}), 7.23-7.17(\mathrm{~m}, 1 \mathrm{H}), 7.10$ (br s, $2 \mathrm{H}$ ), 3.49 (d, $J=11.5 \mathrm{~Hz}, 1 \mathrm{H}$ ), $2.20-2.12(\mathrm{~m}, 1 \mathrm{H}), 2.09$ (dd, $J=$ 12.7, $2.4 \mathrm{~Hz}, 1 \mathrm{H}$ ), 1.92 (ddd, $J=14.9,12.8,4.2 \mathrm{~Hz}, 1 \mathrm{H}$ ), 1.82 (ddd, $J=$ $12.3,8.8,5.6 \mathrm{~Hz}, 1 \mathrm{H}), 1.73-1.59(\mathrm{~m}, 3 \mathrm{H}), 1.53-1.44(\mathrm{~m}, 1 \mathrm{H}), 1.49$ (ddd, $J=11.6,8.1,2.9 \mathrm{~Hz}, 2 \mathrm{H}), 1.44-1.29(\mathrm{~m}, 4 \mathrm{H}), 1.05$ (dd, $J=7.6$, $5.8 \mathrm{~Hz}, 1 \mathrm{H}), 1.02(\mathrm{~s}, 3 \mathrm{H}), 1.00(\mathrm{~s}, 3 \mathrm{H}), 0.85(\mathrm{~s}, 3 \mathrm{H}) .{ }^{13} \mathrm{C}$ NMR $(101 \mathrm{MHz}$, $\left.\mathrm{CDCl}_{3}\right) \delta 192.3,191.5,169.6,168.5,163.5,143.4,128.2,126.2,105.7$, 104.6, 104.1, 84.1, 50.0, 47.4, 44.0, 40.4, 37.6, 36.9, 35.4, 35.1, 33.4, 30.6, 29.3, 26.1, 23.9, 20.7, 20.1. FTIR (NaCl, thin film) 3026, 2945, 2926, 2864, 2720, 1633, 1603, 1493, 1437, 1382, 1363, 1300, 1270, $1251,1231,1184,1154,1143,1031,1006,976,926,917,875,851$, $840,824,768,701,636,618,606,564 \mathrm{~cm}^{-1}$ HRMS (MM) calc'd for $\mathrm{C}_{30} \mathrm{H}_{35} \mathrm{O}_{5}[\mathrm{M}+\mathrm{H}]^{+}$475.2479, found 475.2487 .

\section{Supporting Information}


Synthetic schemes, additional reaction optimization tables, spectral data for all compounds, and crystallographic data. This material is available free of charge via the Internet at http://pubs.acs.org.

The Supporting Information is available free of charge on the ACS Publications website.

\section{AUTHOR INFORMATION}

\section{Corresponding Author}

*reisman@caltech.edu

\section{Author Contributions}

These authors contributed equally.

\section{Funding Sources}

\section{ACKNOWLEDGMENT}

Prof. Greg $\mathrm{Fu}$ is gratefully acknowledged for insightful discussions. We thank Dr. Allen Oliver, Dr. Nathan Schley, and Ms. Julie Hofstra for X-ray crystallographic structure determination and Dr. David VanderVelde for assistance with NMR structure determination. We thank Dr. Scott Virgil and the Caltech Center for Catalysis and Chemical Synthesis for access to analytical equipment, and Materia, Inc. for a donation of HG-II catalyst. Fellowship support was provided by the NSF (L. M. C., C. M. L., Grant No. DGE-1144469), NIH Training Grant (J. C. B., Grant No. 5T32GM007616-39) and SNF (L. W., Grant No. PBZHP2-147311). S.E.R. is an American Cancer Society Research Scholar and a Heritage Medical Research Foundation Investigator. Financial support from the NSF (CAREER-1057143), the American Cancer Society, the Research Corporation Cottrell Scholars program, and DuPont is gratefully acknowledged.

\section{REFERENCES}

(1) (a) Arima, H.; Danno, G. I. Isolation of Antimicrobial Compounds from Guava (Psidium guajava L.) and their Structural Elucidation. Biosci. Biotechnol. Biochem. 2002, 66, 1727-1730. (b) Begum, S.; Hassan, S. I.; Siddiqui, B. S.; Shaheen, F.; Ghayur, M. N.; Gilani, A. H. Triterpenoids from the Leaves of Psidium guajava. Phytochemistry 2002, 61, 399-403. (c) Mukhtar, H. M.; Ansari, S. H.; Bhat, Z. A.; Naved, T.; Singh, P. Antidiabetic Activity of an Ethanol Extract Obtained from the Stem Bark of Psidium guajava (Myrtaceae). Pharmazie 2006, 61, 725-727. (d) Oh, W. K.; Lee, C. H.; Lee, M. S.; Bae, E. Y.; Sohn, C. B.; Oh, H.; Kim, B. Y.; Ahn, J. S. Antidiabetic Effects of Extracts from Psidium guajava. J. Ethnopharmacol. 2005, 96, 411-415. (e) Mukhtar, H. M.; Ansari, S. H.; Ali, M.; Naved, T.; Bhat, Z. A. Effect of Water Extract of Psidium guajava Leaves on Alloxan-Induced Diabetic Rats. Pharmazie 2004, 59, 734-735. (f) Ojewole, J. A. Hypoglycemic and Hypotensive Effects of Psidium guajava Linn. (Myrtaceae) Leaf Aqueous Extract. Methods Find Exp. Clin. Pharmacol. 2005, 27, 689-695. For Isolation of Guajadial (1) and Additional Citations Describing Biological Studies of Psidium guajava, see: (g) Yang, X.-L.; Hsieh, K.-L.; Liu, J.-K. Guajadial: An Unusual Mero- terpenoid from Guava Leaves Psidium guajava. Org. Lett. 2007, 9, 5135-5138, and references cited therein.

(2) For a review of phloroglucinols derived from natural origins, see: (a) Singh, I. P.; Sidana, J.; Bharate, S. B.; Foley, W. J. Phloroglucinol Compounds of Natural Origin: Synthetic aspects. Nat. Prod. Rep. 2010, 27, 393-416. For new meroterpenoids isolated recently, see: (b) Qin, X.-J.; Yan, H.; Ni, W.; Yu, M.-Y.; Khan, A.; Liu, H.; Zhang, H.-X.; He, L.; Hao, X.-J.; Di, Y.-T.; Liu, H.$Y$. Cytotoxic Meroterpenoids with Rare Skeletons from Psidium guajava Cultivated in Temperate Zone. Sci. Rep. 2016, 6, 32748. (c) Shang, Z.-C.; Yang, M.-H.; Liu, R.-H.; Wang, X.-B.; Kong, L.-Y. New Formyl Phloroglucinol Meroterpenoids from the Leaves of Eucalyptus robusta. Sci. Rep. 2016, 6, 39815.

(3) Tang, G.-H.; Dong, Z.; Guo, Y.-Q.; Cheng, Z.-B.; Zhou, C.-J.; Yin, S. Sci. Rep. Psiguajadials A-K: Unusual Psidium Meroterpenoids as Phosphodiesterase-4 Inhibitors from the Leaves of Psidium guajava. 2017, 7, 1952.

(4) Psiguadial A, B: Shao, M.; Wang, Y.; Liu, Z.; Zhang, D.-M.; Cao, H.-H.; Jiang, R.-W.; Fan, C.-L.; Zhang, X.-Q.; Chen, H.-R.; Yao, X.S.; Ye, W.-C. Psiguadials A and B, Two Novel Meroterpenoids with Unusual Skeletons from the Leaves of Psidium guajava. Org. Lett. 2010, 12, 5040-5043.

(5) Psiguadial C, D and proposed biosynthesis: Shao, M.; Wang, Y.; Jian, Y.-Q.; Huang, X.-J.; Zhang, D.-M.; Tang, Q.-F.; Jiang, R.-W.; Sun, X.-G.; Lv, Z.-P.; Zhang, X.-Q.; Ye, W.-C. Guadial A and Psiguadials $C$ and $D$, Three Unusual Meroterpenoids from Psidium guajava Org. Lett. 2012, 14, 5262-5265.

(6) (a) Dehal, S. S.; Croteau, R. Partial Purification and Characterization of two Sesquiterpene Cyclases from Sage (Salvia officinalis) which Catalyze the Respective Conversion of Farnesyl Pyrophosphate to Humulene and Caryophyllene. Arch. Biochem. Biophys. 1988, 261, 346-356. (b) Cai, Y.; Jia, J.-W.; Crock, J.; Lin, Z.X.; Chen, X.-Y.; Croteau, R. A cDNA Clone for $\beta$-Caryophyllene Aynthase from Artemisia annua Phytochemistry 2002, 61, 523529.

(7) Moussa, G. E. Phenol Dehydrogenations. 12. Oxidative Coupling of 3,5-Dimethyl-2,4,6-trihydroxybenzophenone. Acta Chem. Scand. 1968, 22, 3329-3330.

(8) Newton, C. G.; Tran, D. N.; Wodrich, M. D.; Cramer, N. One-Step Multigram-Scale Biomimetic Synthesis of Psiguadial B. Angew. Chem. Int. Ed. 2017, 56, 13776-13780.

(9) Fu, H.-Z.; Luo, Y.-M.; Li, C.-J.; Yang, J.-Z.; Zhang, D.-M. Psidials A-C, Three Unusual Meroterpenoids from the Leaves of Psidium guajava L. Org. Lett. 2010, 12, 656-659.

(10) Tran, D. N.; Cramer, N. Biomimetic Synthesis of (+)-Ledene, (+)Viridiflorol, (-)-Palustrol, (+)-Spathulenol, and Psiguadial A, C, and $D$ via the Platform Terpene (+)-Bicyclogermacrene. Chem. Eur. J. 2014, 20, 10654-10660.

(11) Lawrence, A. L.; Adlington, R. M.; Baldwin, J. E.; Lee, V.; Kershaw, J. A.; Thompson, A. L. A Short Biomimetic Synthesis of the Meroterpenoids Guajadial and Psidial A. Org. Lett. 2010, 12, 1676-1679.

(12) Chapman, L. M.; Beck, J. C.; Wu, L.; Reisman, S. E. Enantioselective Total Synthesis of (+)-Psiguadial B. J. Am. Chem. Soc. 2016, 138, 9803-9806.

(13) Tanino and coworkers recently disclosed an approach to ( \pm )-3, see: Kinebuchi, M.; Uematsu, R.; Tanino, K. Synthetic Studies on Psiguadial B: Construction of Bicyclo[4.3.1]decane Skeleton via 
Double Cyclization Reaction of Alkyne Dicobalt Complex Tetrahedron Lett. 2017, 58, 1382-1386.

(14) (a) Sasmal, P. K.; Maier, M. E. Formation of Bicyclic Ethers from Lewis Acid Promoted Cyclizations of Cyclic Oxonium lons Org. Lett. 2002, 4, 1271-1274. (b) López, F.; Castedo, L.; Mascareñas, J. L. Practical Asymmetric Approach to Medium-Sized Carbocycles Based on the Combination of Two Ru-Catalyzed Transformations and a Lewis Acid-Induced Cyclization. Org. Lett. 2005, 7, 287-290. For related examples, see: (c) Blumenkopf, T. A.; Bratz, M.; Castaneda, A.; Look, G. C.; Overman, L. E.; Rodriguez, D.; Thompson, A. S. Preparation of Eight-Membered Cyclic Ethers by Lewis Acid Promoted Acetal-Alkene Cyclizations. J. Am. Chem. Soc. 1990, 112, 4386-4399.

(15) Arduini, A.; Bosi, A.; Pochini, A.; Ungaro, R. o-Quinone Methides 2. Stereoselectivity in Cycloaddition Reactions of o-Quinone Methides with Vinyl Ethers. Tetrahedron 1985, 41, 3095-3103.

(16) For reviews, see: (a) Willis, N. J.; Bray, C. D. o-Quinone Methides in Natural Product Synthesis. Chem. Eur. J. 2012, 18, 9160-9173. (b) Van De Water, R. W.; Pettus, T. R. o-Quinone Methides: Intermediates Underdeveloped and Underutilized in Organic Synthesis. Tetrahedron 2002, 58, 5367-5405. (c) Ferreira, S. B.; da Silva, F. de C.; Pinto, A. C.; Gonzaga, D. T. G.; Ferreira, V. F. Syntheses of Chromenes and Chromanes via o-Quinone Methide Intermediates J. Heterocyclic Chem. 2009, 46, 1080-1097.

(17) Since 2012, Schneider and others have reported o-QMHDA reactions with cyclic enamides. For relevant examples, see: (a) Saha, S.; Schneider, C. Brønsted Acid-Catalyzed, Highly Enantioselective Addition of Enamides to In Situ-Generated o-Quinone Methides: A Domino Approach to Complex Acetamidotetrahydroxanthenes. Chem. Eur. J. 2015, 21, 2348-2352. (b) El-Sepelgy, O.; Haseloff, S.; Alamsetti, S. K.; Schneider, C. Brønsted acid Catalyzed, Conjugate Addition of $\beta$ Dicarbonyls to In Situ Generated o-Quinone MethidesEnantioselective Synthesis of 4-Aryl-4H-chromenes. Angew. Chem., Int. Ed. 2014, 53, 7923-7927. (c) Saha, S.; Schneider, C. Directing Group Assisted Nucleophilic Substitution of Propargylic Alcohols via o-Quinone Methide Intermediates: Brønsted Acid Catalyzed, Highly Enantio- and Diastereoselective Synthesis of 7-Alkynyl-12a-acetamido-Substituted Benzoxanthenes. Org. Lett. 2015, 17, 648-651. (d) Zhao, J.-J.; Zhang, Y.-C.; Xu, M.-M.; Tang, M.; Shi, F. Catalytic Chemo-, E/Z-, and Enantioselective Cyclizations of 0 -Hydroxybenzyl Alcohols with DimedoneDerived Enaminones. J. Org. Chem. 2015, 80, 10016-10024.

(18) For examples of chiral enol ethers used in o-QMHDA reactions, see: (a) Selenski, C.; Mejorado, L. H.; Pettus, T. R. Diastereoselective [4+2] Reactions of $o$-Quinone Methides with a Chiral Enol Ether: Asymmetric Synthesis of (+)-R-Mimosifoliol. Synlett 2004, 6, 1101-1103. (b) Selenski, C.; Pettus, T. R. R. Enantioselective [4 + 2] Cycloadditions of o-Quinone Methides: Total Synthesis of (+)-Mimosifoliol and Formal Synthesis of (+)Tolterodine. J. Org. Chem. 2004, 69, 9196-9203. (c) Wenderski, T. A.; Marsini, M. A.; Pettus, T. R. R. A Diastereoselective Formal Synthesis of Berkelic Acid. Org. Lett. 2011, 13, 118-121. (d) Marsini, M. A.; Huang, Y.; Lindsey, C. C.; Wu, K.-L.; Pettus, T. R. R. Diastereoselective Syntheses of Chroman Spiroketals via [4 + 2] Cycloaddition of Enol Ethers and o-Quinone Methides. Org. Lett. 2008, 10, 1477-1480.

(19) For seminal studies, see: (a) Shabashov, D.; Daugulis, O. Auxiliary-Assisted Palladium-Catalyzed Arylation and Alkylation of sp2 and sp3 Carbon-Hydrogen Bonds. J. Am. Chem. Soc. 2010, 132, 3965-3972. (b) Zaitsev, V. G.; Shabashov, D.; Daugulis, O. Highly Regioselective Arylation of $\mathrm{sp}^{3} \mathrm{C}-\mathrm{H}$ Bonds Catalyzed by Palladium Acetate. J. Am. Chem. Soc. 2005, 127, 13154-13155. (c) Reddy, B. V. S.; Reddy, L. R.; Corey, E. J. Novel Acetoxylation and C-C Coupling Reactions at Unactivated Positions in $\alpha$-Amino Acid Derivatives. Org. Lett. 2006, 8, 3391-3394. For reviews, see: (d) Corbet, M.; De Campo, F. 8-Aminoquinoline: a Powerful Directing Group in Metal-Catalyzed Direct Functionalization of C-H Bonds. Angew. Chem. Int. Ed. 2013, 52, 9896-9898. For a review, see: (e) Yamaguchi, J.; Itami, K.; Yamaguchi, A. D. C-H Bond Functionalization: Emerging Synthetic Tools for Natural Products and Pharmaceuticals. Angew. Chem., Int. Ed. 2012, 51, 8960-9009.

(20) (a) Gutekunst, W. R.; Baran, P. S. Total Synthesis and Structural Revision of the Piperarborenines via Sequential Cyclobutane CH Arylation. J. Am. Chem. Soc. 2011, 133, 19076-19079. (b) Gutekunst, W. R.; Gianatassio, R.; Baran, P. S. Sequential C(sp3)-H Arylation and Olefination: Total Synthesis of the Proposed Structure of Pipercyclobutanamide. A. Angew. Chem., Int. Ed. 2012, 51, 7507-7510. (c) Feng, Y.; Chen, G. Total Synthesis of Celogentin C by Stereoselective C-H Activation. Angew. Chem., Int. Ed. 2010, 49, 958-961. For reports disclosed after our studies commenced, see: (d) Gutekunst, W. R.; Baran, P. S. Applications of $\mathrm{C}-\mathrm{H}$ Functionalization Logic to Cyclobutane Synthesis. J. Org. Chem. 2014, 79, 2430-2452. (e) Panish, R. A.; Chintala, S. R.; Fox, J. M. A Mixed-Ligand Chiral Rhodium(II) Catalyst Enables the Enantioselective Total Synthesis of Piperarborenine B. Angew. Chem., Int. Ed. 2016, 55, 4983-4987. (f) Ting, C. P.; Maimone, T. J. C-H Bond Arylation in the Synthesis of Aryltetralin Lignans: a Short Total Synthesis of Podophyllotoxin. Angew. Chem., Int. Ed. 2014, 53, 3115-3119.

(21) (a) Ghosh, A.; Banerjee, U. K.; Venkateswaran, R. V. Photolysis of $\alpha$-diazocyclopentanones. Ring Contraction to Functionalised Cyclobutanes and Synthesis of Junionone, Grandisol and Planococcyl Acetate. Tetrahedron 1990, 46, 3077-3088. (b) Banerjes, U. K.; Venkateswaran, R. V. PhoTolysis of $\alpha$ Diazocyclopentanones: Ring Contraction to Functionalised $\mathrm{Cy}$ clobutanes and Synthesis of Precursors to Grandisol and Fragranol. Tetrahedron Lett. 1983, 24, 423-424.

(22) (a) Hodous, B. L.; Fu, G. C. Enantioselective Addition of Amines to Ketenes Catalyzed by a Planar-Chiral Derivative of PPY: Possible Intervention of Chiral Brønsted-Acid Catalysis. J. Am. Chem. Soc. 2002, 124, 10006-10007. (b) Wiskur, S. L.; Fu, G. C. Catalytic Asymmetric Synthesis of Esters from Ketenes. J. Am. Chem. Soc. 2005, 127, 6176-6177.

(23) France, S.; Wack, H.; Taggi, A. E.; Hafez, A. M.; Wagerle, T. R.; Shah, M. H.; Dusich, C. L.; Lectka, T. Catalytic, Asymmetric $\alpha$ Chlorination of Acid Halides. J. Am. Chem. Soc. 2004, 126, 42454255.

(24) (a) Pracejus, H. Organische Katalysatoren, LXI. Asymmetrische Synthesen mit Ketenen, I. Alkaloid-Katalysierte Asymmetrische Synthesen von $\alpha$-Phenyl-Propionsäureestern. Justus Liebigs Ann. Chem. 1960, 634, 9-22. (b) Zhang, Y. -R.; He, L.; Wu, X.; Shao, P. -L.; Ye, S. Chiral N-Heterocyclic Carbene Catalyzed Staudinger Reaction of Ketenes with Imines: Highly Enantioselective Synthesis of N-Boc $\beta$-Lactams. Org. Lett. 2008, 10, 277 280. For a review on catalytic, asymmetric additions to ketenes, see: (c) Paull, D. H.; Weatherwax, A.; Lectka, T. Catalytic, 
Asymmetric Reactions of Ketenes and Ketene Enolates. Tetrahedron 2009, 65, 6771-6803.

(25) As discussed in reference 12, it was determined that 3 equiv 29 was necessary to mitigate a competing photodecarbonylation process, see: Tidwell, T. T. Ketenes, 2nd Edition; John Wiley \& Sons: Hoboken, New Jersey, 2006; pp 443-447.

(26) See Supporting Information for full details.

(27) (a) d'Augustin, M.; Palais, L. T.; Alexakis, A. Enantioselective Copper-Catalyzed Conjugate Addition to Trisubstituted Cyclohexenones: Construction of Stereogenic Quaternary Centers. Angew. Chem., Int. Ed. 2005, 44, 1376-1378. (b) Vuagnouxd'Augustin, M.; Alexakis, A. Copper-Catalyzed Asymmetric Conjugate Addition of Trialkylaluminium Reagents to Trisubstituted Enones: Construction of Chiral Quaternary Centers. Chem. Eur. J. 2007, 13, 9647-9662.

(28) Saimoto, H.; Yoshida, K.; Murakami, T.; Morimoto, M.; Sashiwa, H.; Shigemasa, Y. Effect of Calcium Reagents on Aldol Reactions of Phenolic Enolates with Aldehydes in Alcohol. J. Org. Chem. 1996, 61, 6768-6769.

(29) (a) Prepared directly in $<10 \%$ yield according to: Leuchs, $\mathrm{H}$.; Theodorescu, G. Chem. Ber. 1910, 43, 1243. The corresponding ethyl ester can also be prepared in higher yield ( 20\%) according to: (b) Zhang, Q.; Botting, N. P.; Kay, C. A Gram Scale Synthesis of a Multi- ${ }^{13} \mathrm{C}$-Labelled Anthocyanin, $\left[6,8,10,3^{\prime}, 5^{\prime}\right.$ ${ }^{13} \mathrm{C}_{5}$ ] Cyanidin-3-glucoside, for Use in Oral Tracer Studies in Humans. Chem. Commun. 2011, 47, 10596-10598.

(30) Attempts to employ $\mathbf{5 5}$ directly as an o-QM precursor led to complex reaction profiles for the cycloaddition: The liberated equivalent of morpholine (52) displaced the methoxy ketal in the initially formed cycloaddition products (i.e. 57-60) via thermal oxonium ion formation. Efforts to mitigate this problem by activating $\mathbf{5 5}$ via $\mathrm{N}$-methylation were unsuccessful. For relevant examples, see: (a) Wilson, P. D.; Pettigrew, J. D.; Bexrud, J. A.; Freeman, R. P. Total Synthesis of ( \pm )-Xyloketal D and Model Studies towards the Total Synthesis of (-)-Xyloketal A. Heterocycles. 2004, 62, 445-452. (b) Pettigrew, J. D.; Freeman, R. P.; Wilson, P. D. Total Synthesis of (-)-Xyloketal D and its EnantiomerConfirmation of Absolute Stereochemistry. Can. J. Chem. 2004, $82,1640-1648$.

(31) We do not observe products resulting from cycloaddition with the isomeric enol ether (indicated with a dashed line); presumably, only one isomer reacts due to steric hindrance.

(32) Evans, D. A.; Johnson, J. S.; Olhava, E. J. Enantioselective Synthesis of Dihydropyrans. Catalysis of Hetero Diels-Alder Reactions by Bis(oxazoline) Copper(II) Complexes. J. Am. Chem. Soc. 2000, 122, 1635-1649.

(33) For select examples of $o$-QMs generated using Brønsted acids, see: (a) Hsiao, C.-C.; Raja, S.; Liao, H.-H.; Atodiresei, I.; Rueping, M. O-Quinone Methides as Reactive Intermediates in Asymmetric Brønsted Acid Catalyzed Cycloadditions with Unactivated Alkenes by Exclusive Activation of the Electrophile. Angew. Chem. Int. Ed. 2015, 54, 5762-5765, and references cited therein. (b) Gharpure, S. J.; Sathiyanarayanan, A. M.; Vuram, P. K. Hetero Diels-Alder Reaction of Olefin with $o$-Quinone Methides Generated using ( \pm )-Binolphosphoric acid for the Stereoselective Synthesis of 2,4-Diarylbenzopyrans: Application to the Formal Synthesis of Myristinin B/C. RSC Adv. 2013, 3, 18279-18282.

(34) Notably, this method provides a 1:1 mixture of enol ethers that do not equilibrate at room temperature. Thus, only half of the starting material employed in the $\mathrm{Cu}(\mathrm{OTf})_{2}$-mediated $o$-QMHDA reaction can provide the desired cycloaddition product.

(35) Ananikov, V. P.; Orlov, N. V.; Beletskaya, I. P. Efficient and Convenient Synthesis of $\beta$-Vinyl Sulfides in Nickel-Catalyzed Regioselective Addition of Thiols to Terminal Alkynes under SolventFree Conditions. Organometallics 2006, 25, 1970-1977.

(36)Cho, Y. S.; Kim, H. Y.; Cha, J. H.; Pae, A. N.; Koh, H. Y.; Choi, J. H.; Chang, M. H. Indium Trichloride Mediated Intramolecular PrinsType Cyclization. Org. Lett. 2002, 4, 2025-2028.

(37)For leading references on the Norrish-Yang cyclization, see: (a) Yang, N.C.; Yang, D.-D. H. Photochemical Reactions of Ketones in Solution. J. Am. Chem. Soc. 1958, 80, 2913-2914. (b) Chen, C. The Past, Present, and Future of the Yang Reaction. Org. Biomol. Chem. 2016, 14, 8641-8647. For an example in total synthesis, see: Paquette, L. A.; Sugimura, T. Enantiospecific Total Synthesis and Absolute Configurational Assignment of (-)Punctatin A (antibiotic M95464). J. Am. Chem. Soc. 1986, 108, 3841-3842.

(38) Schwinden, M. D. "The Norrish Type II Reaction in Organic Synthesis" (1990). Retrospective Theses and Dissertations. Paper 9890.

(39) (a) Bach, T.; Aechtner, T.; Neumüller, B. Enantioselective Norrish-Yang Cyclization Reactions of $N$-( $\omega$-Oxo- $\omega$-phenylalkyl)Substituted Imidazolidinones in Solution and in the Solid State. Chem. Eur. J. 2002, 8, 2464-2475. (b) Singhal, N.; Koner, A. L.; Mal, P.; Venugopalan, P.; Nau, W. M.; Moorthy, J. N. Diastereomer-Differentiating Photochemistry of $\beta$-Arylbutyrophenones: Yang Cyclization versus Type II Elimination. J. Am. Chem. Soc. 2005, 127, 14375-14372. (c) Fleming, I.; Kemp-Jones, A. V.; Long, W. E.; Thomas, E. J. Cyclobutanol: Fragmentation Ratios for the Singlet and Triplet Excited States in the Type II Photochemistry of some $\alpha$-Alkylated Cyclohexanones. J. Chem. Soc., Perkin Trans. 2 1976, 0, 7-14.

(40) (a) Winnik, M. A.; Breslow, R. Remote Oxidation of Unactivated Methylene Groups. J. Am. Chem. Soc. 1969, 91, 3083-3984. (b) Breslow, R.; Rothbard, J.; Herman, F.; Rodriguez, M. L. Remote Functionalization Reactions as Conformational Probes for Flexible Alkyl Chains. J. Am. Chem. Soc. 1978, 100, 1213-1218. (c) Andreu, I.; Palumbo, F.; Tilocca, F.; Morera, I. M.; Boscá, F.; Miranda, M. A. Solvent Effects in Hydrogen Abstraction from Cholesterol by Benzophenone Triplet Excited State. Org. Lett. 2011, 13, 4096-4099.

(41) (a) Palucki, M.; Wolfe, J. P.; Buchwald, S. L. Synthesis of Oxygen Heterocycles via a Palladium-Catalyzed C-O Bond-Forming Reaction. J. Am. Chem. Soc. 1996, 118, 10333-10334. (b) Palucki, M.; Wolfe, J. P.; Buchwald, S. L. Palladium-Catalyzed Intermolecular Carbon-Oxygen Bond Formation: A New Synthesis of Aryl Ethers. J. Am. Chem. Soc. 1997, 119, 3395-3396. (c) Parrish, C. A.; Buchwald, S. L. Palladium-Catalyzed Formation of Aryl tert-Butyl Ethers from Unactivated Aryl Halides. J. Org. Chem. 2001, 66, 2498-2500. (d) Vorogushin, A. V.; Huang, X.; Buchwald, S. L. Use of Tunable Ligands Allows for Intermolecular PdCatalyzed C-O Bond Formation. J. Am. Chem. Soc. 2005, 127, 8146-8149.

(42) We were aware of unsuccessful efforts to prepare $\beta$ caryophyllene by ring-closing metathesis. See: Dowling, M. S.; Vanderwal, C. D. Ring-Closing Metathesis of Allylsilanes As a Flexible Strategy toward Cyclic Terpenes. Short Syntheses of Teucladiol, Isoteucladiol, Poitediol, and Dactylol and an At- 
tempted Synthesis of Caryophyllene. J. Org. Chem. 2010, 75, 6908-6922.

(43) Attempts to apply Noyori's aprotic ketalization protocol caused rapid decomposition of 46: Tsunoda, T.; Suzuki, M.; Noyori, R. A Facile Procedure for Acetalization under Aprotic Conditions. Tetrahedron Lett. 1980, 21,1357-1358.

(44) lodide 73 was prepared as an inconsequential 8:1 mixture of olefin isomers.

(45) The major side product in the epimerization of $\mathbf{4 6}$ to $\mathbf{4 7}$ is spirocyclic lactam S3 (see Supporting Information). Formation of S3 is precluded using this alternative sequence, since aza-Michael addition cannot occur when the enone is protected as the corresponding dioxolane.

(46) We were unable to separate all the components in this complex reaction mixture with sufficient purity for definitive characterization.

(47) Spectroscopic data for $\mathbf{8 3}$ matches that reported in the literature: Lee, H.; Yi, C. S. Synthesis of 2-Acylphenol and Flavene Derivatives from the Ruthenium-Catalyzed Oxidative $\mathrm{C}-\mathrm{H}$ Acylation of Phenols with Aldehydes. Eur. J. Org. Chem. 2015, 2015, 1899-1904.

(48) (a) Khomenko, T. M.; Korchagina, D. V.; Gatilov, Y. V.; Bagryanskaya, I. Y.; Tkachev, A. V.; Vyalkov, A. I.; Kun, O. B.; Salenko, V. L.; Dubovenko, Z. V.; Barkash, V. A. Synthesis of Some Dienes with a Caryophyllane Skeleton and their Reactions in Acid Media. Zh. Org. Khim. 1990, 26, 2129-2145.; Khomenko, T. M.; Korchagina, D. V.; Gatilov, Y. V.; Bagryanskaya, I. Y.; Tkachev, A. V.; Vyalkov, A. I.; Kun, O. B.; Salenko, V. L.; Dubovenko, Z. V.; Barkash, V. A. Synthesis of Some Dienes with a Caryophyllane Skeleton and their Reactions in Acid Media. Russ. J. Org. Chem. (English Translation). 1990, 26, 1839-1852. (b) See also: Khomenko, T. M.; Bagryanskaya, I. Y.; Gatilov, Y. V.; Korchagina, D. V.; Gatilova, V. P.; Dubovenko, Z. V.; Barkhash, V. A. Molecular Rearrangements of Isocaryophyllene in a Super Acid. Zh. Org. Khim. 1985, 21, 677-678.; Khomenko, T. M.; Bagryanskaya, I. Y.; Gatilov, Y. V.; Korchagina, D. V.; Gatilova, V. P.; Dubovenko, Z. V.; Barkhash, V. A. Molecular Rearrangements of Isocaryophyllene in a Super Acid. Russ. J. Org. Chem. (English Translation) 1985, 21, 614-615.

(49) For an example of a tertiary alcohol-directed hydrogenation using Crabtree's catalyst, see: (a) Hong, A. Y.; Stoltz, B. M. Biosynthesis and Chemical Synthesis of Presilphiperfolanol Natural Products. Angew. Chem. Int. Ed. 2014, 53, 5248-5260. For a review, see: (b) Hoveyda, A. H.; Evans, D. A.; Fu, G. C. SubstrateDirectable Chemical Reactions. Chem. Rev. 1993, 93, 13071370.

(50) Suchand, B.; Krishna, J.; Mritunjoy, K.; Satyanarayana, G. Lewis acid Promoted C-C and Copper-Catalyzed C-O Bond Formation: Synthesis of Neoflavans. RSC Adv. 2014, 4, 13941-13945.

(51) For select examples, see: (a) Selenski, C.; Pettus, T. R. R. ( \pm )Diinsininone: Made Nature's Way. Tetrahedron 2006, 62, 52985307. (b) Achilonu, M. C.; Bonnet, S. L.; van der Westhuizen, J. H. Synthesis of Proanthocyanidins. Part 1. The First Oxidative Formation of the Interflavanyl Bond in Procyanidins. Org. Lett. 2008, 10, 3865-3868. (c) Bezuidenhoudt, B. C. B.; Brandt, E. V.; Roux, D. G. Synthesis of Isoflavanoid Oligomers Using a Pterocarpan as Inceptive Electrophile. J. Chem. Soc., Perkin Trans. 1 1984, 2767-2778. (d) Hayes, C. J.; Whittaker, B. P.; Watson, S. A.; Grabowska, A. M. Synthesis and Preliminary Anticancer Ac- tivity Studies of C4 and C8-Modified Derivatives of Catechin Gallate (CG) and Epicatechin Gallate (ECG). J. Org. Chem. 2006, 71, 9701-9712, and references cited therein.

(52) (a) Saito, A.; Nakajima, N.; Tanaka, A.; Ubukata, M. Synthetic Studies of Proanthocyanidins. Part 2: Stereoselective GramScale Synthesis of Procyanidin-B3. Tetrahedron 2002, 58, 78297837. (b) Dennis, E. G.; Jeffery, D. W.; Johnston, M. R.; Perkins, M. V.; Smith, P. A. Procyanidin Oligomers. A New Method for $4 \rightarrow 8$ Interflavan Bond Formation using C8-Boronic Acids and Iterative Oligomer Aynthesis through a Boron-Protection Strategy. Tetrahedron 2012, 68, 340-348.

(53) Feng, Z. G.; Bai, W. J.; Pettus, T. R. R. Unified Total Syntheses of (-)-Medicarpin, (-)-Sophoracarpan A, and ( \pm )-Kushecarpin A with Some Structural Revisions. Angew. Chem. Int. Ed. 2015, 54, 1864-1867.

(54) Hendrik, C.; Mouton, L.; Steenkamp, J. A.; Young, D. A.; Bezuidenhoudt, B. C. B.; Ferreira, D. Regio- and Stereoselective Oxygenation of Flavan-S-OI-, 4-Arylflavan- 3-OI-, and Biflavanoid-Derivatives with Potassium Persulphate. Tetrahedron 1990, 46, 6885-6894.

(55) (a) Day, J. J.; McFadden, R. M.; Virgil, S. C.; Kolding, H.; Alleva, J. L.; Stoltz, B. M. The Catalytic Enantioselective Total Synthesis of (+)-Liphagal. Angew. Chem. Int. Ed. 2011, 50, 6814-6818. (b) Olah, G. A.; Salem, G.; Staral, J. S.; Ho, T.-L. Preparative Carbocation Chemistry. 13. Preparation of Carbocations from Hydrocarbons Via Hydrogen Abstraction with Nitrosonium Hexafluorophosphate and Sodium Nitrite-Trifluoromethanesulfonic Acid. J. Org. Chem. 1978, 43, 173-175.

(56) Li, Y. Z.; Li, B. J.; Lu, X. Y.; Lin, S.; Shi, Z. J. Cross Dehydrogenative Arylation (CDA) of a Benzylic C-H Bond with Arenes by Iron Catalysis. Angew. Chem. Int. Ed. 2009, 48, 3817-3820.

(57) Muramatsu, W.; Nakano, K. Organocatalytic Approach for $\mathrm{C}\left(\mathrm{sp}^{3}\right)-\mathrm{H}$ Bond Arylation, Alkylation, and Amidation of Isochromans under Facile Conditions. Org. Lett. 2014, 16, 2042-2045.

(58) Steenkamp, J. A.; Mouton, C.; Ferreira, D. Regio- and Stereoselective Oxidation of Flavan-3-Ol- 4-Arylflavan-3-OI- and Biflavanoid Derivatives with 2,3-Dichloro-56-Dicyano-1,4Benzoquinone (DDQ). Tetrahedron 1991, 47, 6705-6716.

(59) Willson, T. M.; Amburgey, J.; Denmark, S. E. Synthesis of $\alpha$ - and $\beta$-Branched Ethers from Alcohols by Reaction of Acetals with Grignard Reagents: Synthesis of Isopropyl and Isobutyl Ethers of $\left(1 S^{*}, 2 R^{*} S^{*}, 4 R^{*}\right)$-6-methylenebicyclo[2.2.2]octan-2-ol. J. Chem. Soc., Perkin Trans. 1 1991, 12, 2899-2906.

(60) (a) Greene, M. A.; Yonova, I. M.; Williams, F. J.; Jarvo, E. R. Traceless Directing Group for Stereospecific Nickel-Catalyzed Alkyl-Alkyl Cross-Coupling Reactions. Org. Lett. 2012, 14, 42934296. (b) Yonova, I. M.; Johnson, A. G.; Osborne, C. A.; Moore, C. E.; Morrissette, N. S.; Jarvo, E. R. Stereospecific NickelCatalyzed Cross-Coupling Reactions of Alkyl Grignard Reagents and Identification of Selective Anti-Breast-Cancer Agents. Angew. Chem. Int. Ed. 2014, 53, 2422-2427. (c) Dawson, D. D.; Jarvo, E. R. Stereospecific Nickel-Catalyzed Cross-Coupling Reactions of Benzylic Ethers with Isotopically-Labeled Grignard Reagents. Org. Process Res. Dev. 2015, 19, 1356-1359.

(61) (a) Mitchell, T. A.; Bode, J. W. Synthesis of Dialkyl Ethers from Organotrifluoroborates and Acetals. J. Am. Chem. Soc. 2009, 131, 18057-18059. (b) Vo, C.-V. T.; Mitchell, T. A.; Bode, J. W. Expanded Substrate Scope and Improved Reactivity of Ether- 
Forming Cross-Coupling Reactions of Organotrifluoroborates and Acetals. J. Am. Chem. Soc. 2011, 133, 14082-14089.

(62) (a) Lipshutz, B. H.; Wilhelm, R. S.; Kozlowski, J. A. Conjugate Addition Reactions of $\alpha, \beta$,-Unsaturated ketones with Higher Order, Mixed Organocuprate Reagents, R2Cu(CN)Li2. J. Org. Chem. 1984, 49, 3938-3942. (b) Lipshutz, B. H.; Parker, D. A.; Kozlowski, J. A.; Nguyen, S. M. Effects of Lewis Acids on Higher Order, Mixed Cuprate Couplings. Tetrahedron Lett. 1984, 25, 5959-5962.

(63) (a) Rieche, A.; Gross, H.; Höft, E. Aromatic aldehydes. Mesitaldehyde. Org. Synth. 1967, 47, 1. (b) Aukrust, I. R.; Skattebol, L. The Syntehsis of (-)-Robustadial A and Some Analogues. Acta Chem. Scand. 1996, 50, 132-140. (c) Kraus, G. A.; Mengwasser, J.; Maury, W.; Oh, C. Synthesis of Chroman Aldehydes that Inhibit HIV. Bioorg. Med. Chem. Lett. 2011, 21, 1399-1401.

(64) Still, W. C., Kahn, M. \& Mitra, A. Rapid Chromatographic Technique for Preparative Separations with Moderate Resolution. J. Org. Chem. 1978, 43, 2923-2925.

(65) Characterization for this compound was reported previously (reference 12). It is re-presented here for the convenience of the readers.

(66) We have found that concentrated reaction mixtures (e.g. $\geq 2.2$ M) react to full conversion at $0{ }^{\circ} \mathrm{C}$, whereas more dilute reactions (i.e. $1.5 \mathrm{M}$, as reported in ref $21 \mathrm{a}$ ) often require warming to room temperature in order to initiate. This can be dangerous on large scale, as the reaction proceeds quickly and produces $\mathrm{H}_{2}$.

(67) For safety reasons, $p$-4-acetamidobenzenesulfonyl azide ( $p$ ABSA) was used as an alternative diazo transfer reagent in place of tosyl azide.

(68) (a) Vuluga, D.; Legros, J.; Crousse, B.; Bonnet-Delpon, D. Synthesis of Pyrazoles Through Catalyst-Free Cycloaddition of Diazo Compounds to Alkynes. Green Chem. 2009, 11, 156-159. (b) Sato, Y.; Fujisawa, H.; Mukaiyama, T. Bull. Chem. Soc. Jpn. 2006, 79, 1275. (c) Rosenfeld, M. J.; Shankar, B. K. R.; Shechter, H. Rhodium(II) Acetate-Catalyzed Reactions of 2-Diazo-1,3Indandione and 2-Diazo-1-Indanone with Various Substrates. J. Org. Chem. 1998, 53, 2699-2705. For preparation of the 6- and 7-membered ketones used to access $\mathbf{3 8}$ and 39, see: (d) Cernijenko, A.; Risgaard, R.; Baran, P. S. 11-Step Total Synthesis of (-)-Maoecrystal V. J. Am. Chem. Soc. 2016, 138, 9425-9428. (e) Liu, H.; Drizin, I.; Koenig, J. R.; Cowart, M. D.; Wakefield, B. D.; Altenbach, R. J.; Black, L. A.; Zhao, C. Macrocyclic pyrimidine derivatives. WO2009123967, 2009.

(69) Reaction time varies with the age of the lamp. A UV-opaque film slowly develops on the inside surface of the flask facing the lamp upon prolonged irradiation. This film can be removed by soaking the flask in an alkali base bath $\left(\mathrm{KOH}, 4: 1 \mathrm{i}-\mathrm{PrOH} / \mathrm{H}_{2} \mathrm{O}\right)$.

(70) APEX2, Version 2 User Manual, M86-E01078, Bruker Analytical X-ray Systems, Madison, WI, June 2006.

(71) Prepared according to the ligand protocol described in: Bao, $\mathrm{H}_{\text {.; }}$; Qi, X.; Tambar, U. K. Catalytic Enantioselective [2,3]Rearrangements of Amine N-Oxides. J. Am. Chem. Soc. 2011 $133,1206-1208$. We found that the use of $\mathrm{CH}_{2} \mathrm{Cl}_{2}$ as a reaction solvent provided higher and more reproducible yields, compared with THF.

(72) Prepared directly in $<10 \%$ yield according to: Leuchs, H.; Theodorescu, G. Chem. Ber. 1910, 43, 1243. The corresponding ethyl ester can also be prepared in higher yield ( $20 \%)$ according to: (b) Zhang, Q.; Botting, N. P.; Kay, C. A Gram Scale Synthesis of a Multi-13C-Labelledanthocyanin, $\quad\left[6,8,10,3^{\prime}, 5^{\prime}-{ }^{13} C_{5}\right]$ Cyanidin-3Glucoside, for Use in Oral Tracer Studies in Humans. Chem. Commun. 2011, 47, 10596-10598.

(73) Ohira-Bestmann reagent prepared according to: Pietruszka, J.; Witt, A. Synthesis of the Bestmann-Ohira Reagent. Synthesis 2006, 2006, 4266-4268.

(74) Prepared according to: Gambacorti-Passerini, C.; Mologni, L.; Scapozza, L.; Bisson, W.; Ahmed, S.; Goekjian, P.; Tardy, S.; Orsato, A.; Gueyrard, D.; Benoit, J. Alpha-carbolines for the treatment of cancer. WO 2013167730, 2013.

(75) Spectroscopic data for $\mathbf{8 3}$ matches that reported in the literature: Lee, H.; Yi, C. S. Synthesis of 2-Acylphenol and Flavene Derivatives from the Ruthenium-Catalyzed Oxidative $\mathrm{C}-\mathrm{H}$ Acylation of Phenols with Aldehydes. Eur. J. Org. Chem. 2015, 2015, 18991904.

(76) The characterization data were fully consistent with the isolation data reported in ref 4 a. See Supporting Information for NMR comparison tables. 